\title{
TOWARDS AN ECOFEMINIST PRAXIS WITHIN SOCIAL WORK PEDAGOGY
}

BY

JOY MARGERY ANDERTON

\begin{abstract}
A THESIS
submitted for examination to Victoria University of Wellington in fulfilment of the requirements for the degree of DOCTOR OF PHILOSOPHY
\end{abstract}

Victoria University of Wellington

2000 


\begin{abstract}
Environmental sustainability is now widely accepted as a global imperative. Little progress will be made to achieving sustainability without a major paradigm shift. Radical social work has a commitment to social change and social justice. The author argues that social work education, which already has a firm tradition of empowering praxis, is strategically placed to contribute to education for sustainability. In order to make such a contribution, it must add environmental issues to its agenda.
\end{abstract}

The thesis explores the author's application of an ecofeminist epistemology to her own pedagogical practice as a social work lecturer. Ecofeminism was chosen as having potential to contribute to new approaches to social work pedagogy because, like social work, it focuses on multiple injustices. Ecofeminism links social injustices, especially for women and people of colour, to the degradation of the earth.

The thesis explores the history, development and key themes of ecofeminism and identifies elements of an ecofeminist praxis. The contextual background for this development is a discussion of the author's own experience as a social worker and social work educator, including key themes and issues raised by critiques of pedagogy from social work, feminism and ecology.

The writer describes the participatory action research she conducted with social work and tourism students at the University of Lincolnshire and Humberside in the United Kingdom and in her regular social work teaching at Victoria University of Wellington, New Zealand. The teaching focus was 'sustainable community'. Research participants' perceptions of sustainable community were canvassed at different times during workshops and regular teaching sessions. These included lectures, discussions and participatory Boal-type theatre.

The research design was participatory and reflexive, involving cycles of planning/action/reflection and further planning. The reflexive process was assisted by the use of video/audio recording and playback, questionnaires and response sheets. The empirical material was analysed using thematic categories and research outcomes were integrated into an interpretative framework using elements of an ecofeminist praxis.

The author concludes that the ecofeminist praxis she developed makes a significant contribution to social work pedagogy. It expands the social work agenda to include the environment as a focus of concern as well as a source of knowledge. She suggests that the usefulness of ecofeminist praxis lies in its ability to transcend disciplinary boundaries and to make contributions beyond academia. She cites examples of an application of ecofeminism to a pedagogy of sustainability with potential to make creative responses to issues of local and global concern. 


\section{ACKNOWLEDGEMENTS}

This thesis has been much more than a piece of research. It has become a metaphor for my life over the three years of its gestation. During it I have experienced significant change - the death of my mother, who taught me to love people and the planet with an equal passion; the death of my beloved cat; the loss of my career as a teacher at Victoria University of Wellington; and my move from a city to a large rural property. Without the consistent love and support of my family and friends, this thesis would not have been completed.

My partner, Jill Abigail, has been unflagging in her encouragement and practical support. She has undertaken the major tasks of editing and typing much of the thesis, carried out more than her share of the household chores, and, most importantly, kept me focused when my inclination was to retreat to the delights of my garden. For her commitment to see this process through with me, I am deeply grateful.

My two formal supervisors, Jenny Neale and Sara Kindon, have listened, read drafts, made helpful comments and above all, believed that I would actually finish this work. I thank them both. I am also deeply grateful to Pat Shannon and Laurie Jackson, who encouraged me to extend my original Master's thesis.

During my research leave at the University of Lincolnshire and Humberside, I was generously encouraged and supported by Professor Gary Craig, Ms Steph Petrie and Dr Alison Lewis. My thanks go to them, and to the social work and tourism students with whom the research was carried out. I thank also my students at Victoria University for being willing to take part in the research as part of their courses.

Translating ecofeminist principles into social work pedagogy was challenging. Having them shape the guardianship of a precious patch of Aotearoa/New Zealand wetland is even more so. It is a challenge I am embracing with intense joy. 


\section{CONTENTS}

ABSTRACT

1.1 Aims and objectives 1

1.2 Scope and limitations 3

1.3 Personal position 4

1.4 Evolution of the research focus and questions 6

1.5 Style of presentation 9

$\begin{array}{lll}1.6 & \text { Writing roles and purpose } & 10\end{array}$

1.7 Key theoretical ideas and gaps to be addressed 10

1.7.1 Ecofeminism as the praxis framework 11

$\begin{array}{ll}\text { 1.7.2 Social work education } & 12\end{array}$

1.7.3 Sustainability and community $\quad 14$

$\begin{array}{lll}1.8 & \text { Research design and methodology } & 18\end{array}$

$\begin{array}{lll}1.9 & \text { Thesis structure } & 20\end{array}$

CHAPTER 2 ECOFEMINISM AS PRAXIS 22

2.1 History and development of ecofeminist thought and action 22

2.2 Common themes and distinct features 25

2.2.1 Historical and causal 26

2.2.2 Conceptual and theoretical 28

2.2.3 Empirical and experiential 31

2.2.4 Epistemological 32

2.2.5 Symbolic and spiritual 33

$\begin{array}{lll}2.2 .6 & \text { Ethical } & 34\end{array}$ 
$\begin{array}{lll}\text { 2.2.7 Political } & 35\end{array}$

2.3 Elements of an ecofeminist praxis $\quad 36$

2.3.1 Theoretical location and academic status 37

2.3.2 Focus on multiple injustices and privileging voices from the margins $\quad 39$

2.3.3 Focus on identity as embodied and embedded 40

2.3.4 Identification as diversified global movements and as personal, political projects

2.3.5 Parallel discourses of commonality/unity and difference/diversity $\quad 46$

2.3.6 Significance of indigenous and spiritual dimensions 48

2.4 Conclusion

CHAPTER 3

3.1 Introduction: meanings of education and pedagogy

3.2 Personal location within social work sites as oppositional contexts

3.3 Factors shaping my reflective practice as a social work educator

3.3.1 Gender, ethnicity and culture 58

3.3.2 Socio/economic/political influences

3.4 Social work pedagogy: key theoretical components and multiple practices

3.4.1 The primacy of practice teaching 63

3.4.2 The change focus $\quad 64$

3.4.3 The diversity of paradigms 65

3.4.4 The centrality of experiential learning 69

3.5 Feminist critiques and contributions to pedagogy 72

3.5.1 The nature of knowledge and how it is acquired 
3.5.2 Construction of discourses of 'empowerment' and 'power' $\quad 74$

3.5.3 Construction of identity in the classroom 75

$\begin{array}{lll}3.6 & \text { Ecological critiques and contributions } & 77\end{array}$

3.6.1 The ecological principle of 'holism' 78

3.6.2 The ecological principle of 'sustainability' 79

3.6.3 The ecological principle of 'diversity' 80

$\begin{array}{ll}\text { 3.6.4 The ecological principle of 'equilibrium' } & 81\end{array}$

3.6.5 Applying ecological principles in the social $\begin{array}{ll}\text { work classroom } & 82\end{array}$

3.7 Conclusion: The multiple purposes of social work pedagogy 82

CHAPTER 4 THE RESEARCH PROCESS, ACTIVITIES AND RATIONALE $\quad 85$

$\begin{array}{llr}4.1 & \text { Introduction } & 85\end{array}$

$\begin{array}{lll}4.2 & \text { The research process } & 87\end{array}$

4.3 'Upstream' activities and their contribution $\begin{array}{ll}\text { to the research process } & 87\end{array}$

4.4 'Midstream' activities and methodological choices 93

4.4.1 Criteria for my choice of research methods 94

4.4.2 Identifying sites for critical reflection 96

4.4.3 Gaining access to the United Kingdom research sites 102

4.4.4 Building research relationships 103

4.4.5 Recruiting the two groups to participate in the $\begin{array}{ll}\text { research } & 104\end{array}$

$\begin{array}{ll}\text { 4.4.6 Planning Workshop One } & 107\end{array}$

4.4.7 Conducting Workshop One - Lincoln $\begin{array}{ll}\text { tourism students } & 111\end{array}$

4.4.8 Conducting Workshop One - Humberside social work group 
4.4.9 Reflection on Workshop One - Lincoln tourism students and Humberside social work group

4.4.10 Conducting Workshop Two - Lincoln tourism students

4.4.11 Conducting Workshop Two - Humberside social work group

4.4.12 Reflection on Workshop Two - Lincoln tourism students and Humberside social work group

4.5 Planning the 'downstream' activities in Aotearoa/

New Zealand

CHAPTER 5 RESEARCH OUTCOMES AND WAYS OF MAKING MEANING

5.1 Introduction

5.2 Choosing how to 'hear', 'read' and view' the research outcomes

5.2.1 Involving the research participants

5.2.2 Focusing on change

5.2.3 Utilising ecofeminist praxis principles

5.3 Outcomes and process of making meaning

5.3.1 Identity of teacher/students in the pedagogical process

5.3.1.1 'Introductions' as a window on identity

5.3.1.2 The complexity of elucidating identity within the classroom

5.3.2 Generation of knowledge about sustainable community 143 5.3.2.1 Enunciating the concept in the United Kingdom 143 5.3.2.2 Enunciating the concept in Aotearoa/New Zealand 
5.3.3 The role of self-reflective pedagogy in finding change options

5.3.3.1 Bringing about sustainable community $\quad 160$

5.3.3.2 Deepening the levels of understanding 162

5.4 What about the 'feminist' in ecofeminist praxis? 163

$\begin{array}{lll}5.5 & \text { Conclusion } & 164\end{array}$

CHAPTER 6 WEAVING NEW PATTERNS: ECOFEMINIST PRAXIS IN SOCIAL WORK PEDAGOGY - AND BEYOND

6.1 Ecofeminism on theoretical intersections and academic margins

6.2 Ecofeminism's focus on identity as embodied and embedded

6.3 Ecofeminism's parallel discourses of commonality/unity and difference/diversity

6.4 Ecofeminism's focus on indigenous and spiritual dimensions and on 'voices from the margins'

6.5 Extending the ecofeminist canvas: within and beyond the academy

6.5.1 From ecofeminist praxis towards a pedagogy of sustainability

6.5.1.1 Building an inclusive learning community

6.5.1.2 Expanding identity - lived-in bodies and

bodies in living systems

6.5.1.3 Community as mediating process between unsustainability and sustainability

6.5.1.4 Engaging in appropriate knowledge exchange and generation

6.6 Can social work education accept ecofeminist challenges? 
GLOSSARY OF MAORI WORDS

BIBLIOGRAPHY

191

APPENDICES

215 


\section{CHAPTER 1}

INTRODUCTION

As part of the ongoing flow of my life's activity, its spaces, actions, thoughts, feelings and directions, the writing of this thesis is presented as a selfconscious focus on my activities and reflections as a teacher. It captures fragments of my personal and professional life and weaves them together. It is not an autobiography, yet it contains biographical material; it is not an essay, yet it draws on literature in the field and critically appraises it; it is not a letter, yet it seeks to convey a sense of meaningful connection with the reader; it is not a sermon, yet it seeks to articulate a message of challenge and hope. It is a doctoral thesis.

\subsection{Aims and objectives}

The aim of the thesis is to explore ecofeminist principles in the context of social work education, and in particular to apply these principles to the discourse and practice of social work pedagogy. With the sustainability imperative in mind, it focuses on the development of 'sustainable community" as a process to which social work activity could contribute. It aims to lay the foundation for further research towards the development of expanded pedagogies reaching beyond social work education to other disciplines.

Specific objectives flow from these broad aims:

- an exploration of ecofeminism focuses on the question "What are the origins, common themes and distinct features of ecofeminist thought and action?"

- an application of ecofeminist principles to social work pedagogy focuses on the question "What are the key issues and dilemmas within current social work pedagogy and how might an ecofeminist praxis address them?"

- an application of ecofeminist praxis to educating for sustainable community illuminates a question for the present - "How could I prepare social work students to face the challenges of addressing social and environmental injustice, employing theoretical rigour and realistic practice?"- and for 
future research - "Can principles derived from an ecofeminist praxis within social work pedagogy be extended to other educational endeavours?".

The relationship between the aims and objectives can be represented by the following diagram:

Figure 1.1

\section{RELATIONSHIP BETWEEN RESEARCH AIMS AND OBJECTIVES}

\section{AIMS}

\section{OBJECTIVES}

\section{Explore:}

ecofeminist principles in context of social work education

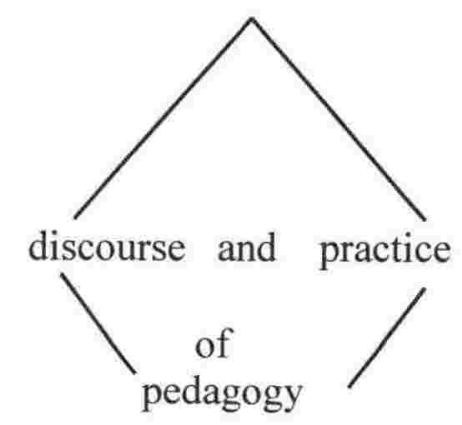

Apply:

ecofeminist principles ecofeminist praxis

sustainable community

\section{Extend:}

ecofeminist praxis social work pedagogy and beyond 


\subsection{Scope and limitations}

The areas covered within this thesis are complex and span a diversity of philosophical, conceptual and multi-disciplinary perspectives. The delineation of the thesis may be represented by the following diagram:

\section{Figure 1.2 SCOPE OF THESIS}

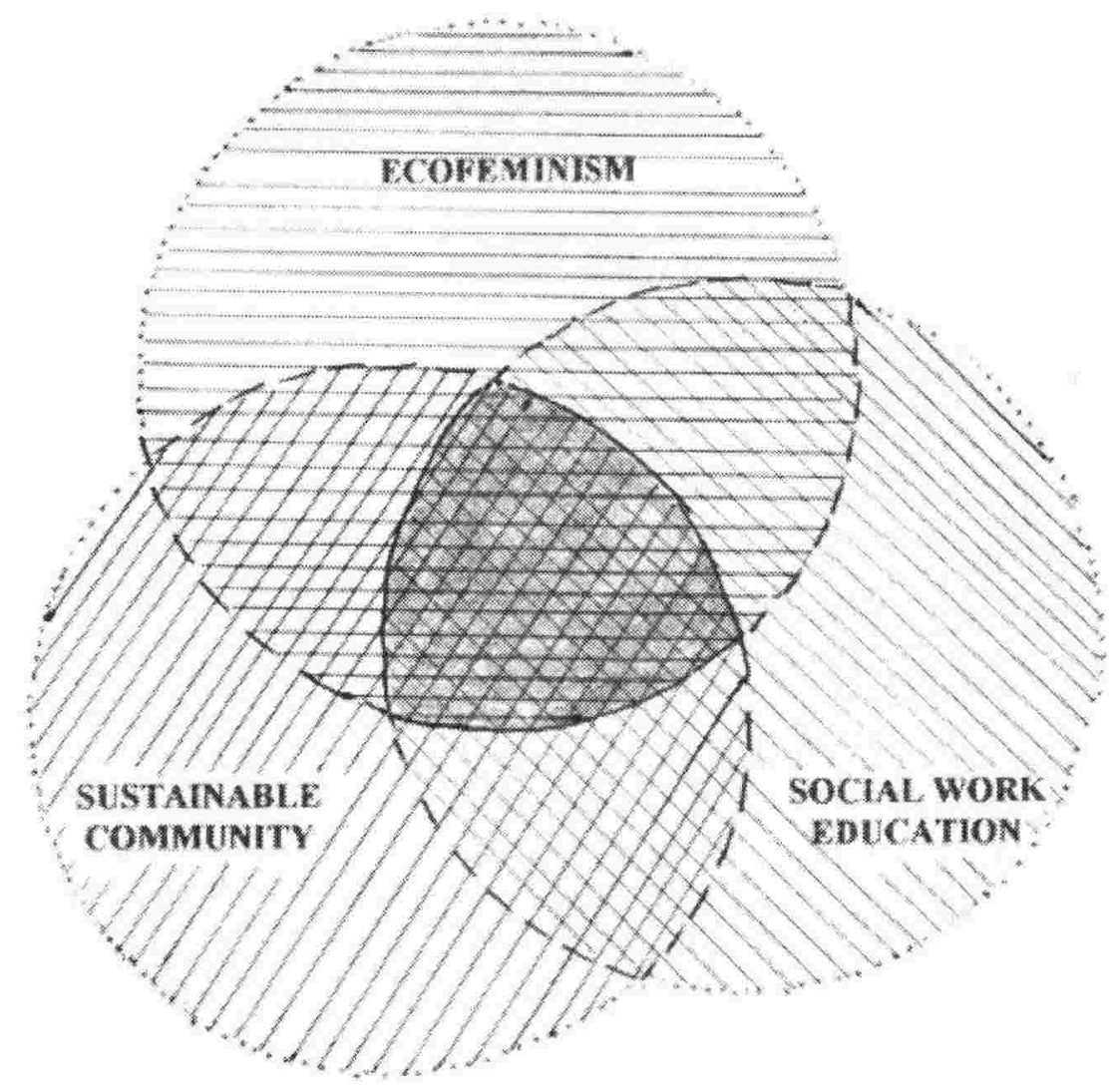


To give contextual meaning to the thesis, connections between the three main areas of study are included (represented by the three areas with double line shading in Figure 1.2). The theoretical focus lies at the intersections of ecofeminist, social work education and sustainable community discourses (represented by the most densely shaded area in Figure 1.2). The research focuses on the interactions between (1) students (some social work and some from another applied humanities discipline), (2) me as the facilitator of learning and (3) the knowledge generated in a reflective process of learning and teaching. In this case, the desired outcome from the learning/teaching process is an ability to understand and apply 'sustainable community'. These two aspects are at the heart of the research.

\subsection{Personal position}

Over the years my personal interests and academic study have resulted in a complex web of interconnected strands from which the fabric of my position as a person and as a lecturer has been woven. This position includes at least two main strands. The first involves: a love of the earth (gardening); exploring the natural world (tramping); studying the earth (studying science subjects to university level and a continuing interest in natural sciences); wanting to protect the earth (involvement in environmental groups); enjoying the earth and wanting to share that enjoyment with others (establishing a women's walking group). The second strand includes: studying the social sciences (a BA in education and sociology and a Diploma in Social Work); choosing a career in social work (ranging from generic governmental social work and family therapy to community work, supervision and group facilitation); policy development in local and central government; and teaching in a university social work programme. The writing of this thesis replicates the interweaving of these diverse influences and honours a feminist commitment to holding connection and difference in creative tension.

Between the personal and professional positions I occupy, tensions often develop. The contradictory values and action commitments inherent in these positions contribute to the tensions. For example, as a New Zealander of Irish 
and English descent I am part of the dominant culture which imposed its colonising will on Maori ${ }^{1}$, an imposition which has contributed directly to their being disproportionately represented as consumers of the social work services. I have for many years participated in the training of both Maori and pakeh $a^{2}$ for employment within these services. As a lesbian, my primary emotional, political and sexual identification is with women, and thus on the margins of the dominant heterosexual culture; yet much of my time is devoted to teaching theories about human experience which, by design or ignorance, excludes homosexual experience. As a person over the age of 50 and therefore considered 'older', I believe my life and work experiences have made me wise; yet I operate in a technologically sophisticated and constantly changing environment which can easily make me feel inept. As a woman, I experience discrimination on the basis of gender in Western patriarchal society; yet amongst family and friends I am highly regarded.

My involvement in feminist analysis from the early 1970s sensitised me to the oppression of women in the family and in the structures of society; and my social work with clients of the social services highlighted for me their experiences of social injustice, classism, and racism. Parallel with this, firsthand experience of climate change, air and water pollution and species loss alerted me to the environmental crisis and the reality and pervasiveness of ecological injustice.

My working class family background had inculcated in me a strongly pragmatic view of the world - words without deeds were considered empty. When I became a social work educator, I regarded education as a vehicle for facilitating change. I was committed to a "praxis of social change" (KramerDahl 1995:22). It was a natural step, then, for a dual focus on social and environmental justice to fuel my interest in looking for theory which could illuminate the possibility of common threads between these areas and that would enable me to address these issues in the classroom.

\footnotetext{
${ }^{1}$ Technical limitations have prevented my using macrons on Maori words in this thesis.

${ }^{2}$ Pakeha means New Zealander of European descent. There is a glossary of Maori words at the end of the thesis.
} 
Reading post-modern literature exposed the socio/cultural/historical/political 'situatedness' of social work practice and social work pedagogy discourse. For me, postmodernist approaches to 'making meaning' resonated with the feminist literature I had been reading in the 1970s and 1980s. The discourse of feminism gave me a language to articulate my experience as a woman. 'Sisterhood' brought a sense of solidarity and a context for action. Exposure to the later feminist critiques, however, soon made me aware that no one feminism could speak for all women. Differences derived from class, race, age and sexual orientation, to name a few dimensions, meant that there had to be 'many feminisms.' What feminism did was to highlight the patterns and processes which are common to the oppression of women and people of colour and to class differences. Ecofeminism extends that analysis to include the so-called 'natural' world.

Writing this thesis therefore has meant that I have brought to it my own subjectivity as a middle class (by education), older, lesbian woman social work educator in a university context. These multiple identities influenced and shaped all aspects of the thesis, from how I formulated the research focus to how I made meaning from the outcomes.

\subsection{Evolution of the research focus and questions}

It has become my practice over the last few years to keep a teaching journal as part of my commitment to reflective practice (Schon 1983,1987). It is one thing, however, to be self-reflective and quite another to commit oneself to academic writing open to peer critique. Like Batsleer et al. (1985:9-10, quoted in Kramer-Dahl, op. cit.:22), I view academic writing as holding the potential for either "regulation and exploitation" or "resistance, celebration and solidarity". Both these options were open to me in this doctoral degree process. They existed from the origins of the research questions to the actual writing and presentation of the thesis. 
Inasmuch as it is ever possible to trace the origins of research questions which lie deeply embedded within the researcher's own life experiences, the first discernible emergence of questions around this topic arose out of my reflections on several contradictions. They included on the one hand my enjoyment of the natural world as a walker and gardener and my experience of living in a warmly supportive family and community; and on the other hand my growing awareness, through reading and personal observation, of the alarming rate at which social and environmental systems are breaking down. While working at the practice end of my social and community work career, I was thoroughly socialised by the capitalist industrial ideology which saw the family, the community and the wilderness as places in which to recuperate from the labour of the capitalist economy. But it was in the area of my spiritual reflection about my place in the world that questions about the existence of a different quality of social/environmental connection began to arise.

Early feminist writers on spirituality (e.g. Gray 1979, Reuther 1975) inspired reflection on questions about how to connect the social and the natural worlds. For example, I began to question whether my interpretation of the concept of 'community' itself was too narrow. What were the links between the communion of saints, my family, friends, school, neighbourhood, and the communities of plants and animals and the so-called inanimate material composition of the earth?

The environmental writers of the 1980s (e.g. Milbrath 1989) added the dimension of the question related to sustainability. I already knew from my career movements from individually oriented counselling and social work to working with families and communities, that efforts to sustain healthy, productive social relationships presented an increasingly complex challenge for me as well as for the people I worked alongside professionally. When the natural world - which from my science training I had assumed was a dynamic but inexhaustible resource - began to be described as under threat of collapse and having almost reached its limits (Lovelock 1979, Milbrath op. cit.) the 
whole question of both social and environmental sustainability began to take shape.

The assumption I make about the notion of sustainable community is that there are limits to growth (Meadows et al. 1992). Current economic and social policies that rely on endless growth result in unsustainable outcomes. Conflict over diminishing resources is likely to escalate to unmanageable proportions (Craig 1998). Social work cannot avoid, in my view, addressing issues of such concern.

Because both the global and the personal were intimately linked in the emergence of the questions, the struggle for me to confine them to manageable proportions forced me to ask more grounded ones. "What is sustainable community?" pared down to "What can social and community workers do to facilitate sustainable communities?". This still left a large chasm between what I was actually doing and what could realistically be undertaken in a research project. What I was actually doing was facilitating the learning of social work students about working with communities and families. So, like tracing the ripples of a stone thrown into a pond back to the stone and then to the thrower herself, the focus moved to what I do as a reflective facilitator of learning.

With this foundation, the evolution of the research questions did not proceed in a linear fashion. Instead, it became a dynamic, dialectic spiralling interaction between elements sometimes dualistically related. In this construction, questions revolving around theory and practice, local and global, student and teacher, content and process, personal and political are inseparable, imploding into each other. The epistemological foundation became the referent space within which I chose to participate in the dance around the questions as they swayed, oscillated, and vibrated between the dancers and the dance. Lest I succumbed to the dizzy seduction of the movement, everything from the students' questions of how all this related to the lives of the people in their communities through to my own battle with 
restoring balance in the garden, kept me and the research question firmly grounded.

\subsection{Style of presentation}

Post-modernist thought, like feminist thought before it, raises consciousness not only about what is said and done but also about the vehicle used to express it (Weedon 1987:21). Thus issues of voice, language and audience exert influences on the presentation of this thesis. My voice is unashamedly privileged, since the focus is on my activity as a teacher. My voice, however, is not singular, but multiple.

It is usual to distinguish the 'voices' of other writers and of participants in thesis research by using quotation marks or italics. I attempt to acknowledge the multiple voices when I speak by allowing the style of language to reflect the diversity of the voices. Thus, when using the 'anecdotal or autobiographical' voice the language is more personal and metaphorical; when discussing and analysing literature and its relevance to my teaching, it will be more impersonal (Kramer-Dahl op. cit.:22). As much as possible, when student voices are included, their own words, as recorded in written, video or audio-taped form, are displayed as quotations.

Inevitably, the selection of whose voices are heard and what language is used represent a conscious - or maybe sometimes unconscious - but deliberately partial choice (Stanley 1992:17). This is also true when the readership of the thesis is considered. I am assuming for the purposes of assessment that the audience will be academic, knowledgeable and professionally competent to judge this work according to prescribed academic standards. I am also committed to 'speaking' to a wider audience, and this makes me acutely aware of the extent to which my integrity as a writer is tested, as what to include, and how, is constantly weighed against these potentially diverse 'audiences'. Communicating clearly to one may fail to satisfy another. 


\subsection{Writing roles and purpose}

There were several reasons behind my decision to undertake this research. These different reasons jostled for priority as the research and writing of the thesis proceeded. Writing a thesis while teaching students involves participation in an important reversal - the assessor becomes the assessed; the supervisor becomes the supervised. There are a number of ways that this process parallels the experience of social work students who, by 'passing papers' demonstrate the degree to which their 'socialisation' into the academic role is successful. Their success in this role may come into direct conflict with professional social work agencies' expectations that they have the ability to write in quite different ways, in 'agency speak' for example. Just so, the purpose of my writing a thesis to demonstrate the ability to conduct postgraduate research involved tensions between that and other purposes. At times, the requirements of academic writing and research conflict with the creative, passionate performance of teaching practice. The challenge was to balance academic accountability to perform at a standard of excellence as a teacher in the university with professional accountability to engage in reflective practice as a social work educator.

As well as pursuing professional and personal goals, there was for me an additional political purpose in writing this thesis. I wanted to extend the traditional change focus of social work, and of feminism, to include environmental change. My hope was that particular pedagogical strategies applicable to bringing about social and environmental change would emerge. Such a political purpose is congruent with ecofeminist epistemology, which avoids false separation of political activity and theory.

\subsection{Key theoretical ideas and gaps to be addressed}

The key theoretical ideas enunciated in this thesis are grouped under three headings: ecofeminism as the praxis framework; social work education; and sustainability and community. The first two are covered in Chapters 2 and 3 
and the third is woven into the fabric of the thesis throughout. What follows is a brief introduction to these key theoretical ideas.

\subsubsection{Ecofeminism as the praxis framework}

The role and purpose of social work has been contested since its beginnings. Yet, at least for those approaches loosely described as 'emancipatory' (Dominelli 1998:3), finding ways of eradicating social injustice has been the primary purpose. The messages of how seriously human injustices continue to be perpetuated around the world are conveyed constantly through international communication channels. At the same time those channels carry increasingly urgent warnings about the escalating level of environmental degradation. The implications of the environmental crisis are that the earth may one day be unable to support human life because we have destroyed that capacity. Human activity as it is currently enacted upon the earth is indisputably oppressive to many peoples and to the planet (Meadows et al. op. cit.; United Nations Conference on Environment and Development 1992).

The modern social worker, then, faces the imperative to add environmental justice to a social justice agenda (Anderton 1997). Interrogation of the causes of injustice and a search for change options inevitably involves a wide scan of complex and multiple theoretical positions. Ironically, at a time in history when globalisation facilitates the spread of knowledge not only of injustices but also of ways of addressing them, grand causal theories as well as universal solutions to gender, race, class and environmental injustices have largely lost traction (Adams, Dominelli and Payne 1998:243).

Echoing feminism, post-modern renderings of the context or 'situatedness' of all activity highlighted for me that a useable praxis in social work would necessarily be one which paid close attention to the diverse, multiple and oppositional contexts of the profession (Harre Hindmarsh 1992). The impact of post-modern and feminist critiques of social work have seen some broadening of the context to include economic, political, and cultural components (op. cit.). I argue that, in spite of social work's early commitment 
to an ecological approach (Meyer 1995:16), there is little evidence that the profession appreciates the human species' total dependence on the natural world, or considers such appreciation worthy of serious study (Anderton op. cit.). For example, a recent social work text has in its 400 pages of relevant, impressive, scholarly writing, only one reference to the natural environment in connection to social work (Adams, Dominelli and Payne op. cit.).

It is not surprising, then, that the search for theory and practice integrating environmental and social concerns led me outside the confines of social work. In this instance it was to a body of writing and action generally termed 'ecofeminism'. Some features of ecofeminism that offered both affinity for and challenge to my theoretical and practice knowledge included:

- its plethora of theoretical approaches located on the intersections of multiple disciplines, both within and outside the academy

- its focus on addressing multiple injustices and attention to the condition of the under-privileged

- its identification as a diversified global movement and a personal political project

- its focus on identity as embodied and embedded

- its recognition of commonality/unity and difference/diversity as both important in the discourse of human/nature and human/human interactions

- its recognition of the significance of indigenous and spiritual dimensions.

These features are considered in detail (see 2.3.1 to 2.3.6). Arenas in which the theoretical and practical aspects of ecofeminism have been applied have continued to expand (Warren 1997). Social work education seems to be one area that has largely been excluded from such an application. My intention in this thesis is to change that situation.

\subsubsection{Social work education}

As an activity distinct from the pre-industrial 'caring' carried out by the family, the church and the community, social work is inextricably linked to the 
rise of the welfare state in capitalist, industrialised nations. Social work has always been closely involved with theories and practices variously aimed at:

- assisting individuals to adapt to difficult social situations

- challenging social exclusion and working for citizens' rights

- problem-solving in relation to interpersonal problems

- challenging social systems to become more responsive to human needs and

- locating and supporting the natural networks within communities in order to strengthen them (Payne 1997).

Despite decades of social work intervention under the umbrella of the welfare state, social disruption in human communities - indicated by, for example, increased incidence of domestic violence, youth suicide, child sexual and physical abuse, poverty and family break-up - is increasing. Social work education has been one amongst many areas thought to have the potential to influence the effectiveness of social caring or societal change.

Yet social work education itself is replete with tensions about what the focus of its attention needs to be in order to ameliorate human suffering. It is claimed that the inherent 'oppositions' evident in social work practice are replicated in social work education (Harre Hindmarsh op. cit.). Students are expected to apply 'ideal type' theories to social work situations. When positive change in client situations fails to materialise, the accusing finger of government, social service managers or communities is variously pointed at inadequate agency funding, inept social workers and/or inappropriate education.

Dedicated educationalists have provided a plethora of responses to 'improve' the process of educational work, i.e. pedagogy, to make it more empowering (Ellsworth 1992), liberating (Freire 1973) or relevant (hooks 1994). Social work educators have drawn on feminist, critical and liberatory approaches within the social work classroom, but still students, agencies and universities are embroiled in a repetitive cycle of 'blame and resist change' (Harre Hindmarsh op. cit.). 


\subsubsection{Sustainability and community}

No-one would question the appropriateness of social work's focus on human suffering and its prevention or alleviation (Dominelli 1998). No-one denies the importance of the search for more effective ways to educate social workers (Lishman 1998). However, it is no longer possible to ignore the scale and pervasiveness of the environmental crisis that threatens the very survival of human societies.

Concern for the escalating rate of the decline of the earth's natural resources, loss of species diversity, climate change induced significantly by human activity and exponential destruction of natural ecosystems by pollution and overuse, have pre-occupied environmentalists for a long time (Grove 1990:11). These people were often regarded as irrational, eccentric extremists (Pepper 1996). As environmental concerns gained popular attention from the 1960 s onwards, scientists and activists expended energy in arguing about the accuracy of claims concerning the declining state of the environment, the reasons for that decline, and what should be done about it (Hawken 1993).

The deliberations of a number of international fora (World Commission on Environment and Development 1987; UNCED op. cit.), which for the first time had scientists, politicians and environmentalists sharing knowledge, led to a stark conclusion. This was that growth-oriented economies, which rely on ever-increasing use of non-renewable natural resources and production of waste destructive to ecosystems, must change if the planet and its human populations were to survive.

'Sustainability' was the newly popularised word which began to be used in the late 1980 s as governments were unable to ignore what had once been the refrain only of environmentalists and some scientists - that human societies face an indisputable challenge to change fundamentally our relationships with the environment (Ife 1995:10). While the rhetoric of sustainability seems attractive, its translation into action poses a real challenge (Nattrass and 
Altomare 1999:6). So strong are the metaphors supporting dominant Western capitalist patterns of consumption and growth that sustainability's demand that we meet the needs of the current generation without making it impossible for the world's future citizens to meet their needs (WCED op. cit.) provides many opportunities for side-stepping the really difficult issues.

Sustainability is a socially constructed idea and as such has no single and agreed meaning. It reflects the economic, social, cultural and political context in which it is used (Huckle 1996:3). For example, when used as an adjective there is a danger that its power as a concept is weakened. In 'sustainable development', for instance, its meaning changes depending on how 'development' is understood and enacted. If development relies on the progressive use of non-renewable resources, sustainable development becomes an oxymoron (Sachs 1993). If, however, development is seen as an organic process, operating within constraints and processes consistent with sustainability principles, then the two concepts are mutually reinforcing.

The fluidity of sustainability's meaning and application can obscure the fact that despite the diversity of interpretations there is striking consistency between how many hundreds of groups (largely non-governmental) understand and apply the notion (Hawken 1998). These commonalities include a focus on the future, on flexibility, and on wisdom, to make new decisions about the relationship between human resource use and the earth (Meadows et al. op. cit.:209). New 'mental models' (Hawken op. cit.) based on sustainability principles are used by widely divergent groups. The resonance between them exists because the principles are derived from living systems, not imposed from outside. Central to the exploration of how sustainability is to be understood and applied is an acknowledgment that indigenous communities and 'people on the margins' retain much of the knowledge about sustainability buried by the constructions of the industrial revolution and colonisation.

Addressing the negative impacts of industrialisation and colonisation on individuals, families and communities has been the preoccupation of social 
workers and community workers. While generic social work activity includes conscious effort to include the community as an integral factor in the design and delivery of social services, it was the more political, more structurally focused features of working directly with communities that was the focus of my teaching on the social work programme at Victoria University.

Like 'sustainability', the notion of 'community' is surrounded by confusion. Social science formulations of the notion of community wrestle endlessly with its complexity (Pearson 1990). Those who view community as an organic form of social organisation suggest it has the following characteristics: it is human scale; it incorporates a sense of belonging and identity; it involves obligations; it encourages interactions with others as 'whole people' (Gemeinschaft); and it endorses diversity of culture as a dynamic identifiable aspect of social organisations (Ife op. cit:90-91).

The very vagueness of the term in popular usage leaves it open to 'capture' by ideologies at both ends of the political spectrum. It can be used to justify retrenchment of publicly provided social services. For example, 'community care' means more work is done in the community to care for its vulnerable members, with the load falling unequally on some - usually women (Mayo 1994:55). It can also be seen as one of the elements of movement towards a sustainable society (Shuman 1998:180).

'Sustainability' and 'community' are both highly contested terms. When they are linked, the resultant notion - 'sustainable community' - can be well nigh impossible to define. Yet at least in the United States the notion enjoys considerable popularity amongst community developers and futurists (Yamaguchi 1997). Ife (op. cit.:89) suggests that when ecological perspectives (what is feasible) and social justice perspectives (what is desirable socially), are taken together, they form the basis for a vision of a future society. I argue that when feminist perspectives are included the outcome is the basis for a notion of 'sustainable community'. The values associated with such a notion include cooperation, empowerment, compassion, 
long-term perspectives, global outlook and sustainability (Yamaguchi op. cit.:112).

The challenge is how to translate such values into tangible social, environmental and feminist policy and practice. Most writers agree that what is needed is a revolution of thought and detachment from old paradigms which have kept most of the West, at least, "addicted" to ways which are unsustainable socially and environmentally (Beare and Slaughter 1993; Huckle and Sterling 1996; Milbrath op. cit.; Schaef 1992a and 1992b). Cycles of unsustainability, like cycles of addiction, are notoriously difficult to break. Just as destructive patterns of behaviour persist in the interpersonal and intrafamilial fields of social work activity, so societal patterns of unsustainability show amazing resilience against attempts to change them. A common claim in the literature is that the change in consciousness required to bring about a paradigm shift goes beyond the cognitive and involves a deep, pervasive and infinitely diverse spirituality (Schaef 1998; Milbrath op. cit.).

I argue in this thesis that if social work education accepts the sustainability imperative, it will need to re-examine its commitment to 'community work'. There is a long history of ambivalence towards the subject within tertiary institutions. It is sometimes accorded a place in tertiary programmes, sometimes not (Craig 1987:100). In New Zealand there has been significant tension between social and community work, with traditional social work attracting more resources and recognition. Community work's emphasis on radical social action made it less attractive to governmental funding bodies (Nash 1997:16). In challenging the social work profession about its mission, Specht and Courtney describe as "unfaithful angels" practitioners who abandon social work's founding commitment to viewing people in their social/political/cultural context, in favour of individualistic, therapeutic models:

"The major objective of social work practice is to develop and strengthen communally supported services and to enable participants to make use of social resources available to them" (Specht and Courtney 1994:171). 
The challenge this thesis poses is for social work not only to renew its examination of 'community' as a working model for empowering human communities, but also to expand its application to non-human ecosystems. I argue that social work has two tendencies in regard to this expansion. On the one hand, its grounding in the paradigms of dominant, white, Western capitalism, make it potentially resistant to any call to expand its vision for action. On the other hand, its unusual location on the intersections of a number of different disciplines such as sociology, psychology, education, anthropology and philosophy means that it has greater potential to move into a new conceptual space opened up by the notion of sustainability.

New wine, however, needs to be contained in new bottles. One of the flaws in the old paradigms supporting unsustainability is the false separation between the human and the non-human. It is to a 'transgressive' epistemology ecofeminism - that this thesis looks for inspiration to inform a new social work pedagogy.

\subsection{Research design and methodology}

The design of this research was informed by the principle of congruence. A prominent discourse in social work relates to congruence between supervision styles, for example, and the approaches employed when working with people and structures in society. If social workers are to engage in reflective practice, social work supervision follows a reflective stance. Similarly, since I operated as a reflective social work educator, research aimed at illuminating pedagogical processes needed to be congruent with this stance.

Therefore, far from proceeding along linear lines of progression from "warmup, work-out and cool-down" (Janesick 1994:209), as some of the literature on qualitative research design suggests, this research was designed to facilitate planning/action/observation/reflection/action spirals (Carr and Kemmis 1986:186). One aspect of the design - comparing what was planned for a teaching module with what actually happened, and why, as recorded in my 
teaching journals - was already in place before the research began. It followed that all the decisions about what to do to forward the research were made in the light of the pattern already established.

Although my aim was primarily to initiate feedback loops on my personal reflections, the ecofeminist epistemology framing the study rendered unacceptable an exclusion of the other players located within the learning community - i.e. the students. To this end, I planned research strategies that made students pivotal in the reflective process. I wanted to include their perceptions of the impacts of an ecofeminist praxis on their understanding of the notion of 'sustainable community' and how such community could be brought about. I devised two questionnaires that asked students to reflect on the notion. The first was given before the workshop or teaching sessions, and the other at the conclusion of these activities. As a way of ensuring that this exercise was genuinely part of the research participant's learning, and not solely for my use as a researcher, the questionnaire responses were summarised and returned to the students. In the research workshops in the United Kingdom, this enabled the students to reflect on their initial responses. In the teaching modules in New Zealand, it had the added role of contributing to the resources on which students could draw to complete their assignments.

My reflection on the usefulness of the questionnaires given to my classes in New Zealand prior to my research leave informed the development of more refined strategies of interpretive data collection for use in the main part of the research, which was conducted in the United Kingdom. At the University of Lincolnshire and Humberside I ran workshops and lectures within degree programmes to both social work and tourism students. In planning these workshops, which were to consist of two sessions, I decided to expand the reflective potential by video-recording the sessions. This would enable me to see and hear myself and also to see and hear the students' responses to the material presented and to the pedagogical processes. In addition, I was inspired by the idea that the students themselves could participate more actively in the reflective process if they too, in the second session, viewed the video of the first workshop, and together we reflected on the meanings and 
outcomes of the session. The expectation here was that deepened learning might emerge for all those involved, both the researcher and the researched (Elden 1981).

The video-recording of the second workshop sessions, with the students and I reviewing the video of the first session, formed part of a triangulation of research methodologies (Janesick op. cit.:214). Analysis of the questionnaire responses, two sets of video recordings and a rating response form, formed the basis of the research design and methodologies.

Upon my return to New Zealand, I wove what I had learned in the United Kingdom into a final research exercise that was carried out during normal course teaching. This involved: the use of questionnaires; my own reflections on the teaching, including results of student learning evident in their assessed assignments; and analysis of one video-taped session.

\subsection{Thesis structure}

The thesis is divided into five further chapters. Chapter 2 provides an overview of the literature on ecofeminism, exploring its history, development and key themes. It then develops elements of an ecofeminist praxis, with special reference to application within social work education. Chapter 3 opens with an exploration of the meanings of education and pedagogy. It considers social work pedagogy against the backdrop of my personal and professional path as a social work educator and against social work, feminist and environmental literature on pedagogy.

Chapters 4 and 5 focus on the research process and outcomes. I argue that the activities and reflections described in these chapters are not, in reality, separable because of the dynamic nature of action research. However, for convenience of presentation Chapter 4 describes the process, activities and rationale for the research, while Chapter 5 focuses on what emerged from the research activities, how I analysed the material and what meanings I attached to them. 
Chapter 6 draws together the components of the ecofeminist praxis I developed and how I applied it within social work pedagogy. It also examines the wider implications of an ecofeminist praxis for other disciplines and the wider community. Finally, it discusses the question "Can social work education meet ecofeminist challenges?". 


\section{CHAPTER 2 ECOFEMINISM AS PRAXIS}

"It is usually at the edges where the great tectonic plates of theory meet and shift that we find the most dramatic developments and upheavals. When four tectonic plates of liberation theory - those concerned with the oppressions of gender, race, class and nature finally come together, the resulting tremors could shake the conceptual structures of oppression to their foundations." (Plumwood 1993:1)

Race and class oppressions have commonly had an established place within social work theory and practice. Gender has attained a tentative place. Nature is rarely on the agenda (Anderton 1997). The history, common themes and criticisms of ecofeminism provide a backdrop to the discussion of those aspects of this relatively rarely used framework which have potential to 'unsettle' the foundations of social work pedagogy.

\subsection{History and development of ecofeminist thought and action}

Ecofeminism emerged in the 1970 s, alongside second-wave feminism and the green movement (Mellor 1997:1). While most ecofeminists credit French writer Francoise d'Eaubonne with coining the term in 1974 (Seager 1993:316; Warren 1994:1), Ariel Salleh suggests it appeared spontaneously across several continents in the 1970s (Salleh 1997:17). Ecofeminism appeared in response, suggests Mellor (op. cit.:46) to two crises of modernity:

disenchantment with science, development and technology; and the failure of liberal feminism to deliver the promised social and economic emancipation of women.

Since then, the term has been applied to a wide variety of perspectives, where some emphasise the ecological more than the feminist, and others the feminist more than the ecological. All ecofeminists, however, "refer to a variety of socalled "women-nature connections" - historical, empirical, conceptual, 
religious, literary, political, ethical, epistemological, methodological, and theoretical connections on how one treats women and the earth" (Warren ibid).

Because of the many shades of feminism and of ecology, the breadth of the topic makes for a complexity that can be difficult to grasp. Mary Mellor describes this complexity as "a tangle of ideas, an interweaving of many threads that will sometimes gather into untidy knots or trail out in numerous loose ends" (op. cit:8). This wonderful and sometimes frustratingly chaotic theoretical reality is just what could be expected when the multiple constructions of 'woman' and 'women's lives' are linked to the endlessly complex constructions of 'nature'. Ecofeminist origins in feminism and ecology have involved interrogation of the socially and politically constructed categories 'woman' and 'nature' and the connections between them.

During the late 1960 s and early 1970 s, liberal and socialist feminist theorists influenced the meaning of 'woman' in two distinct ways. There was, according to Dann, a tendency to revalue and "re-sacralise" (1992:346). To be re-valued, women needed to receive a fair exchange value for their work, access to paid work, recognition for unpaid work and improvements in their working conditions. The re-sacralising tendency, rather than favouring direct political action within social structures, relied more on women's personal actions to take back their 'natural' powers, and sometimes to disengage from existing social and political systems (ibid).

In recent years, ecofeminist writing has come from a wide variety of academic disciplines. These include philosophy (Cuomo 1998; Plumwood 1992, 1993, 1994; Warren 1994, 1997), sociology (Mellor 1992, 1997; Mies 1986; Salleh 1997), women's studies (Sturgeon 1997), geography (Rocheleau et al. 1996; Seager 1993; Silvey 1998); environmental studies (Merchant 1992) and physics (Shiva 1989, 1997). There is a reluctance on the part of some researchers within the 'ecology-feminism nexus' to use the label 'ecofeminist' 
(Silvey op. cit.:43). ${ }^{1}$ Alternative terms include 'feminist political ecology' (Rocheleau et al. 1996) and 'feminist environmentalism' (Seager 1993).

Ambivalence towards the term has led some writers who initially used it to abandon it (e.g. Biehl 1991), while others who in earlier writings avoided it now embrace it (Mellor 1997). Reasons for this ambivalence will be discussed later in this chapter (see 2.3.1).

In exploring theoretical perspectives to apply within social work, I drew from a broad spectrum of the gender-environment discourse, whether or not writers specifically used the term 'ecofeminism'. What is of interest to me in this study is how ecofeminism as an object of knowledge, as a political identity, and as a set of political strategies within the convergence of local and global environmentalisms, academic and activist feminisms, and anti-colonialist, anti-racist and anti-militarist movements (Sturgeon 1997) can be translated into praxis within social work pedagogy. ${ }^{2}$

Ecofeminism does not only represent a number of theoretical formulations but is, like feminism, a social movement. It grew out of the actions of countless women world-wide who saw the connections between what was happening to the environment and what was happening to themselves and their children (Seager 1993:237). Indeed, like feminism, ecofeminism had its origins in the arena of action, spurred by pressing political and practical concerns. The introduction of the term by Francoise d'Eaubonne was an attempt to bring attention to women's potential for bringing about an ecological revolution. As a natural consequence of reflection on grassroots activism, the analyses that

\footnotetext{
'In the early period of my research I was persuaded by Cuomo's arguments to use the term 'ecological feminism' as a subset of ecofeminism. This stance focuses on the "links and patterns among the treatment of oppressed, exploited or undervalued beings or entities" (Cuomo op. cit.:6). Cuomo distinguishes this from a stance that focused on the objects of oppressive and exploitative thought and action. Later, I reverted to using the term 'ecofeminism' for two reasons. False separation of the objects and the patterns that link them can easily reinforce dualistic relationships. Secondly, I wanted to rivet the term as a respectable theoretical one in the face of fierce criticism within the academy (Silvey op. cit.:243).

${ }^{2}$ In this thesis I use the term 'praxis' to involve the "theorising of practice and the development of theory through practice" (Everitt 1998:110). In particular, "the point is to change the world, not only to study it" (Stanley 1990:15).
} 
have developed have sought to explain, clarify and guide that praxis (Warren 1996:xvi).

The interweaving of theoretical and activist strands has produced patterns of common themes and distinctive features. Tracing these common threads and detecting distinct features from amongst the many ecofeminist offerings is a rewarding, if daunting, task.

\subsection{Common themes and distinct features}

Ecofeminist scholars have recently documented the complex interweaving of ideas that constitutes ecofeminist thought (Mellor 1997; Salleh 1997; Warren 1997). Just as ecology has many different shades (deep, social, human, radical) and just as feminism has many shades (liberal, socialist, radical, cultural, post-modern), so ecofeminism as a discourse has diversity resulting from the plurality of disciplines involved and the experiential environment that has shaped the writers.

The common ground occupied by all ecofeminist writers is that there are important connections between environmentalisms ${ }^{3}$ and feminisms. The ideologies that authorise injustices based on gender, race and class are significantly linked to those that sanction the exploitation, domination and degradation of the environment. If the connections between the domination of women and other subordinates and the domination of nature are not recognised, inadequate feminisms and environmentalisms result (Sturgeon 1997:27; Warren 1996:x).

Stanley and Wise have suggested that categorising in one-dimensional ways is a form of masculinist interpretation (1983:40). For similar reasons, and like

\footnotetext{
${ }^{3}$ Some ecofeminists use the term 'ecology' instead of 'environmentalism' as one of the contributing strands. This difference often reflects the different theoretical preoccupations of the contributing writers. I favour 'environment' for its political flavour, but use 'ecology' as an alternative term.
} 
Mellor, I resist pigeon-holing ecofeminists according to which strand of feminism or ecology most influenced their interpretations of ecofeminism (Mellor op. cit.:46). Such categorisation sometimes imposes limitations that unfairly restrict the intentions of the original writers. I prefer to think of these writers as taking up preferred vantage points from which some features of the ecofeminist landscape come into sharper focus.

I have adapted Warren's typology of the nature of feminist-environmental connections (Warren op. cit.:xi ff) in order to discuss the various vantage points occupied by ecofeminist writers. These include: historical and causal; conceptual and theoretical; empirical and experiential; epistemological; symbolic and spiritual; ethical; and political.

\subsubsection{Historical and causal}

Writers focusing on this connection argue that the current global environmental crisis is a predictable outcome of patriarchal culture (Mellor op. cit.; Salleh op. cit.). There is no single Western or capitalist or patriarchal world view, yet ecofeminists can trace common themes in the narratives that have shaped thought and action.

Patterns of domination that characterise patriarchal culture are identified by some as arising from ancient invasions of earlier partnership cultures (Eisler 1988; Spretnak 1990). Eisler describes the era before such invasions as matrifocal, matrilineal and peaceful (op. cit.:23-24). Such societies, she claims, exhibited an 'ecological consciousness' based on feminine values such as caring, compassion and non-violence. While Eisler's work has contributed to a re-reading of masculinist archeology, her romanticised account of history has been refuted by other research into the social and environmental behaviour of early cultures (Biehl op.cit.).

Other ecofeminist writers go underground and back into history to search the headwaters of the streams of thought which now irrigate our dominant epistemologies. They explore the role played by rationalism in classical 
philosophy as the basis of conceptual dualisms and disconnected consciousness (Plumwood 1993; Ruether 1975, 1992). They identify Plato, Aristotle, Descartes and Newton as having contributed to the development of such a consciousness (Plumwood op. cit.:97-103; Mellor op. cit.:180; Merchant op. cit.:57).

"Consciousness now divides the universe completely in a total cleavage between the thinking being and mindless nature, and between the thinking substance and 'its' body, which becomes the division between consciousness and clockwork. Gone is the teleological and organic in biological explanation. Mind is defining of and confined to human knowers, and nature is merely alien" (Plumwood op. cit:116).

Concrete evidence of alienative consciousness is in the way dualistic thinking pervades Western culture "like a fault line running through its entire conceptual system" (Plumwood op. cit.:42). The pervasive influence of dualistic thinking means that the distinct but connected aspects of social, political and cultural life have become not only separated, but also unequally valued. For instance, women's work and men's work become interlinked with the undervaluing and overvaluing, respectively, of reproduction and production (e.g. Salleh op. cit.:76 ff.). Separation of male from female and human from nature was reinforced through the interaction of industrialisation, capitalism and the technological revolution (Kimbrell 1997; Shiva et al. 1997). Because dualistic thinking persists in many guises, dealing with them forms a significant part of ecofeminist conceptual frameworks.

The scientific revolution put the final touches to the separation between 'wild nature' and nature that was to be mechanised, controlled and exploited in the interests of capitalist progress (Merchant op. cit.:41-59). The impact of the scientific revolution, which sanctioned the exploitation of nature and subordination of women, is documented by a number of ecofeminists (Merchant 1989, 1996; Mies and Shiva 1993; Shiva 1989). 


\subsubsection{Conceptual and theoretical}

Most ecofeminist analyses of the conceptual framework operating particularly in Western tradition maintain the twin dominations of women and nature (Gray 1979; Griffin 1978; King 1990; Merchant 1996; Plumwood op. cit.; Ruether 1975; Salleh op. cit.; Warren 1994, 1996, 1997). In particular, some locate the dominations in value dualisms, where the pairs are seen as oppositional and exclusive, and value hierarchies, where, using an up-down metaphor, higher value is placed on those items located above others (Gray op. cit.; Griffin op. cit.; Ruether op. cit.). Examples frequently used to illustrate these hierarchically organised value dualisms include reason/emotion, $\mathrm{mind} /$ body, culture/nature, human/nature, and man/woman dichotomies. One of the mechanisms by which dualisms are maintained is the extreme separation of the polarities, despite the fact that the very existence of the hierarchical relationship relies on the two being connected. Plumwood argues, for example, that viewing 'human' and 'nature' as separated allows for a relationship of domination of human over nature (Plumwood 1991:51-52).

Warren $(1994,1996,1997)$ expands the value dualism and hierarchy concepts to embrace a larger, oppressive patriarchal conceptual framework that undergirds all 'isms' and results in a 'logic of domination'. Not only does dualistic thinking result in artificially constructed separation, but also such separation 'naturalises' the domination of one part by the other. The 'logic of domination' (Warren 1996:21), for example, makes colonisation of peoples and lands a natural consequence of an alienative, disconnected consciousness. According to Warren, "a framework is oppressive if it explains, justifies and maintains relationships of domination and subordination...[It is] patriarchal when it explains, justifies and maintains the subordination of women by men" (Warren 1996:xii. Emphasis added).

Dualistic thinking is so ingrained that slippage is always possible. Haraway, along with other theorists, is concerned that feminist and socialist writers unintentionally deepen the very dualisms they seek to question or obliterate (Haraway 1991, cited in Cuomo op. cit.:84). While all ecofeminists aspire to 
the reconstruction of relationship and identity in terms of a non-hierarchical concept of difference (Plumwood op. cit.:67), the strategies used have not been very successful. Mellor, for example, suggests that attempts to transcend, dissolve or rebalance dualisms have failed (op. cit.:181-2).

For ecofeminists who are weary of what they perceive as the unrealistic and sometimes unappealing 'Mother-Earth-goddess ecofeminism', Haraway's use of a cyborg image offers a "helpful and provocative model of transgressive, insubordinate nature and culture-loving relationships and identities" (Cuomo op. cit.:85). A cyborg is a hybrid of machine and organism, which does not strengthen problematic dualisms. Its utility is that it playfully traverses and inhabits the boundaries between "nature/culture, human/animal, man/woman, scientific knowledge/'embodied' or 'intuitive' knowing"- categories, argues Haraway, which are "incredibly durable" (Haraway 1991, cited in Cuomo op. cit.:83).

Some ecofeminists find the 'cyborg' problematic, for a number of reasons. It betrays scientific and technical determinism (Scott 1989, cited in Cuomo ibid); it lacks sexuality and desire (De Lauretis 1994, cited in Cuomo ibid); and it smoothes the path for continued intrusive, oppressive technological body (especially female body) relationships (Shiva 1997). Despite these difficulties, recent ecofeminists cautiously acclaim its potential for envisioning women and nature "as political allies [emphasising] the importance of women as political activists and [stressing] the agency of nature" (Alaimo 1994 cited in Sturgeon op. cit.:194).

Another variation on conceptual linkages between feminism and the environment is based on sex and gender differences, particularly in development of consciousness. Salleh describes the degree to which consciousness is shaped by the separate experiences of men and women. She claims that female bodily experiences (e.g. of reproduction and childbearing), not female biology per se, situate women differently with respect to nature. The outcome of the alienative consciousness that develops is that "both nature 
and those who labour with nature are treated as 'resources' without intrinsic, that is 'human' value or rights" (Salleh op. cit.:187).

Drawing on historical accounts already described, some ecofeminists focus on the metaphors and models of mechanistic science as being responsible for a change in the conception of nature. Prior to the 17 th century, nature was metaphorically described as a benevolent female, a nurturing mother (Merchant 1980) Following the scientific revolution, the metaphor changed to that of a machine, inert and dead. Merchant claims that the move from organic to mechanistic imagery conceptually paved the way for the exploitation of the (female) earth, an exploitation that had been prevented when nature was treated as a living organism (in Maori terms, Papatuanuku). This rather simplistic view denies the reality of the exploitation and abuse of women even when the earth was symbolised as 'woman'. Warren suggests the ecofeminist challenge is to overcome metaphors which "feminize nature and naturalize women to the mutual detriment of both nature and women" (Warren op. cit.:xiii).

Efforts to organise the conceptual feminist-environment connections into coherent theoretical frameworks has spawned many different and sometimes competing positions. This is only to be expected in a field that is still emerging. The necessity to achieve theoretical rigour is spurred on by the gender invisibility in many of the burgeoning environmental theoretical positions. The result has been an increase in ecofeminist writing that has welldeveloped, thoroughly researched and coherent theory (e.g. Cuomo op. cit.; Salleh op. cit.; Mellor op. cit.: Sturgeon op. cit.). As Sturgeon says, "We do not need to produce a new and more perfect ecofeminism, but rather to recognise as necessary the dance of critique and consolidation that is part of theorizing and political action; the dialectic of creating, deconstructing and reforming political identities, new alliances, complex analyses, and creative oppositional strategies" (op. cit.:195). 


\subsubsection{Empirical and experiential}

Many ecofeminists have documented empirical evidence linking women and the environment. Such evidence points to the health risks associated with low level radiation, pesticides and toxins as being disproportionately borne by women and children (Diamond 1990; Warren 1997) and in particular by those living in the global South ${ }^{4}$ (Mies 1986; Salleh 1990, 1997; Shiva and Moser 1995). Others have produced experiential data linking 'First World' development policies and practices regarding food, forests and water with the inability of women to provide adequately for themselves and their children (Mies op. cit.; Salleh 1997).

As the theoretical framework of ecofeminist thought and action has expanded, there has been a corresponding increase in the breadth of topics considered by ecofeminist research. For example, Warren's 1997 collection of empirical studies covers not only the more traditional fields of ecofeminist inquiry, such as 'Third World' women and seed diversity, forest and ecosystem despoliation and animal rights, but extends to soil maintenance, chemical engineering, rape and war, care of children, work, leisure, indigenous people's rights and community.

The pre-occupation of some early ecofeminist empiricists was to study experiences of the 'other', such as women in the 'Third World'. More recently, under the influence of post-modern theorising, the focus is changing. The trend is increasingly for ecofeminists to interrogate their own practices and write about them rather than about 'the other' (Cuomo op. cit.:89).

\footnotetext{
${ }^{4}$ I use 'North' and 'South' as global descriptors. 'North' refers to the economically wealthy of industrialised nations usually located in the northern hemisphere as well as the wealthy in so-called 'developing' nations. 'South' refers to the economically poor of 'developing' nations usually located in the southern hemisphere, as well as the poor in richer countries.
} 


\subsubsection{Epistemological}

In response to these first three sets of linkages between feminism and the environment, mainstream views of reason, rationality, knowledge, and the nature of the knower have come under scrutiny by a number of writers (Cuomo op. cit.; Griffin 1997; Spretnak 1997). As a consequence, the wide range of ecofeminist theoretical positions is complicated by critiques of the epistemologies underpinning the many feminisms and ecologies. Feminism draws largely on constructionism and subjectivism, while the so-called natural sciences have traditionally been based on objectivism (Giddens 1984). Simply put, constructionism views meaning as coming into existence in and out of human engagements with realities in the world. In subjectivism (expressed in structuralist, post-structuralist and post-modern forms of thought), meaning is imposed on the object by the subject or comes out of nothing. Objectivism holds that meaning or objective truth exists apart from the operation of any consciousness (Crotty 1998:8-9).

Some feminists have challenged the social/nature divide and suggested that whether or not the object of human interaction is described as social or natural, the basic generation of meaning is always social (Oakley 1974). In claiming a distinctive 'feminist epistemology', other feminists argue that women not only 'know' in a different way from men, but also theorise the act of knowing differently (Fonow and Cook 1991; Gilligan 1982; Harding and Hintikka 1983). Salleh (op. cit.), Mellor (op. cit.) and Spretnak (op. cit.) pay considerable attention in particular to the social constructionist perspectives on 'woman' and 'nature'. Both Mellor and Salleh accept that women's subordination and ecological devastation have social causes, but they reject a radically social constructivist position (Mellor op. cit.:7; Salleh op. cit.:9). There are a number of reasons for this rejection.

The first argument is that the ecological basis of ecofeminist thinking requires the natural world be afforded a dynamic of its own beyond human 'construction' or control (Mellor ibid.). Yet Fuss takes up another position by suggesting theorists should question the constructionist position which 
assumes that "nature and fixity go together (naturally) just as sociality and change go together (naturally)" (Fuss, quoted in Sturgeon 1997:16).

A second argument is that the post-modern leap from noting that concepts are socially constructed to concluding that there is nothing but social construction in human experience results in "an impractical nihilism when applied to everyday life" (Salleh op. cit.:9). As a corollary, some ecofeminists fail to wholeheartedly embrace post-modern epistemologies because of the inaccessibility of much of the language used. This difficulty can contribute to a false and deeply problematic division between feminist theory and feminist activism (Sturgeon op. cit.:16) if theory is developed in the university and inaccessible to activists and if activists' reflections are not appropriately acknowledged and incorporated into theoretical development.

\subsubsection{Symbolic and spiritual}

A number of ecofeminist writers have explored the symbolic association and devaluation of women and nature that appear in art, literature, religion and theology (Legler 1997; Reuther 1992). Others have explored the potential for creating alternative languages (Daly 1978, 1987; Griffin 1978) and the symbolic connections between sexist and naturist language (Adams 1990). Women are often described in animal terms and nature in female terms.

"The claim is that language which so feminizes nature and naturalizes women describes, reflects and perpetuates the domination and inferiorization of both by failing to see the extent to which the twin dominations of women and nature are, in fact, culturally (and not merely figuratively) analogous" (Adams 1990:61, cited in Warren 1996:xv).

Many of the feminists of the 1970s and 1980s came to their analysis through an exploration of the powerful symbolism enshrined in patriarchal religion. The sacred canopy which patriarchal religion provided legitimised an hierarchical ordering of God, men, women, children, animals, and plants (see especially Collins 1974; Gray 1979; Griffin 1978; Ruether 1981; Starhawk 
1982). Those at the top of this hierarchy were more highly valued than, and in a dominant position over, those beneath them. It is not surprising that it was largely feminist theologians who were making these connections explicit. Christianity highlighted the contradictory place women held in society, as saints or whores, but not as people with equal standing before God. Awareness of such contradictory, socially constructed personal identities had the effect of transforming in dramatic ways women's perceptions of themselves and what they could achieve.

\subsubsection{Ethical}

Complex and sometimes contradictory ethical positions have arisen among ecofeminists debating, in particular, aspects of animal rights (Slicer 1991) and aspects of care and respect (Curtin 1996) applied to women's role and to the land.

It is of particular interest to social work that ecofeminists often rely on an 'ethic of care' when formulating their own ethic (Diamond and Orenstein 1990). The ethic of care arose out of Carol Gilligan's (op. cit.) critique of the different moral development of men and women and resulted in valuable interrogation of previously male-dominated research. The problem in using this as a basis of an ecofeminist ethic is that despite the value of reclaiming what patriarchy has devalued in both men and women's behaviour and moral judgements, there is a danger of leaving intact a system which still places high value on machismo and contradictory socialisation for young males (Cuomo op. cit.:129). On a practical level, 'caring' treads a fine line between empowerment and paternalism. This point can easily be lost sight of when ecofeminists propose women as 'natural' stewards of the land.

Social work practice, based as it often is on models of care, has a history of crossing the empowerment/paternalism line, with unhelpful consequences. Whilst the language of social work activity with regard to children is that of 'care and protection' and 'guidance', there is ample evidence that issues of power have turned care into control and guidance into domination (Rowlands 
1997). Likewise, the lessons from social work about the unreliability of an 'ethic of care' would do well to be heeded by ecofeminists in applying care ethics to wilderness, lest a similar paternalism denies the sentience of earth's wild places and their right to be left alone (Gruen 1997).

As an alternative to an 'ethic of care', Cuomo proposes what she describes as an 'ethic of flourishing' (op. cit.:62-80). This ethic involves responding to non-human as well as to human communities with "respect, attending, responsibility, commitment and duty" (op. cit.:72). All flourishing depends on the flourishing of others - viz, it happens in communities; it is embedded. Likewise, it is embodied. An awareness of physical embodiment requires attention to what is needed by all beings to thrive. An ethic of flourishing, in order to move from rhetoric to action, occurs in process, where it can be applied and evaluated over time. The process element of this ethic requires integrity and self-directedness. When this is applied to non-human communities it may mean "promot[ing] the unhindered unfolding of nonhuman life through policies of human non intervention" (op. cit.:76). The usefulness of the notions of embodiment and embeddedness for social work are expanded in section 2.3.3.

\subsubsection{Political}

Ecofeminism became recognised as a movement in 1980 with a major conference in the United States on Women and Life on Earth: Ecofeminism in the '80's and the ensuing Women's Pentagon Actions in 1980 and 1981 to protest anti-life nuclear war and weapons development (Mellor op. cit.:39-40; Merchant op. cit:184). Since then, ecofeminist actions have always grown out of pressing political and practical concerns. These have included issues of health, development, technology, the treatment of animals, peace, anti-nuclear and anti-militarism activism (Griffin 1989; Lahar 1991; Spretnak 1989; Warren 1997).

Ecofeminism has increasingly turned its attention to issues of global significance. One example is the way ecofeminists have introduced a 
challenge to the environmental hegemony of dominant development discourses (Sturgeon op. cit.:136). Another is the way ecofeminist activism has facilitated coalition between Southern and Northern activists (ibid.).

\subsection{Elements of an ecofeminist praxis}

The many streams of ecological and feminist thought which mingle to contribute to the sea of ecofeminist thought and action carry with them residues of flawed thought and action which still contaminate the emergent praxis. Rigorous scholarship, by itself, can only detect and filter. The ecofeminist project requires reflexive activism. Held together, action and reflection can keep the project from academically induced paralysis on the one hand and action induced fatigue on the other. Ecofeminist praxis has much to learn from the long journey social work pedagogy has already taken to rework the theory/practice nexus.

From the complex array of themes and positions, critiques and prescriptions in the ecofeminist literature, I have selected six elements that I identify as having most potential for development into an ecofeminist praxis within social work pedagogy.

The questions I have used in establishing these elements are:

- Do they have relevance for a social work course located within a university?

- Do they resonate with and challenge social work practice issues, critical debates and theoretical concerns?

- Do they speak to the 'lived reality' of pedagogy: student, teacher and the knowledge produced?

- Do they have relevance for local and global social and environmental issues?

- Do they offer positive alternatives for interrogating the current discourse of social work pedagogy? 
The six elements or areas of focus are now discussed in turn.

\subsubsection{Theoretical location and academic status}

In describing the theoretical underpinnings of ecofeminism, several writers use metaphors of 'intersections' (Cuomo op. cit.:35; Warren 1997:4) or 'tectonic plates' (Plumwood 1993:1) to suggest that it cannot be confined to a simple addition of feminism and ecology. Its focus on multiple causal explanations and implications of various interlocking oppressions means its study is not confined to any one discipline. Its location as an academic discourse is dynamic and pluralistic (Cuomo op. cit.:36). Ecofeminism's transgression of many academic disciplinary boundaries resonates with social work education, since the theoretical base of social work is also drawn from a wide range of disciplines (Payne 1997).

While this pluralistic discourse enriches and expands ecofeminist contributions to academic writing and political action, it is also problematic. Some shades of feminism imported into ecofeminist thought are obviously incompatible with an ecofeminist remit (Dann 1992:347). For example, Ynestra King, one of the founders of the movement, challenged the liberal feminist argument for equal opportunities within the present socio-economic system by asking "What is the point of partaking equally in a system that is killing us all?" (King 1990, cited in Mellor op. cit.:6). Lack of internal consistency is likewise a hallmark of social work's theoretical base. For example, some strands of psychological and social theory (viz. Freudian psychology and positivism) are incompatible with a liberatory social work project (Dominelli 1997b; Specht and Courtney 1994).

Ecofeminism shares with social work a relatively short history. As an emergent theory, ecofeminism has rightly been the subject of lively debate, but some critics seem more intent on academic posturing than on critiques which should, according to Sturgeon, be "aimed at concrete, material power relations, hegemonic discourses and practices", rather than "damaging already fragile and internally contested modes of opposition" (op. cit.:195). The 
internal criticism of ecofeminism, particularly within the academy, has been cited as one reason for its low status there (Sturgeon op. cit.168). There is tangible evidence of ecofeminism's unpopularity in the academy. Two writers cite instances of repeated rejection by reputable journals of articles using the word 'ecofeminist' in the title (Salleh op. cit.:xiii; Sturgeon op. cit.168).

It would be unfair to dismiss all criticism of ecofeminism as arising from selective academic gate-keeping. Plumwood asserts that much writing on the subject is "theoretically weak and doubtfully liberated" (op. cit.:1). More dramatically, Biehl, who initially supported ecofeminism, was so disturbed by developments in socialist ecofeminism that she withdrew her support from it. She described the theory as so fraught with "irrational, mythical and selfcontradictory meanings that it undercut women's hopes for a liberating ecologically-sane society" (Biehl quoted in Merchant 1992:195).

A few have relegated ecofeminism to popularist and activist arenas, preferring to describe their own work as 'feminist political ecology' or 'feminist environmentalism' (Rocheleau et al. 1996; Seager 1993). Silvey suggests that rather than being always a consequence of genuine criticism, the unpopularity of ecofeminism represents the struggle of academic feminists to be "taken seriously as political actors within the academy" (op. cit.:244. Emphasis in the original). Salleh sums up the situation:

"[E]cofeminism is more than a manifesto, it already lives in the actions of women. Even so, as a specific body of knowledge and practice, it is an absence in the mainstream consciousness. Neither the public at large, nor activists, nor academics are yet making all the connections libidinal, ideological, organisational - needed for an equitable and sustaining political agenda" (op. cit.:xiv).

Such debates resonate with social work education, which sometimes clings precariously to a legitimate foothold within the academy. The applied rider to its social science status does not necessarily mean that equal value is placed on fieldwork teaching or agency practice, which its teachers consider crucial to credible pedagogy. Joyce (1998:23) suggests that use of the term 'fieldwork 
teaching' reflects a subordinate relationship of practice teaching and learning in relation to theoretical, classroom learning. Just as the activism of ecofeminism devalues its status, so does social work practice within social work courses - "which are already largely marginalised within academic institutions" (ibid).

\subsubsection{Focus on multiple injustices and privileging voices from the margins}

Ecofeminism and social work share a common focus on multiple injustices. Ecofeminism does not confine itself to woman-nature connections, but is "intrinsically a movement to end racism, classism, heterosexism, ageism, antiSemitism and ethnocentricism" (Warren 1997:4). Drawing on the Marxist connections of some feminisms, ecofeminists carry forward the project of not only 'hearing different voices' but privileging the experiences derived from disadvantage. The disadvantage experienced by women on the basis of unequal gender relations is said to produce a perspective on society that is denied or obscured for the advantaged. Ecofeminists do not imply that being 'woman' per se produces a critical perspective. Rather, a combination of particular experiences and an analysis of women and the sex and gender systems provides a powerful political agency for women and other subordinated groups. The privilege accorded to women by virtue of their structural disadvantage forms the basis of 'feminist standpoint theory' (cited in Mellor op. cit.:106). Ecofeminists use this notion to claim that from this under-privileged position, women are able to perceive the relationship between humanity and nature more clearly than can (relatively) privileged men. Plumwood extends the privileged standpoint to the exploited, the marginalised and the planet (1993).

Care is required in interpreting an ecofeminist privileging of the marginalised. Haraway warns that preferential choice by theorists of subjugated positions should not be naive:

"The standpoints of the subjugated are not 'innocent' positions. On the contrary, they are preferred because in principle they are least 
likely to allow denial of the critical and interpretive core of all knowledge. They are knowledgeable of modes of denial through repression, forgetting, and disappearing acts - ways of being nowhere while claiming to see comprehensively....... 'Subjugated' standpoints are preferred because they seem to promise more adequate, sustained, objective, transforming accounts of the world" (1988:579).

Social work pedagogies that draw on Marxist and Freirian theory have been only too aware of the dangers of an uncritical elevation of subjugated viewpoints. Preferential options for the poor are not about glorifying poverty but are about providing a launching pad for revolutionary politics. The everpresent danger is that the oppressor/oppressed dualism gets reversed, leaving the dualism basically unchallenged. This can also happen in the microcommunity of the classroom, a situation discussed in 3.3.1.

One of the goals of ecofeminism, like Freirian praxis, is to produce human subjects fully participating within communities based on connection rather than on separation and opposition (Mellor op. cit.:107). The implication for an ecofeminist pedagogy is that it will facilitate learning communities where partial, locatable critical knowledges sustain "the possibility of webs of connections called solidarity in politics and shared conversations in epistemology" (Haraway op. cit.:255-6).

\subsubsection{Focus on identity as embodied and embedded}

What could emerge from a "new strategic and embodied politics" (Sturgeon op. cit.:196) is a critical awareness of how the freedom of the few has been achieved at the expense of the painful embodiedness and embeddedness of the many.

Ecofeminist theory argues that we all inhabit temporal bodies - we are embodied. Our human bodies are totally dependent on a finite, other-thanhuman nature. We are embedded within the natural world - of it, not apart 
from it. We could not survive without it. Yet because an alienated consciousness has caused disconnection from their bodies and from the earth, "[a] minority of the human race is able to live as if it were not embodied or embedded, as if it had no limits, because those limits are borne by others, including the earth itself" (Mellor op. cit:190. Emphasis added).

While women and men inhabit physical bodies, ecofeminists claim that women are more acutely conscious of our embodiedness than men are. We are not essentially closer to nature or the earth, but are more aware of our involvement in biological time (Mellor op. cit:184). Just as those closest to the kitchen are the first to be aware that the meal is burning, so poor people, most women, and most indigenous peoples feel the social and ecological heat first. Out of such embodied and embedded experience, much ecofeminist activism has been fuelled.

Ecofeminists recall that much of the activism of the early feminist movement arose out of women's consciousness of their subjugated position under patriarchy (Firestone 1979). They also acknowledge the significant contribution post-modern critiques have made in deconstructing identities (Salleh op. cit.:176; Sturgeon op. cit.:196). What they hold in tension is the desire to affirm the utility of collective identity to galvanise social and environmental action, while avoiding the mistakes of early feminist denials and deletions of difference.

In affirming a form of identity politics, ecofeminism sometimes becomes hoist on its own petard. In the cut and thrust of academic charge and countercharge, ecofeminism is frequently and often unfairly accused of being 'essentialist'. Biologistic essentialism presumes that their bodies determine women's social experiences. Shiva (1988) and Spretnak (1982), for example, include elements of women's embodiment of the feminine principle as giving women a special relationship to the natural world. So do Merchant (1980) and Warren (1987), but they also argue that the social construction of women's tie to nature is what needs transformation. More recent ecofeminist writers agree that some early ecofeminist writings did not sufficiently problematise the 
categories 'woman' and 'nature', but that an unwarranted 'essentialist' label is attached, uncritically, to all ecofeminism (Mellor op. cit.; Sturgeon op. cit.; Cuomo op. cit.). What ecofeminists now want is:

"to claim a space in which to discuss the connections among whatever gets labelled 'natural' and the humans (women, people of color, the poor) who tend to be discursively, practically, and conceptually associated with the natural, and whose association with nature is detrimental to them" (Cuomo op. cit.:115).

Another aspect of the essentialist charge is the tendency of some ecofeminists to universalise. This occurs when theorists extrapolate the experiences of women from one time and place to another with different class, race, religion and nationality dimensions. As I have mentioned earlier, the impacts of health risks resulting from environmental damage are rightly claimed to fall disproportionately on women and children (Diamond and Orenstein op. cit.). Other data support the view that men and the poor of the South are disproportionately affected compared to richer women of the North (Silvey op. cit.:245). Universalizing womanhood can have the unintended consequence of reinforcing classist and racist ideologies.

First Wave, and to a lesser extent, Second Wave Feminism was similarly flawed in much of its exclusion of the different experiences of women of colour, working class women and lesbians (Nicholson 1997:3). These flaws did not prevent feminism's utility as a vehicle for social change, nor preclude theorists' continual refinement of its claims. Sturgeon argues for similar acceptance of ecofeminism as a movement which experiences "essentialisms and non-essentialist moments within a process of political struggle" (op. cit.:173). We need an embodied ecology and an embedded feminism (Mellor op. cit.:180), an ecofeminist activism which resists the unconscious state (Saul 1995) and reawakens our conscious connection to each other and to the earth.

In the social work classroom, engagement in the struggle with identity politics is inescapable. The presence of students from a number of different ethnic backgrounds, socio-economic class, sexual orientation, gender and age, make 
application of theory that genuinely speaks to difference an imperative.

Ecofeminism is attractive to me because it supports feminist insights into the social construction of different identities within the classroom, whether they are 'Maori', 'pakeha', 'female', 'male', 'gay', 'lesbian', 'heterosexual', 'rural' or 'urban'.

While some ecofeminists seem happy with uncritical acceptance of, for example, indigenous cultures' formulations of women-nature connections (Shiva 1993), others favour an approach which views all categories and relationships as "unstable, dynamic and contested" (Sturgeon op. cit.:169). Translating the rhetoric of theory into useable praxis is at the heart of an ecofeminist challenge to social work pedagogy. The ultimate test comes when students leave the classroom and face real life situations in their fieldwork placements. The integrity of pedagogy from an ecofeminist stance is affirmed if students are able to resist the temptation to make universalised assumptions about their clients' lives, and be genuinely open to difference.

\subsubsection{Identification as diversified, global movements and as personal, political projects}

Identification as diversified, global movements and personal, political projects are two aspects of ecofeminism that are deliberately discussed together to challenge their false separation by some academic critiques (Sturgeon op. cit.).

As feminism has been differently theorised and practised in different geographical, cultural, political, and class environments, so has ecofeminism. For women in the global North, ${ }^{5}$ despoliation of the environment has been viewed as a matter of quality of life. Threats to health through dumping of chemical waste and dispersal of pollutants into the air and the soil, evidence of miscarriage, foetal deformities and pesticide residues in breast milk, and high incidence of child asthma, have been the kinds of issues that have roused 'ordinary' women to action (see e.g. Seager 1993, 1996). Such actions have

\footnotetext{
${ }^{5}$ See footnote 4.
} 
sometimes earned them the label of "hysterical housewives" (Seager 1996:279).

For women in the South, degradation of the environment affects their very survival. Development policies and practices which involve the felling of trees to clear land for export cash crops, the destruction of traditional farming practices, replacement of diversity of crops with monocultural crop production and the drenching of land with pesticides, affect access by the people of the South to the basic necessities of food, fuel and clean water (Mellor op. cit.:16 ff; Merchant 1992:183 ff; Mies and Shiva 1993:70 ff). The impact on women's health through their agricultural labour on land where pesticides have been used is evidenced throughout so-called 'developing' countries. For example, in Nicaragua women agricultural workers have twenty times the level of DDT in their breast milk than that of non-agricultural workers (Merchant op. cit.:204). Women's action groups in countries in the South have concentrated on activities like tree planting, forest and water conservation, rebuilding soil fertility and preserving ecological diversity (Merchant op. cit.: 206; Shiva et al. n.d). Protest action by women in the South has often come at a high price - loss of jobs (Merchant ibid) or even imprisonment (Mellor op. cit.:20).

In the 1980 s, concern about destruction of the earth through militarism and nuclear warfare saw millions of women actively involved in the peace movement (Salleh 1997:21). Aotearoa/New Zealand women were part of this. In 1983, a call by Greenham Common women for an International Day of Action for Disarmament on 24 May saw "15,000 women marching in Auckland, women in Wellington encircling Defence Headquarters and sticking flowers, photos of children, banners and other objects...on the walls, and women in other towns engaging in similar protest actions" (Dann 1992: 340). Women for the Environment was an explicitly feminist environmental group which was formed in Auckland in 1978 and ran for several years (Dann op. cit.:341). It included women who had leading roles in the Values Party, the forerunner of the present Green Party. Women in Green Parties 
throughout the world have been active in promoting the cause of women (ibid).

The dichotomy between the activism of the North and the South is challenged by Rocheleau et al. (1996:5) because "[t]oxic wastes, contaminated food, and work-place environmental hazards have become more than quality of life issues in many urban and industrial communities as well as in the remote rural areas affected by the same processes", and because preservation of endangered species is also a pre-occupation with some countries of the South.

Aotearoa/New Zealand's location in the geographical South while having a 'developed' status highlights the inadequacy of the North/South divide on these complex issues (see footnote 4).

Christine Dann points out that:

"In New Zealand there was the additional element of Maori protest. By 1983 Maori women had been involved in opposition to nuclear testing in the Pacific for several years, linking with other indigenous people of the Pacific... [T] hey made a firmer link between the issues of nuclear disarmament and indigenous people's rights. This may have helped sharpen awareness of the issues at stake among New Zealand ecofeminists - Pakeha women could not see themselves as purely innocent females opposing warmongering males when they were being reminded of their complicity as members of a colonizing race, and the alienation of indigenous people 's land and culture" (1992:340).

As has been mentioned, some in the academy have shunned ecofeminism for its activism. Conversely, another criticism levelled at ecofeminism, particularly cultural ecofeminism, is that it eschews political struggle, instead emphasising the spiritual and personal, individual action of women. Again, it is instructive to discuss what happened during feminism's history.

The early actions of people with raised levels of awareness form the foundations of any social movement. The focus for some remains on activism 
in a local or global capacity; for others their response takes the form of interpersonal actions and personal transformation. For women whose consciousness was raised by the early feminist movement there were models of both activism and personal transformation to emulate. For example, Gloria Steinem's 1983 book Outrageous Acts and Everyday Rebellions, a collection of her feminist activist writings, was followed almost 10 years later by Revolution from Within. This was a plea from a feminist activist for women to avoid the burnout and disillusionment that sometimes accompanies unremitting activism, to pay attention to their personal wellbeing, especially aiming to increase self-esteem. She defended her changed emphasis from accusations that she had abandoned her political fervour by claiming it to be a more integrated approach.

In a somewhat similar fashion, social work education has traditionally balanced itself on the cusp of the personal/political divide, sometimes emphasising personal change and less frequently focusing on structural change (Specht and Courtney op. cit.). Feminist social work challenges a dualist handling of the personal/political nexus and many ecofeminists believe that ecofeminism should too. If it does not, it is being unfaithful to its challenge of other dichotomies being falsely dualised (Cuomo op. cit. $136 \mathrm{ff}$ ). There is no reason why attention to a personal process need be separated from issue-based organised political activism (Schaef 1998:125).

\subsubsection{Parallel discourses of commonality/unity and difference/diversity}

The tendency for ecofeminists to adopt a listening rather than a controlling attitude towards the natural world where diversity flourishes has sometimes resulted in a call for diversity for its own sake. Cuomo suggests that Shiva, whose committed activism she deeply admires, is in danger of giving the impression that diversity is always, intrinsically, good. Clearly, Cuomo argues, not all diversity is life-enhancing for human beings and for the planet (Cuomo op. cit.:131-2). The diversity of cruel child abuse is one example; the endless variety of non-biodegradable plastics is another. 
Cuomo argues instead that, in a similar vein to the privileging of marginalised human voices, some differences, particularly neglected ones, need to be given prominence, particularly for the questions they raise and the hegemony they challenge. She cites Harding on this issue:

"The activities of those at the bottom..., the experience and lives of marginalised peoples, as they understand them, provide particularly significant problems to be explained, or research agendas (Harding 1993:54 cited in Cuomo op. cit.:132, emphasis in the original).

In the natural world, the importance of biodiversity is also recognised as being crucial to the health of the planet (Pepper 1996:133). Some conflicts surround the interface between biotic and human communities with some ecologists (for example, deep ecologists) arguing that such is the destructive nature of the human impact on non-human biodiversity that it would be better for the planet if the human species became extinct. Yet recent research has shown a very strong correlation between stable human habitat and the flourishing of the widest range of non-human species (Nabhan 1997:3). As Nabhan observes:

"Natural diversity and cultural diversity share many of the same patterns of distribution across the face of the earth, and enrich our lives in many of the same ways" (op. cit.:5).

Ecofeminists do well to affirm the importance of diverse communities, but need to do so on the basis of sound research. This calls for much more interdisciplinary research. Fruitful partnerships between social work, human geography and ecology, for example, could enrich theorising and action, avoiding much of the destructive conflict that can result when human and natural communities appear to compete for resources.

If uncritical calls for diversity seem like avoidable flaws in ecofeminists praxis, so do unexamined claims to unity. Cuomo challenges Spretnak's belief in a 'cosmic consciousness' that seems to allow no room for difference and certain kinds of separation. The problem with this emphasis lies with who or what is left out when unity of being or mind is promoted. Cuomo cautions: 
"Historically, the interests of members of groups considered Other by those with hegemonic power are ignored or destroyed in the interest of unification, and even those with power must sometimes sacrifice autonomy or aspects of themselves to achieve racial, ethnic and other kinds of unity" (op. cit.:135).

This is similarly a concern for social work pedagogy when exploring notions such as 'family' or 'community' in a classroom where students' widely disparate experiences give little reason to assume any kind of bland unity. This concern applies as well to labels such as 'indigenous' that similarly mask enormous differences.

\subsubsection{Significance of indigenous and spiritual dimensions}

Ecofeminism is replete with examples of diverse attempts to integrate indigenous and spiritual dimensions into its theory and practice. Influenced by feminist endeavours, early discussions involved reclamation of pre-patriarchal spiritual images, repudiation of male-centred spirituality and the creation of new theologies and rituals (Clark et al. 1981; Collins op. cit.; Gray op. cit.; Ruether op. cit.; Starhawk op. cit.). Given the significance of ecofeminist critiques of the culture/nature dualism, it is not surprising that ecofeminism turned for inspiration to indigenous cultures whose ideologies and practices affirmed mutuality between nature and social systems.

According to Sturgeon, Native American and Asian Indian cultures and spiritual traditions have been used by white ecofeminists, particularly in the United States, in formulating templates for action and personal spiritual practice (op. cit.:115 ff). This practice is problematic for a number of reasons: white appropriation of selective cultural and spiritual rituals ignores the social, political and historical context in which they occur; it promotes an essentialising of indigenous people as closer to nature; it fails to inspire a relevant model of spiritual custom for industrialised urban people; and it patently ignores the diverse realities of the people whose culture is being selectively emulated (Sturgeon ibid). 
Rather than perpetrate what one Native American woman, Andy Smith described as "spiritual abuse" (cited in Sturgeon op. cit.:121), other white ecofeminists have opted for a spiritual focus derived from their own European - mainly Greek and Celtic - pagan and nature-based traditions (Christ 1990; Ruether 1992; Spretnak 1982; Starhawk 1990; Sturgeon op. cit.:128 ff). The resurrection of goddess worship and pagan rituals within ecofeminism attracted much criticism, especially from Janet Biehl (op. cit.). Sturgeon suggests that few writers have been brave enough to put spirituality back on the ecofeminist agenda following Biehl's stinging attack (op. cit:39). Carol Adams explains the main reason for some ecofeminist writers giving spirituality a wide berth:

"Spirituality is thought to derail the ecofeminist engagement with social conditions and political decisions that tolerate environmental exploitation, encourage unbridled consumerism, and fail to rein in military spending" (1993:4).

In a similar vein, efforts to draw on New Age spirituality in ecofeminist writings attracted criticism especially because of its "crass materialism" (Seager 1993:8).

Not all ecofeminist efforts to include a spiritual dimension have been so troubled. One of the earlier writers uncovered within classical religion a legacy of liberation. Rosemary Reuther did this by invoking the prophetic tradition in Judeo-Christian thought which called for a preferential option for the poor and the marginalised. Reuther argued for "fundamental reconstruction of the way resources are allocated within the world community" (1975:3). More recently, she has incorporated the Gaia principle - in which the earth is viewed as a self-regulating, living organism - into her proposals for social, political transformation of the way we relate to each other and to the planet (Ruether 1992).

In Aotearoa/New Zealand, ecofeminist formulations of spirituality have been influenced by international trends, but there are differences. European colonisation of this country saw the importation of seasonal religious festivals 
and rituals totally unrelated to what was happening in the natural world and the new colony. This incongruence reinforced the pakeha settlers' "alienation from the natural world and our ability to identify with it" (Batten 1995:12). Such a position contrasted sharply with that of the Maori, the tangata whenua, a name implying connection to the land.

According to Jessica Hutchings (1996) Maori ecofeminism is grounded in Maori epistemology, where relationships between tangata (people), tupuna (ancestors), whenua (land), wairua (spirit), and whakapapa (genealogy) are inseparably interwoven. Hutchings enunciates the principles of Maori ecofeminism in relation to developing a new model of consultation for Maori women under the Resource Management Act (1991). She demonstrates that Maori ecofeminism is 'context specific' to New Zealand, drawing its principles for praxis from kaupapa Maori. Her juxtapositioning of the social status of Maori women and the male-dominated models of consultation in regard to environmental resource decision-making illuminates the unique contribution Aotearoa/New Zealand has made to ecofeminist praxis.

When the different worlds of Maori and pakeha meet in the social work classroom, there are not only different histories and different social, cultural and economic realities, but also very different notions of spirituality. At one end of a continuum, spirituality and social work share no common ground; while at the other, spiritual ideals form the main motivation for social work activity. When some pakeha students first encounter the richness of Maori ritual, they "tap the hollow vessel of their own spiritual vacuum" (Batten op. cit.:15). For others the same experience facilitates engagement with the strength of their own sacred ground.

Social work education's agenda within the academy in this country can be neither exclusively secular nor exclusively spiritual. A continuing challenge for ecofeminist praxis is to contribute a discursive space that is spiritually enriched and culturally diverse. 


\subsection{Conclusion}

"While continually challenging each other and working to create an ecologically astute and feminist ethic, ecological feminists should respect, encourage, and learn from a variety of effective methods and theories. In that way, ecofeminism could then become an alliance of varied theories and methodologies that share common goals and values, rather than a unified movement" (Cuomo op. cit.:139).

Feminist visions went beyond 'add women and stir,' and ecological visions for the future go well beyond the notion of 'sustainable development'. As liberal views of how to achieve women's liberation left the oppressive system untouched, so 'sustainable development' is a notion which can easily mask a deeply entrenched attachment to business as usual, socially, environmentally and economically (Mellor op. cit.:37). Likewise, expectations emerging from an ecofeminist praxis share similar degrees of cynicism about easy solutions to complex problems, preferring to eschew totalizing theory and universal prescriptions for action in favour of engagement in a "decentered political struggle" (Quinby 1990, cited in Cuomo op. cit.:139). Ecofeminist visions are a kaleidoscope, revealing situated, useful knowledges; ethics of flourishing; insights to inform more inclusive political coalitions; coalitions of radical activists and radical scholars; embodied ecologies and embedded feminisms (Cuomo op. cit:73; Mellor op. cit.:194, Sturgeon op. cit.:196).

In drawing on ecofeminism as a praxis framework within social work pedagogy, I am presented with a rich array of theoretical and practical offerings which are "multiple, diverse and intersecting" (Silvey op. cit.:247). My task within social work education is to question them at their deepest levels and to apply them creatively and courageously. 


\section{CHAPTER 3}

SOCIAL WORK EDUCATION

"It is not the kicks from the back, from the past, that impel us, but the attraction, the lure of the future and its attractive possibilities that entice us: that is what keeps life - and, indeed, the world - unfolding." (Popper 1988, quoted in Beare and Slaughter 1993:103. Emphasis in original)

\subsection{Introduction: meanings of education and pedagogy}

It is well documented that the motivation to enter the social work profession sometimes has its genesis in impelling 'kicks' from a person's past (Lishman 1998, cited in Adams, Dominelli and Payne 1998:93). One hopes that it is more often the attractive possibilities of contributing to a just and sustainable future that entice social work teachers to make the transition from practice to education. However, both the goal and the means of achieving sustainability and justice are contested. Debates within the wider political, social and economic discourse revolve around whether sustainability and justice can be achieved through the current practice of research, educational management and pedagogy (Beare and Slaughter 1993). As the demands of a highly sophisticated workplace influence education towards a market-driven approach, old paradigms resurface alongside newer formulations. Diverse educational approaches reflect the plurality of meaning attached to education itself.

An indication of the range of classical meanings attached to the term 'education' is reflected in dictionary entries. For example, the Concise Oxford Dictionary's (1982) definition of education includes terms like 'systematic instruction' and 'development of character', while the verb 'educate' is defined as 'giv[ing] intellectual and moral training'. Social work education, if defined broadly, could therefore include all the life experiences that contribute to a student's development as a social person, as well as any systematic 
instruction about the knowledge, values and skills required specifically for competent social work practice.

In this study I accept that life experience and supervised social work practice both contribute to social work education, and cannot, in practice, be separated from other aspects. However, my particular interest is in the pedagogical processes used to conduct the classroom component, the so-called 'formal' part, of social work education. ${ }^{1}$

Derived from the Greek paidagogos, meaning 'a slave who led a boy to school', pedagogy has come to mean 'the science of teaching, instruction or training' (Chambers 1965). The definition often quoted is that of Lusted: "the transformation of...consciousness that takes place in the intersection of three agencies - the teacher, the learner and the knowledge they together produce" (Lather 1992:121). From Lusted, Lather argues that:

" the concept of pedagogy focuses attention on the conditions and means through which education is produced. All pedagogies are situated-specific and contingent to the cultural fields within which they operate" (ibid).

Moving far from the notion of education as transmission of knowledge by neutral teachers to passive students, pedagogy has come to pay particular attention to the interactive nature of the teacher, the learner and knowledge. The power and knowledge politics at the centre of all pedagogical relations and practice is evident in the defining framework of pedagogy:

"[P] edagogy refers to culture-specific ways of organising formal teaching and learning in institutional sites ...[It] is divided into curriculum, instruction and evaluation: referring respectively to cultural knowledge and content, classroom interaction, and the

\footnotetext{
${ }^{1}$ Because it is difficult, and undesirable, to maintain a false separation between social work education and social work pedagogy, both terms will be used in this thesis. While the particular focus is 'pedagogy', when the broader context is being considered, 'education' will be the preferred term.
} 
evaluation of student performance...[It] entails a 'selective tradition' of practices and conventions... [and] insofar as such selections serve the interests of particular classes and social relations, decisions about...pedagogy are ultimately ideological and political" (Luke 1996:5).

Knowles challenged the use of the word 'pedagogy' at all in relation to adult learning. He proposed instead the term 'andragogy' to denote a theory of adult learning (Knowles 1972, cited in Solas 1994:63). Solas contends that despite Knowles' attempt to distinguish pedagogy from andragogy, basic assumptions still support a "classical, structuralist approach to teaching and learning: expertise, homogeneity, instrumentalism, linearity and rationalism" (Solas op. cit.:66). The term 'andragogy' also leaves intact androcentric and ethnocentric assumptions. I decided to retain the word 'pedagogy' in my discussion, interrogating its theoretical bases rather than attempting a 'reformist' approach to the language.

The central aim of this chapter is to scan the pedagogical landscape for fault lines and footholds that indicate inadequacies and point to opportunities for a revisioning of social work pedagogy. In this study, that revision takes place in the light of ecofeminist challenges. The picture that emerges will be shaped by a critical reflection on my own practice. This takes place against two backdrops. The first is of my personal experience as a student, a social worker and a social work lecturer. The second is of literature on pedagogy.

\subsection{Personal location within social work sites as oppositional contexts}

In presenting a brief description of my experience as a social worker, student and lecturer, I follow a feminist tradition in claiming the right to use reflection on experience as a legitimate focus of study (Kramer-Dahl 1996:243). My reflection is selective. It is shaped by the interlocking forces of new ideas gleaned from reading the reflections of others and by the social, emotional and physical influences on my life. In choosing to frame this reflection using the notion of 'oppositions', I am employing a concept used by Harre Hindmarsh, 
in her study of new social work graduates, to describe "radically conflicting social work agenda" (Harre Hindmarsh 1992:245) within the agencies employing the graduates. These oppositions were seen as "manifestations of structural oppositions, especially those related to class, gender, race and power" (ibid). It is to an account of my own experience along these structural intersections that I now turn.

I had been employed as a social worker with the Child Welfare Division of the Department of Education for three years when I applied in 1971 to attend the Victoria University two-year Diploma in Social Work (then called the Diploma in Social Science). I was accepted as a candidate for this professional social work qualification on the basis of my ability to study at a tertiary institution (I had three units of a BSc) as well as on the basis of my experience as a social worker. This degree pathway acknowledged practice in social work as a sound foundation for a professional qualification. I came to the educational experience on the social work course with practice dilemmas and the reality of agency constraints firmly embedded in my mind.

This pathway contrasted with that followed by those who first completed an undergraduate degree and then enrolled in an MA (Applied) in Social Work. My three years' experience as a social worker plus a two-year course of study enabled me to complete a Diploma, while the postgraduate students who completed the same course but wrote a thesis graduated with the higher and more prestigious Master's degree. This regime reinforced an hierarchy of value characteristic of Western paradigms of knowledge which favour the ability to manipulate words and critique writings over the ability to speak of and reflect on experience. In the university, practice knowledge is accorded a lower status than theoretical knowledge, even in an applied discipline.

In the 1970s it was not only experiential knowledge that occupied a lower status within the university. Traditional Maori wisdom and indigenous practice models were not highly valued. Despite the fact that a high proportion of the people with whom I had worked in Child Welfare were Maori, the models of social work practice to which I was introduced were 
exclusively British or American. As well as this, there were few Maori students on the university social work programmes, and while some of the pakeha staff had strong connections with Maori communities (McCreary 1994), none of the teaching staff were Maori.

Because Victoria University - the first in Aotearoa/New Zealand to run a social work course - has been producing social work graduates since 1949 , their presence has influenced the shape of New Zealand professional social work. ${ }^{2}$ Victoria graduates are highly represented nationally as lecturing staff, practice teachers and social work agency managers. While this commonality might be expected to have produced some cohesion in what is expected of a university social work qualification, the wide varieties of post-qualifying experience and the essentially political nature of the social work project have produced a web of tensions that resonate with those evident in a complex society. There is dissonance between the various sites that are occupied (Harre Hindmarsh op. cit.).

My own social work education was situated right at the cusp of two periods in social work educational history that Nash (1997:15) describes as recognition (1949-72) and consolidation (1972 -86). High on the agenda of my course in 1972-73 was the need to give us a professional approach to our practice.

During my socialisation to professional social work therefore, I experienced two contradictory influences.

As an applied discipline, social work education has always involved paying attention not only to changing theoretical positions but also to the political and social changes in the institutions in which it is carried out. When I was a student I experienced tension around the construction of social work as a profession in both the site where I had worked (the social work agency) and in the university. In the latter we were exposed to models of practice that sought

\footnotetext{
${ }^{2}$ I note with some irony that as I was writing this thesis the Social Work Department at Victoria was disestablished.
} 
scientific legitimation. In the social work agency, academic and practice knowledge were unequally valued, but in the reverse order to the academy's position. This was brought home to me in remarks made by one of my Child Welfare employers, who expressed the hope that all social work graduates would "work the university out of their systems before they return to my district".

After my graduation from the Diploma in Social Work course, I managed the 'social work oppositions' inherent in agency practice by choosing to work as part of multidisciplinary teams in the statutory health sector where the 'professional' aspects of social work enjoyed some degree of acceptance. From there I went to the voluntary sector, where the essentially political nature of social work found ample expression for me in both family therapy and community work. My subsequent moves to statutory policy positions and local authority community services management can, on reflection, be seen not only as a search for variety and breadth of experience, but also as an "active response to oppositional practice experiences" (Harre Hindmarsh op cit :230).

When I joined the university as a lecturer in 1989 it was with the hope that my years of experience in the health sector, family therapy, community development and policy, combined with my academic study of education, ${ }^{3}$ would enable me to contribute to social work education from a strong base of both theory and practice. I soon confronted the reality that social work education within the university itself occupies a complex site with a number of potentially dissatisfied stakeholders: university management if the course fails to deliver academic standards it considers appropriate; social work organisations if they perceive students to be ill equipped for immediate employment as social workers; students if they wish to see only their own world views reflected in the course content and staff composition; and lecturers if they are unsure that what they are teaching genuinely prepares students for a future in social work.

\footnotetext{
${ }^{3}$ I had completed a BA in Education in 1984 during my time as a social worker and manager.
} 


\subsection{Factors shaping my reflective practice as a social work educator}

Far from isolating me from the tensions and disruptions, social work education within the university offered expanded opportunities for more in-depth reflection than I had found possible during my personal traverse of social work's other oppositional sites. As I prepared teaching material and reflected on how to use it in the classroom, I was exposed to post-modern critiques of the nature of pedagogy. In addition, the presence of oppositional discourses within the classroom and in the wider society kept the challenge alive. In this section I discuss what I consider to be some of the key factors that shaped reflections on my pedagogical practice within the university.

\subsubsection{Gender, ethnicity and culture}

It is impossible to overestimate the impact of the complex and contested nature of the relationships between gender, ethnicity and culture on the educational project in Aotearoa/New Zealand. Recent scholarship documents examples which challenge a naive reading of our colonial histories that equates the colonised with Maori and the colonising with men and women of Anglo-Celtic ethnicity. Laing and Coleman (1998:4-5) argue that:

"The legacy that has 'white' women complicit in the discursive practices of inexorable male-dominated colonial control is too simple".

The actions of the women they describe offer an historical mandate for the subversion of the current colonising influences of educational institutions. Despite the fact that those women perpetuated the colonial task, they also disrupted it. Just as new research reveals buried treasure amidst the rubble of colonial history that has been largely gender blind, so early feminist research brought to light new meanings to the categories 'women' and 'men'.

It was the feminism of the 1970 s that drew attention to the social construction of gender (e.g. Belotti 1975; Sharpe 1976). The impact of feminist analyses of 
the family in the 1980s, and of women's roles within it, brought changes in understanding of 'selves' as socially constructed (Thorne and Yalom 1982; Weedon 1987). In turn, women social workers changed the way we brought ourselves to the all-important worker-client relationship. Some women practitioners were applying feminist critiques to our practice as social workers (Pilalis and Anderton 1986). By contrast, inside the university, despite the predominance of women in the social work profession and in the client population, feminist critiques made few inroads into the design and delivery of social work courses. Why did it take so long and involve so many struggles for the insights of feminism to influence the social work classroom, when practitioners were already engaged in that project? As with any complicated issue, the contributing factors are many and complex. What was happening in the wider socio-political context had repercussions inside the classroom.

The 1980s in New Zealand saw the start of unprecedented economic restructuring, with concomitant social, cultural and environmental changes (Kelsey 1995). Some social commentators point to the events surrounding the 1981 Springbok tour protests as providing a catalyst for making explicit many of the underlying tensions and inequalities which were present in Aotearoa/New Zealand society (Spoonley 1990:82-97). In this climate of increased awareness it was often pakeha feminist women who, already conscious of their own unequal place in society, exposed the reality of racial injustice in this country. Broadsheet, Aotearoa/New Zealand's feminist magazine, published numerous articles on racism and Treaty issues during the 1980 s, and made a significant contribution to raising awareness of Maori grievances through publishing Donna Awatere's major work Maori sovereignty (Awatere 1984).

In the mid 1980s a group of women - all feminist, and mostly lesbian - within the Department of Social Welfare in the Auckland area were deeply concerned about what they saw and described as institutional racism within the Department. They articulated their concerns in a report to the DirectorGeneral entitled Institutional Racism (Department of Social Welfare 1984). This report recommended changes in the ethnic composition of staff, in staff 
recruitment, selection and training, and in the departmental environment, with the view to all these areas being made responsive to Maori. Their report, amongst others, led to a process in which Maori all around the country reported their experiences of injustice at the hands of the Department. This process in turn led to a ground-breaking report, Puao-te-ata-tu (Department of Social Welfare 1986), which resulted in major changes being proposed in the Department of Social Welfare and in social work practice and education throughout Aotearoa/New Zealand (Nash 1994:45).

Puao-te-ata-tu has been given a great deal of attention and publicity from those in the social work education field, especially at Victoria, where it forms the bedrock of the bicultural programme. Yet the fact that a challenge by pakeha feminists to institutional racism contributed directly to the report is rarely included as part of the story (see e.g. Tait-Rolleston et al. 1997), even though the report itself does acknowledge it (Ministerial Advisory Committee, 1988:16).

With a long-overdue challenge to monocultural educational practices well and truly on the agenda, focus in social work education turned naturally to processes within the classroom. There, attempts were made to acknowledge the social, cultural, historical and economic locatedness of knowledge and of the differences between the lives of Maori and pakeha within this nation and, in particular, within the social services (Nash op. cit.:51). The cultures that emerge from multiple positionings on gender/ethnic intersections have the potential to enrich the educational discourse within the social work classroom. As a feminist, I believed that the ethnic challenge complemented, rather than competed with, that of acknowledging the different experiences of women in all their social and personal roles. However, what should have been a strengthened partnership between Maori (men and women) and pakeha women in the deconstruction and reconstruction of the classroom's masculinist culture in its broadest sense failed to materialise. In the Social Work Department at Victoria, Maori staff members of both sexes, and pakeha men who have allied themselves with Maori oppression to the exclusion of any other cause, have refused to acknowledge the perspective of gender. Staff 
and students alike have often interpreted attempts to raise feminist issues as a competition between oppressions. ${ }^{4}$

The struggle to have feminist issues occupy a central place in social work education is not limited to Victoria University. Nash and Munford (1994:234) found that feminist social work theory and practice models were scarce up until the late 1980s. In her role as National Advisor to the New Zealand Council of Education and Training in the Social Services during 1993-95, Moses observed that in social service training and development throughout the country, gender perspectives had been overridden by culture issues (Moses 1997, personal communication). The turmoil within social work education in particular, and social work practice in general, was to a large extent a reflection of changes in the wider social, economic and political arenas.

\subsubsection{Socio/economic/political influences}

In Britain in the early 1900s, then in Aotearoa/New Zealand in the 1940s, social work education moved from within agencies to universities. The mandate for a separation of service and education arose out of negotiations between service providers and universities (Harre Hindmarsh op. cit.:18; Nash 1997). This negotiation reflected prevailing socio/economic/political ideologies.

In recent years, at the same time as challenges from Maori and feminists have been demanding attention from social work educators, social work itself has been reshaping in response to other influences. One of the most powerful of these impacts is the changing ideology about the role of the state in human services (Yelloly and Henkel 1995:10). The period 1986-1995 was characterised by deconstruction and diversity (Nash op. cit:15). It is not

\footnotetext{
${ }^{4}$ Some Maori women also question patriarchal power. Laing and Coleman point out, however, that "there are dangers in thinking that our similar position vis-a-vis this power comes out of a similar history, inspires similar modes of resistance, or seeks similar results in its subversion" (op. cit::11).
} 
surprising then, that social work education from 1986 onwards has become fractured by "fundamental issues of power and conflicts of interest" (Harre Hindmarsh op. cit.:29).

The current revision of social work education within universities is being influenced not only by changes in the nature, purpose and functions of the original partners in social work education (i.e. the social service organisations and the universities) but by changing socio/economic and political ideologies (Dominelli 1997:3; Fook 1997:9). These influences include: firstly, the dismantling of the welfare state; secondly, the increasing requirement of the social work 'industry' for social workers to act as technocrats, regulating poverty (Shirley 1997:13) rather than empowering marginalised members of our communities; and thirdly, the emphasis being placed on family and community self-reliance, when both are relying on diminishing public funding. All three influences are interconnected and are part of the impact of globalisation, which has introduced "changes of a fundamental nature into the profession and has affected its infrastructure, value base, methods of working, work-place relations and workers' relationships with clients" (Dominelli ibid.). Social work pedagogy has also been affected by these changes.

\subsection{Social work pedagogy: key theoretical components and multiple practices}

My experience is that 'gender troubles', cultural minefields and changing socio/political/economic structures reinforce the university classroom as an oppositional site within social work education. At the same time, the theoretical landscape moves both reactively and responsively to many contradictory forces. This section explores the key theoretical components of social work pedagogy, with examples of my teaching drawn from the multiple possible practice applications. 


\subsubsection{The primacy of practice teaching}

The education of social workers has been characterised by the attention paid to integration between the theory taught and the operationalisation of that theory into practice skills and activities (Mattaini 1995:62). This has largely been achieved by including supervised fieldwork practice as a significant proportion of the educational course. The parallel processes observed between 'good' supervision and 'good' practice were a part of early social work writing (Heap 1975). In contrast, very little attention has been paid in social work literature to the connection between effective teaching and sound practice (Joyce 1998:24; Solas 1994:2).

What has been written has tended to focus attention on the learning occurring within the social work practicum itself rather than on what occurs in the classroom (Doel and Shadlow 1996). Nor has much attention been paid to researching this area (Harre Hindmarsh op. cit.; Solas op. cit:5). In the absence of any clear guidelines on what and how subjects should be taught, university social work lecturers, if appointed from the social work practitioner field, draw heavily on their own practice skills and knowledge base. This was certainly true for me. Convinced as I was from the theories I had learned during my education degree that didactic lecturing was not an effective method for the transfer of learning, I developed facilitation and group work skills as the basis of my teaching practice. The content was informed by relevant theoretical reading, case material and the application of approaches to problem-solving, which again I drew directly from practice. Fortunately, because my social work practice had included a wide variety of fields, the practice base from which I drew was very broad.

A balance of theoretical analysis illustrated by practice examples is possible only as long as the teacher's practice base remains current. As the teacher's distance from relevant practice increases, it becomes crucial to maintain close working relationships with practitioners and agencies (Joyce ibid.). If this does not happen, changes in the field may not be included in the agenda of the social work classroom. 


\subsubsection{The change focus}

Variously called 'emancipatory', liberatory, or 'transformative', approaches to pedagogy which broadly focus on education as a process of change aimed at 'freeing', 'liberating' or 'transforming' the student, were inspired by educationalists like Freire (1972,1973), Giroux (1983,1988), McLaren (1995) and Weiner (1994).

In a series of essays on her own teaching practice, bell hooks describes her engagement particularly with the ideas of Paulo Freire in a way which I found closely paralleled my own (hooks 1994). Influenced by her feminist perspective, she uses the term 'engaged pedagogy' in order to show that the change resulting from this approach to pedagogy involves the student and the teacher. Engaged pedagogy emphasises well-being both of the teacher and of the students (op cit:15), values student expression, involves the teacher in growth-oriented learning, makes the classroom a democratic setting, accepts critical student comment as a positive sign, achieves the immediate affirmation of the teacher's work and makes explicit the painful process associated with shifting paradigms in the pedagogical process (hooks op. cit:15-43).

hooks' formulation of 'engaged pedagogy' is one of many formulations drawing on Freire's education ideas. The first class I taught in community development in the late 1980s was framed around structural analysis, an approach that draws heavily on his educational concepts. The four phases of the process were aimed at enabling students to both experience and learn a process that they could apply in working with communities. These phases included location of self, naming and defining the issue or situation, analysing the situation using social/cultural/political and economic parameters, and developing strategies for change (Barndt 1989, cited in Munford and WalshTapiata 1999:36; Hope, Timmel and Hodzi 1984). Pedagogical practices based on Freire's ideas rest on praxis and are rooted in "communal knowing or dialogue" (Burstow 1991:196). Some have called into question Freire's 
universal and abstract claims. For example, Weiler argues for "a more situated theory of oppression and subjectivity, and for the need to consider the contradictions of such universal claims of truth or process" (Weiler 1995:28). However Freire's pedagogical thought continues to illuminate the central question of political action (ibid).

There has been a growing body of criticism in the literature on pedagogy about the way in which the rhetoric of emancipation and transformation applied to the classroom seldom translates into practice. One of the reasons given for this failure is that the context in which the practice of pedagogy is performed is one of opposition to the principles of engaged pedagogy (Ellsworth 1992; Harre Hindmarsh op. cit.; Luke and Gore 1992). hooks put the case strongly:

"The objectification of the teacher within bourgeois educational structures seem [s] to denigrate notions of wholeness and uphold the idea of a mind/body split, one that promotes and supports compartmentalisation" (op. cit.:16).

Unexamined diversity of the paradigms to which social work pedagogy subscribes often lies at the heart of conflicts within institutional settings.

\subsubsection{The diversity of paradigms}

The paradigms underlying classroom practice in social work can be grouped as 'classical' and 'contemporary' (Solas op. cit.) Classical approaches derived from the early writings of Reynolds (1942) and Towle (1954), who in turn influenced the authors of texts still in use during my social work training (Hollis 1972; Perlman 1962). Their work sought to apply the contributions of Freudian psychoanalytic psychology to the practice of social work and to professional education. These classical approaches assume a generic, unitary approach to teaching and learning which obfuscates individual differences such as class, gender and race. Teachers are expected to teach a particular code of ethics, body of knowledge and set of skills for specific purposes sanctioned by the profession. Dissent is discouraged and failure to meet 
learning expectations is viewed as a problem of personal or interpersonal adjustment (Solas op. cit.:56 ff.). While the prevalence of this instrumental paradigm in its classical form has greatly diminished, remnants still persist, particularly with the increase in demand for competency-based practice, leading to the training of competent, technical practitioners (Harre Hindmarsh op. cit.:240-241).

Some contemporary paradigms are derived from the classical models, modifying and drawing on recent educational theory, whilst others attempt more radical constructions. 'Reflection-in-action' or 'practical reflectivity' paradigms draw on an interpretive mode of discourse. Traditional ways of knowledge-building based on an empirical approach are replaced by practical action where the problem is defined as one of explicating and clarifying assumptions and predispositions (Harre Hindmarsh op. cit.:241). When applied to social work pedagogy, the reflective approach is inductive in nature. Theory is implicit in action and the supposed dichotomy between knowing and action is false (Fook 1999:201; Harre Hindmarsh ibid).

The purpose of reflection in action is to "improve communication, understanding and social interaction through the development of consensual norms or common value commitments, grounded in the intersubjectivity of the mutual understanding of intentions" (Harre Hindmarsh ibid, citing Gould 1989:14). Here, gaps between the 'ideals' of theory and the 'realities' of practice, for example, are viewed as value conflicts. Many of the 'transfer of learning' formulations are aimed at addressing and closing these gaps (Gardiner 1984; Harris 1983). Social work educators such as Papell and Skolnik (1992) and Gould and Taylor (1996) have applied variations on the work of Argyris and Schon (1974) and Schon (1983, 1987), who popularised the reflective approach. Papell and Skolnik suggest that the reflective approach had already been foreshadowed in "social work's educational heritage" (op. cit.:20).

While not departing from the reflective approach, critical reflective approaches arise out of a critical social science tradition (Carr and Kemmis 
1983, 1986). In this tradition, social structures are perpetuated through the operation of a 'false consciousness', such that members of society are unaware that present social structures and relations are constructed and therefore transformable (Fook op. cit.:203).

The focus of critical reflectivity on change appeals particularly to those social work educators who view education as a political and moral endeavour (Harre Hindmarsh op. cit.:243 citing Beyer and Zeichner 1987:312). The project of pedagogy becomes the empowerment of the students to "reflect on their own life situations and to speak out about deficiencies and possibilities therein" (Harre Hindmarsh ibid). Reflective pedagogy becomes critical when it considers how power undergirds, frames and distorts educational processes and when it questions assumptions and practices which work against long term, desirable educational goals (Brookfield 1995:8). This approach builds on and includes rather than discards elements from the interpretivist, the critical and the instrumental, but all are "subsumed within a critical mode of discourse" (Harre Hindmarsh op. cit.:260).

Fook cites Kellner and Best (1991) as suggesting that there are many similarities between critical social science, post-modernism and poststructuralism (Fook op. cit.:205). She gives examples of Rossiter (1996) and Leonard (1997) as having developed new critical approaches to social work (Fook op. cit.:205-6). In relation to pedagogy, a post-structural approach entails a need to attend to difference, a refusal of dualistic terms and assumptions such as educator/student or knower/known, and a need to construct "classroom practices that engage with the discursive and material spaces left by the politicisation of differences in equality, power and dialogue" (Solas op.cit:83). This approach calls for the politicising of social work pedagogy to the extent that "individuals and affinity groups are constantly engaged in the process of unsettling received ideas and multiplying and making more complex the subject positions possible and visible" (op. cit.:84).

A critical post-modern approach to pedagogy thus involves a critical deconstruction of received ways of thinking (Pease and Fook 1999:227-8). 

Social workers joining a degree course after years of experience in the field are able to identify aspects of their practice that 'fit' the theories of social work practice presented. Likewise, as a reflective teacher I was able to identify aspects of my practice which emulated theories of pedagogy. As well, I consciously operationalised theoretical approaches in the search for more effective outcomes within the classroom and developed these ideas by keeping a daily teaching journal in which I recorded, for each class taught, what I intended to do and why, what actually happened in the classroom and, after the course, what I had learned. I also kept in the journal summaries of books and articles that I was reading.

\subsubsection{The centrality of experiential learning}

Learning from experience, then, occupies a central place in the education of social workers whether the focus is the teacher or the student. Summarising the main themes from the literature on experiential learning, Yelloly and Henkel suggest it takes three forms:

- learning by doing in practice, involving cycles of action and reflection

- learning by observation and attention

- learning through reflection on the here and now (Yelloly and Henkel 1995:8).

But for them, a further distinctive feature of social work action/reflection includes an aspect of 'thought' that is more than cognitive. It includes:

"...unconscious and often primitive and unverbalised feelings aroused in the worker by the impact of the work which is often intense, intimate, conflictual, and may have resonances with the worker's own internal world" (ibid).

They suggest that for this aspect of learning to be encouraged the context of social work pedagogy needs to permit vulnerability on the part of the student. 
One of the legacies of the psychoanalytic influence on social work, which occurred in the early part of the 20th century, is the centrality of the need for people working with others 'in need', distressed or 'deviant', to develop selfawareness. For this to occur within an educational context, the student may well become vulnerable. Thus, not only knowledge about human development, both 'normal' and 'abnormal', theories of how people interact within families, communities and society, and how welfare policies are designed, but how social workers use 'ourselves in relationships' (Cournoyer 1991:2) is considered an essential ingredient in social work education. Attention to this aspect is important because it is within a social worker's relationships with clients that options for positive change within the client's intra- or inter-personal relationships are forged (Lishman 1998:89 ff).

In the classroom, or more usually within smaller tutorials and in supervision relationships, students are encouraged to become conscious of their own patterns of behaviour, their values and the residues of unresolved personal issues that may be triggered by parallel situations of their clients. A number of pedagogical methodologies are designed to enhance the student's ability to reflect on experience. Structured role plays, video-recorded micro-skills practice sessions and the use of anecdotal material to illustrate classroom theory are just some of the ways experience is employed as a pedagogical 'tool'. Many of these pedagogical practices follow Vayda and Bogo who developed an integration of theory and practice model that is an adaptation of Kolb's experiential learning theory (Vayda and Bogo 1991:271). Solas has criticised these approaches as 'teacher-directed and instrumental' (Solas op. cit.:69). In addition to this criticism, I have over the years been aware that for some Maori students role-playing and similar 'exercises' can be experienced as alien.

I began therefore to search for alternative ways of honouring the experiential learning tradition in social work without reducing the complexities of the interactive process that is the essence of actual social work practice. In recent years I have been attracted to the work of Boal, who, like Freire, is concerned with the transformation of the social and personal reality of people who are 
suffering oppression. For Freire, genuine dialogue is the proper function of liberatory pedagogy. Boal's political philosophy was expressed in the language of the theatre when in 1974 he established the Theatre of the Oppressed (Boal 1979).

Boal's ideas provide another 'space' in which such dialogue could occur. In addition to the discursive space provided by discussion of student/staff identities and reading and writing about the topic, an aesthetic space is created by Boal's theatre. Boal claims that an aesthetic space has properties which "stimulate knowledge and discovery, cognition and recognition: properties which stimulate the process of learning by experience" (Boal 1995:20). Boal's theatre space has three characteristics which resonate particularly well with a pedagogical project of stretching paradigms and expanding understandings - in short, of being creative for the purpose of opening options for social work students and, ultimately, for their clients.

The aesthetic space of Boal's theatre is firstly, plastic. As in dreams, what occurs there is both the real and not real; time and space, people and objects, can be changed, condensed and unfolded; memory and imagination interact creatively (Boal op. cit.:21; Feldhendler 1994:94). Secondly, it is dichotomous in nature, "dealing with a space within a space: two spaces occupy the same place at the same time" (Boal op. cit.:23). The spaces are both identical and different, because the actors and the 'spect/actors' ( $\mathrm{sic}$ ) breathe the same air in the same room, yet each spect/actor and actor is both the person performing and the character performed. I was excited by the potential of such a playful dance of self-observation between dichotomous relationships to be employed in dismantling dualisms, since the distance between actor and spect/actor is maintained yet playfully transgressed. Thirdly, the aesthetic space uses the theatre as "a place where everything acquires new dimensions, becomes magnified, as under a powerful microscope" (Boal op. cit.:27).

"The stage brings to today, to here and now, what has happened long ago, far from here: that which had been lost in the mists of time, had deserted memory or fled into unconscious" (ibid.). 
'Playing Boal' offers potential for students of many different ethnic, cultural and class backgrounds to 'perform' from within their various histories and current perceptions. Employing an approach that encourages students to explore past memories and experiences is particularly important for women, people of colour and any others whose minds have been 'colonised'. For these students, the hegemony of the traditional classroom means some experiences are admissible while others are denied.

Current critiques of social work pedagogy address in particular the challenges of facilitating learning for students from diverse cultural and ethnic groups (e.g. Dominelli 1997c). This challenge was first issued by feminist critiques of education. In developing an ecofeminist praxis within social work pedagogy, it is appropriate that I explore the contributions of both feminist and ecological critiques.

\subsection{Feminist critiques and contributions to pedagogy}

Earlier feminist analyses of education concentrated on the processes leading to the exclusion of girls and women from educational institutions, and on the gendered nature of the curriculum and of the teacher's activities (e.g. Spender 1982; Weiner 1994:2-3). When social work texts make only passing reference to the impact of feminism on social work praxis (e.g. Payne 1997) and when the stories, examples and illustrations used by lecturers focus exclusively on male experience as the norm, women students are denied access to feminist scholarship and the experience of seeing themselves reflected in the culture of the classroom.

More recently, attention has been drawn not only to such specific examples of exclusion but also to the interaction between them as sources of inequality and oppression for women and other marginalised groups (Lather op. cit.:121). Many of the pedagogical processes employed in the interests of creating emancipatory classroom experiences for all students fail to achieve this goal. The most cogent critiques of a whole range of both critical and feminist 
pedagogies comes from feminist educators, who point out that it is very hard to put into practice highly abstracted theories (e.g. Ellsworth 1992). A study of Luke and Gore's anthology of critical feminist pedagogy (1992) reveals the key items on the feminist pedagogy agenda. What is common is a focus on the partial nature of knowledge, the concept of power as it operates through the construction of new discourses, the often contradictory nature of identity as 'moving sites' and the need to translate the highly abstract theorising of critical pedagogy into educational practice. These will be considered in turn.

\subsubsection{The nature of knowledge and how it is acquired}

What counts as knowledge, as well as how it is acquired, has come under the scrutiny of feminist and ecofeminist critiques. For example, the notion of 'freedom', a cornerstone in the education of free citizens, is claimed by Luke to be achieved through a uniquely male experience of opposition and confrontation with others (Luke 1992:42). Such a process is characterised by a struggle with nature and with other human beings and is preoccupied with domination.

Dore (1994:99) utilises Belenky's discovery of the divergent paths taken by women compared with men in the gaining of knowledge and summarises the five modes of knowledge acquisition that are of particular significance in the social work classroom:

- women students often learn in silence, a mode in which they experience themselves as 'mindless and voiceless' (Belenky et al. 1986, quoted in Dore ibid);

- in received knowledge mode, students participate more in the learning process but still suppress their own voices to that of a higher authority. Female students in particular succumb to this mode;

- subjective knowledge has the student conscious of many and often conflicting interpretations, but with a growing recognition of their 
own subjectivity. There is no translation of the basically intuitive impressions into meaningful argument that could be shared;

- in the procedural knowledge mode students are able to internalise their ideas and reformulate them into arguments which can be shared;

- in the constructed knowledge mode students are able to "create new knowledge using both subjective and objective means and to use this knowledge in personally and socially productive ways" (Dore op. cit.:100).

One of the tasks of feminist pedagogy is therefore to acknowledge that the partial knowledge within the classroom is also processed differentially along gendered lines. Central to many of the critiques of knowledge generation in the classroom is an analysis of the discourses of power.

\subsubsection{Construction of discourses of 'empowerment' and 'power'}

The recognition that education offered a potential site for liberation came with the so-called 'third-wave' sociology of education. It centred on hope, liberation and equality with new goals of "self-empowerment and critical agency' (Gore op. cit.:64). The notion of empowerment is central to a range of educational discourses (Dore op. cit.:100; Gore op. cit.:54). In the threads of critical pedagogy that have emerged out of broad and shifting social and educational visions, and in the concern with specific instructional practices in education, empowerment is a major preoccupation. The notion of empowerment, often used without clear definition in the social sciences, has a generally accepted meaning within the contexts of social work and education.

"There is broad agreement within these disciplines that empowerment is a process; that it involves some degree of personal development, but that this is not sufficient; and that it involves moving from insight to action" (Rowlands 1997:15). 
The literature identifies a number of weaknesses in some of the feminist and critical pedagogical discussions of empowerment. Gore is firstly concerned with the ascription of agency to the teacher as the empowerer (op. cit.:57), suggesting that the location of teachers in patriarchal institutions makes this an unrealistically high expectation. Feminist pedagogy suggests that when the authority of the teacher is deified, as it is in traditional classrooms, the empowerment of students and achieving a sense of community is significantly impeded (Dore op.cit.:100) A dualistic separation is created between teacher as empowering and student as the 'other' to be empowered. Secondly, some critical pedagogies claim a 'zero-sum' notion of power, where if one person has more power than another, their gain is at the expense of the other's power. Feminist pedagogy rejects this static and quantifiable notion of power. The concept of power described by Foucault (Foucault 1980) is preferred by Gore. In his formulation, power is not an entity, nor a substance of which people can possess more or less, but is relational and exists only in its exercise (Gore op. cit.: 59; Rowlands op. cit.:12) Thirdly, Gore cautions both feminist and critical pedagogues against the 'decontextualization of power', citing Sawicki's suggestion that "no discourse is inherently liberating or oppressive... The liberatory status ...is a matter of historical inquiry, not theoretical pronouncement" (Sawicki 1988:166, quoted in Gore op. cit.:60). Rather, to contextualise is to view "social actors whose personal and group histories position them as subjects immersed in social patterns" (Gore op. cit.:61, emphasis in the original).

\subsubsection{Construction of identity in the classroom}

Pedagogical processes that are liberating and empowering for one group of students can be disempowering for another. For example, when classes are held on marae where much of the speech is in Maori and where the processes are familiar to Maori but not to many pakeha, some pakeha students feel excluded. In the same way, when the vast majority of the course is conducted in Western style classrooms and lecturers use English exclusively, many Maori feel excluded. The challenge posed by feminist critiques of many of the pedagogical processes employed in social work education is for these 
oppositional situations to be interrogated and used creatively to demonstrate ways of acknowledging difference and dealing with potential conflict.

The feminist critique of critical pedagogy's claim to empowerment through giving voice to marginalised students revolves around the use of personal accounts in the classroom. One of the key elements of Freirean pedagogy frequently used by social work educators is the practice of encouraging the 'naming of experience' so that objects of oppression become agents of change (Freire 1973:116). Both Luke (op. cit.:37) and Weiner (op. cit.:11) cite other writers as warning against the uncritical use of personal experience as the basis for knowledge generation which may deny the 'situatedness' of personal "accounts within interlocking discourses and networks of institutionalised gender and power relations" (Luke op. cit.: 37).

Stanley and Wise in the early 1980 s were already sounding a different warning. They acknowledged that the consciousness-raising activity of early feminism sometimes led to the development of an hierarchy of consciousness which in itself was elitist (Stanley and Wise 1983). They argued, however, that feminist theorists who abandoned the centrality of experience as a legitimate basis for knowledge were in danger of favouring a more highly valued 'objectivity' over 'subjectivity' and thus returning to dualistic thinking (op. cit.: 67). The challenge is thus to enable students to understand experiences not as transparent windows on reality but as the product of their exposure to a variety of practices and discourses in a number of different circumstances (Kramer-Dahl 1996:253). In my classrooms I have experienced the 'battle for the bottom' of the oppression scale as Kramer-Dahl describes it: "The minority students viewed themselves as the ones with superior "insiderknowledge" of more "authentically" experienced oppressions, relegating the white students to marginal observer-status, with no legitimate contributions of their own to offer" (ibid).

Finally, feminist pedagogy issues a challenge to itself as well as to critical pedagogues to make the language it uses accessible. Heavily committed 
educators cannot be blamed for giving up on some writing when each sentence has to be read three times before the meaning becomes clear!

Just as the social sciences express knowledge in terms that are sometimes hard to follow, the natural sciences have traditionally used jargon that is like a foreign language to the uninitiated. This is only one of the challenges faced by an ecofeminist praxis that draws on ecology in application to social work pedagogy. It is to these contributions and challenges that I now turn.

\subsection{Ecological critiques and contributions}

During my secondary education and in my first year at university, I majored in the natural sciences, intending to pursue a career in biochemistry. After I switched to studying the social sciences, my interest in the natural world continued. I sought ways of integrating knowledge across what, in the $1960 \mathrm{~s}$ and 1970s, seemed like reasonably impermeable disciplinary boundaries. The impact of this early training and interest meant that when I was working with individuals and families as a social worker, I frequently drew on metaphors from the natural world. Later, in the social work classroom, I continued this practice. In addition, the literature on social work practice theory included an ecosystem framework. Central to this perspective is an holistic view of phenomena which sees transactions between various systems as crucial to an understanding of social work practice (Germain and Gitterman 1980; Vayda and Bogo op. cit.). This early literature utilised the relational aspect of an ecological system, but totally ignored the actual connection between natural and social systems.

Just as social work theory favours a narrow interpretation of 'ecosystem' that leaves out the tangible natural world, a scientific one tends to exclude social aspects. 'Ecology' is defined in the Concise Oxford Dictionary (1982) as a "branch of biology, dealing with organisms' habitats, modes of life, and relations to their surroundings". In its narrow form it is the study of nature, using scientific methods. But as Sylvan and Bennett (1994) point out: 
"An ecology is... an environment of living items (one or a set, normally a community) where the modes of life of these items unfold, so that what is dealt with in ecology occurs there" (op. cit.:37).

The narrow range of scientific activities associated with ecology is expanded by application of ecological principles to social or environmental problems (Zabinski 1997:315). Such a transgression of a pure/applied dualism can contribute to 'environmentalism', a term which is sometimes used instead of ecology. Ife (1995) suggests, however, that 'environmentalism' is usually restricted to the resolution of specific problems by finding discrete solutions using linear thinking. The solutions found are usually located within the existing social, economic and political order (op. cit.:24-25). For these reasons, Ife prefers to use the term 'ecological perspective' to describe a process which has four basic principles, namely "holism, sustainability, diversity and equilibrium" (op. cit.:43). Each of these will be considered in turn and applied to social work pedagogy.

\subsubsection{The ecological principle of 'holism'}

Holism requires that every event or phenomenon must be understood as part of a whole. It can only be properly understood with reference to every other part of the larger system (Ife op. cit.:44). This interdependence between every event and entity has implications for pedagogy. For example, learning processes can be seen as part of a "seamless web of complex interconnecting relationships" (ibid.). In a learning community, teachers, students, administrators, relatives, industry and community members are interlinked in a network of relationships (Bowers 1995:206).

Fundamental to the notion of holism is a rejection of a total reliance on differentiation and classification as the dominant Western forms of analysis. An holistic principle calls for the inclusion of integration and synthesis. Embedded within this call is a focus on organic change that avoids settling for simplistic, universal solutions. An integrative approach avoids dualistic thinking characteristic of the dominant positivist paradigm of Western 
intellectual thinking and as such resonates with the claims of ecofeminist philosophers like Plumwood (1993). Within the classroom, this principle implies that teaching does not flow from the top down, but in a cyclical exchange with everyone in the system being both the teacher and the learner (Bowers op. cit.). This principle is paralleled in an indigenous Maori model of learning. Ako means both 'to learn' and 'to teach', as well as the 'thing taught or learnt' (Pere 1982).

\subsubsection{The ecological principle of 'sustainability'}

Indigenous learning and teaching dismantles dualistic connections between the teacher and the learner. In a similar way, the ecological principle of sustainability focuses on a non-dualistic relationship between the past, the present and the future. As I have already indicated, the meaning of sustainability is a contested one (see Chapter 1). In broad terms it means: "that systems must be able to be maintained in the long term, that resources should be used only at the rate at which they can be replenished, that renewable energy sources should be utilised, that output to the environment should be limited to the level at which it can adequately be absorbed, and that consumption should be minimised rather than maximised" (Ife op. cit.:45).

As a social construct, the term's meaning changes according to its location within social, political, cultural and economic contexts.

Of particular interest to social work pedagogy is the way principles of sustainability challenge the political ideologies on which the practice of social work rests. Huckle divides sustainability into two categories, 'weak' and 'strong' (Huckle op. cit.:10). 'Weak' sustainability includes the libertarian, socialist camp whose strategies for change include regulation and technomanagerialism. The state is believed to be the most appropriate vehicle to lead by example in including nature within the market, setting environmental performance targets and encouraging democratically organised groups within society to involve citizens in active 'critical pedagogy' (op. cit.:11). 'Strong' sustainability includes more radical, green perspectives, favouring revival of 
forms of self-sufficient community development using appropriate technologies in support of sustainable livelihoods (op. cit.:10).

Translated into the classroom, the sustainability imperative scrutinises the social work curriculum for those values and beliefs that have been at least partly responsible for producing a society which is no longer sustainable (Beare and Slaughter 1993; Huckle and Sterling 1996; Milbrath 1989). In addition, it emphasises the long-term impacts of the whole pedagogical process on students' personal and professional lives.

\subsubsection{The ecological principle of 'diversity'}

Feminist and post-modern critiques of social work pedagogy have challenged its uncritical stance (Harre Hindmarsh op. cit.; Solas op. cit.). These critiques have seldom, however, taken up the challenge of diversity to the degree to which it is interpreted by an ecological perspective. According to Capra, the "stability of an ecosystem depends on the degree of complexity of its network of relationships, in other words, on the diversity of the ecosystem" (Capra 1993, cited in Bowers op. cit.:207).

If social work pedagogy applies this principle, the task will be more complex than any focus on learning specific, measurable competencies. It will need to include a wide variety of learning approaches (Bowers op. cit.:207).

A corollary of diversity being seen as intrinsic to the pedagogical process is the extension of that diversity outside the classroom. While for social work this has always occurred during fieldwork placement, the restriction of fieldwork to social settings is challenged by the ecological principle of diversity. Diverse learning means learning from the significance of place and connection to the natural world as well as to the built environment (Jensen 1995; Park, K 1996; Park, G 1995).

"[L]ooking intently at a landscape we live in or value... [we] see what it reveals of systems of wisdom and warning. Reading the landscape is 
like collage, interweaving the patterns of ecology and the fragments of history with footprints of the personal journey" (Park 1995:16).

Including nature in the kaleidoscope of pedagogical experiences is an attempt to recapture the human ability to learn from nature rather than only about nature (Jensen op. cit.). I have taken social work students to places like Papaitonga, a coastal wetland reserve of ecological and spiritual significance, in an effort to expose them to this kind of learning.

\subsubsection{The ecological principle of 'equilibrium'}

Broadly defined, the principle of equilibrium emphasises the "importance of the relationships between systems and the need to maintain a balance between them" (Ife op. cit.:48). The simplicity of this definition obliterates the complexity of its operational implications. In nature, the interdependencies among the various parts of ecosystems involve complicated energy and matter exchanges, the subtle interplay of competition and cooperation, and countless forms of partnership (Bowers op. cit.:206-7). Equilibrium is a clear example of how natural systems incorporate apparently opposing positions: it is maintained by flexibility and the interplay between creation and mutual adaptation.

Translated into classroom practice, this principle supports learning communities as open, democratic and involving dynamic change and fluidity. For example, during one of my courses, the death of a Samoan leader necessitated several class members leaving a week-long module on Working with communities to attend the funeral. Instead of viewing this event as a disruption, we were able as a group to temporarily abandon the teaching schedule, discuss how students would convey the group's condolences in a culturally appropriate manner, and turn the whole situation into an important learning experience. The equilibrium that developed as the group picked up the threads of the scheduled learning was deepened by the experience of responding with creativity to the dynamics of the group's life. 


\subsubsection{Applying ecological principles in the social work classroom}

With notable exceptions (e.g. Bowers op. cit.; Ife op. cit.) ecological principles have not generally been taught outside the natural sciences. This failure has perpetuated the isolation of ecological and social theory from each other. The potential for both to inform and transform the other has been largely unexploited. Just as feminist critiques need to be integrated into all disciplines in order to bring about change, so ecological critiques need to extend across the boundaries artificially erected around various faculties within the academy.

Ellsworth (op. cit.) is sceptical of the ability of feminist pedagogy to employ truly liberatory and empowering practice within the academy. Sterling expresses the same equivocal sentiments with regard to the ability of formal education, located as it is within the dominant cultural, social and political context, to contribute to radical social change (Sterling 1996:21). Given such warnings, I was conscious of the enormity of the challenge to develop an ecofeminist praxis within social work pedagogy and within the academy.

\subsection{Conclusion: The multiple purposes of social work pedagogy}

I have traced my biographical footprints within social work as a student, a social worker and a social work educator. Oppositions have fractured the landscape. The social, cultural, and political climate has changed dramatically during my thirty-year journey.

I have reflected on my experiences in the light of personal and societal changes. As well I have invoked the literature that has been most influential in shaping my own practice as an educator. This literature has been drawn from writings about two of the most powerful movements of this century, feminism and ecology. These two areas have been singled out as appropriate for two reasons. Firstly, they speak to the social and environmental imperative for social work education. Secondly, they have engaged me academically and galvanized my actions both personally and professionally. 
Social work pedagogy has been enriched by its appropriation of a wide range of theoretical formulations - yet none have, in my opinion, adequately addressed the challenges facing it. Challenges to social work pedagogy can only be appropriately met if indeed the purpose of this activity is interrogated. The results of such interrogation are highly political:

"Social work is one of the most political of all professions. Indeed, it has virtually no role, no identity outside the welfare institutions where it is located. These in turn are shaped and developed by government policies" (Yelloby and Henkel op. cit.:9).

Under the rise of the 'evaluation state', professions have had their autonomy stripped away. They are evaluated in terms of what they actually do in relation to consumer demand, and competence as a measure of successful practice is an extension of the trend to greater executive control of the economic workplace. This approach is "firmly rooted in behaviourist, reductionist theories of individual performance" (Jones and Joss op. cit.:19).

It follows that if one of the roles of social work pedagogy is to prepare students for entry into the social work profession, current practice should confine itself to what Jones and Joss describe as teaching to develop the "technical expert". Learning approaches that are often static and didactic provide knowledge and academic theory plus rules and guidance. Process skills are "bolted on" as an extra dimension, while the relevance of the client's knowledge is downplayed or denied (op. cit.:26).

If, on the other hand, one of the legitimate tasks of social work pedagogy is to equip students to reflect critically on the oppositional roles they occupy within the social, cultural, political and economic context of the social services and to contribute to social transformation, then models which view knowledge as process must be employed. Such knowledge is not a product but is learnt by doing, observing, reflecting, conceptualising and experimenting in a cyclical manner. 
One of the challenges facing the world is that awareness about our collective social and ecological troubles does not necessarily lead to change for the better, either for human beings or for the rest of the planet. If social work pedagogy is prepared to transgress the boundaries between the social and the ecological it may be able to entice students to do the same. An exploration of the social work classroom as a site of such transgression is the focus of the next chapter. 


\section{CHAPTER 4}

\section{THE RESEARCH PROCESS, ACTIVITIES AND RATIONALE ${ }^{1}$}

\subsection{Introduction}

My research grew from a desire to make changes in my teaching that would in turn contribute to the effectiveness of future social workers. The research aims to apply ecofeminist principles to social work education. Specifically, it interrogates an application of these principles to the discourse and practice of educating towards sustainable community. Literature on social and ecological sustainability is becoming more prevalent (Ife op. cit.). When I first conceived the idea for this research there was very little written about the educational implications of this increasingly common discourse. As far as I could ascertain, there was a total void in relation to its application to social work pedagogy. To the socially derived meanings of social constructions like 'community', ecofeminist epistemology adds ecological ones. It follows that my choice of research design and methodology needed to be congruent with my ecofeminist epistemology. It was predominantly within qualitative research methodologies that I found the most useful approaches.

My approach to pedagogy brings together sources of knowledge from diverse disciplines, from learners of diverse cultural and social positions. Researching the interactions between such socially constructed, complex and ever changing elements requires qualitative methodologies that are concerned with a search for patterns amongst pluralistic and complex social phenomena (Glesne and Peshkin 1992:6). It follows that qualitative approaches encourage the use of multiple methods to interpret complex and interweaving variables that change throughout the period circumscribing the research.

\footnotetext{
${ }^{1}$ I have divided the research activity into two chapters for clarity of presentation. In reality, the research activities, outcomes, and reflections leading to new research activities wove into one another. Linear, consecutive description obliterates this process. I have included figures that illustrate the flow of activity and reflection and thereby go some way to addressing this presentation difficulty.
} 
The diversity and colour available within the qualitative palette enabled me to draw on the many shades of feminist qualitative research. For Oleson, feminist research emphasises subjectivity, relationship and interaction, social movements, organisations, structures and policy (Oleson 1994:161-2). These areas were relevant in my study, which focused on me as both researched and researching, in interaction with students, as part of a changing profession within a conventional university and involved in social and environmental community organisations. Communicating research findings to research participants is espoused by feminist research. In line with ecofeminism as a social movement as well as a theoretical approach, I was keen to communicate research findings not only to research participants, but also to audiences beyond academia (Cuomo 1998:148 ff).

The generation of useable knowledge accessible to research participants and beyond is not confined to feminist research. According to Reason, a world view which "sees human beings as co-creating their reality through participation: through their experience, their thinking and their action" (1994:324) has given rise to a whole raft of qualitative research approaches loosely described as 'participatory inquiry'.

Within this genre, theoretical and methodological attention is paid to collaboration and processes which encourage liberatory dialogue (op. cit.:325). I was already familiar with, and to a large extent utilising, ideas drawn from feminist research (Reinharz 1992; Stanley and Wise 1993), liberationist education (Freire 1973) and systemic thinking (Bateson 1979). My research focus on activity within the social work classroom resonated therefore, with many of the themes of participatory inquiry generally, and with participatory action research in particular. Qualitative methodology gave me the option to choose particular methods according to the pedagogical and research requirements of each part of the research process. Nelson et al. use the term 'bricolage' to describe qualitative methodologies in which choice of methods is "pragmatic, strategic and self-reflexive" (Nelson et al. 1992:2, cited in Denzin and Lincoln 1994:2). 


\subsection{The research process}

A feature of praxis is that there is no clear demarcation between practice and research. To this extent, the research process exists before the specified research and has implications beyond it (Fook 1996). I like to think of the activity that contributes to the design of the research proper as happening 'upstream', the research proper as 'midstream' and the follow-up on implications of the research proper as 'downstream'. ${ }^{2}$ This metaphor should be understood not only as the linear flow associated with a stream, but as including the whole water cycle from rain as precipitation from clouds, falling on mountains, flowing as streams through valleys and underground water tables and out to the sea where evaporation returns water as vapour to the atmosphere. It is the non-linear, dynamic, and complex research relationships that I want this metaphor to illuminate.

\section{3 'Upstream' activities and their contribution to the research process}

Reflexive practice is a well-documented approach within social work practice (Fook op. cit.). Because I had come to university teaching and research after twenty years of social work practice and management, the tasks of planning, monitoring and reflecting on my social work activity were habitual. It seemed 'natural' that I continued this practice as a social work educator (Papell and Skolnik 1992).

I gained access to my actions and reflections, the two components of pedagogical praxis, in several ways: through my teaching journals, which recorded my plans of what and how I teach; through my reflections on a wide range of literature; through observation of myself in action in video-recorded teaching sessions; through student feedback on module content and process; and, to some extent, through students' ability to complete their assignments competently.

\footnotetext{
${ }^{2}$ While some (e.g. Ellen 1984:10 quoted in Glesne and Peskin op.cit.:11) suggest that the language of qualitative research now includes different metaphors from those used in quantitative research, I have noticed that the dominance of quantitative metaphors still persists - for example, 'data collection', 'analysis', even 'methodology'. I have tried to use language which, wherever possible, denotes a critical rather than a positivist stance and describes in nonscientific terms the activities in which I was engaged. I therefore use words and phrases such as 'process', 'research activity' and 'making meaning'. I also rely heavily on the use of metaphors from nature and the language of narrative.
} 
To count as praxis, actions must change as a result of reflection (Freire 1972:28). In the classroom, a dynamic action/reflection process occurs which includes teacher and students. The students' reflective responses to the material and to how it is taught thus inform my practice and my reflections and so on, round and round.

Before embarking on the specific research for this thesis I had already formed ideas about the content and process of teaching the principles of social and ecological sustainability. As the focus of one of the modules I taught at Victoria University was the theory and practice of working with communities, the meaning surrounding 'sustainable community' and possible approaches to its development provided the 'upstream' outcomes which helped to shape the design of what went into the mini-lectures given later to research participants in England.

During a Working with Communities module in Wellington in March 1997, I asked students to express in any form the meanings of 'community' and 'community work'. From their responses I identified recurrent symbols and words. Symbols included circles connecting other circles, boxes connecting other boxes, circles and squares within other circles and squares, arrows connecting related ideas; rivers, pathways, roads; houses, wharenui, churches; men, women and children; sun, rain, wind, trees. One of the Maori students gave permission for me to reproduce his work and I include it because it illustrates the rich symbolic meaning he gave to the concepts. This is shown in Figure 4.1. He explained that for him as a Maori, the notion of community linked the sky father, Ranginui, with the earth mother, Papatuanuku. The weaving included symbols of spirituality and symbols of culture. 
Figure 4.1 MEANING OF COMMUNITY

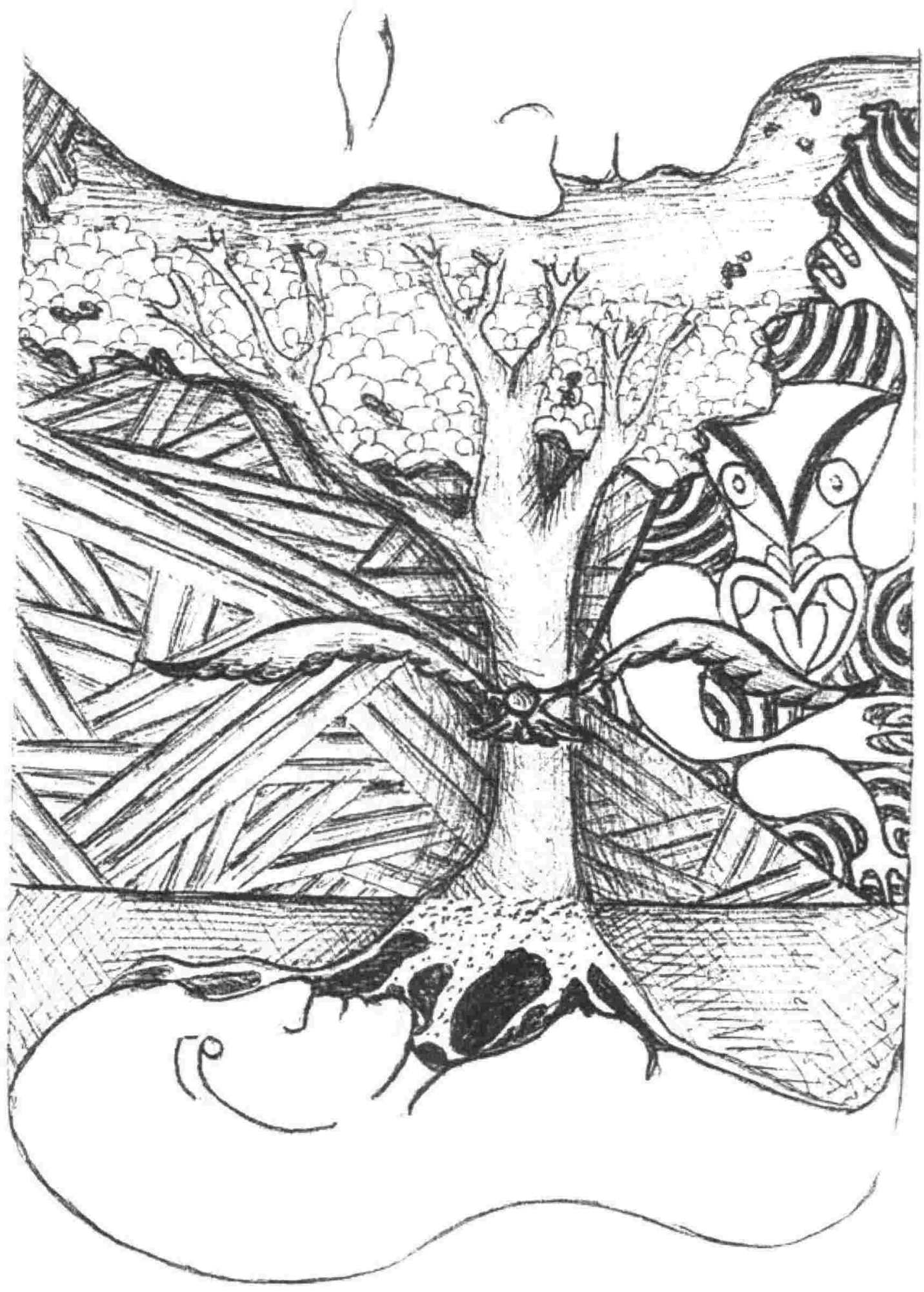


Words used at least once included: networks, processes, whanau, hapu, iwi, groups, kaupapa, meetings, residents, support, voluntary and government agencies, laws, access to resources, organisational constraints, funding, skills, common land, religion, aims and aspirations, animals, environment, marae, whare, karakia, facilitation, and knowledge.

I observed that the words and symbols thus evoked by the question I posed in the ordinary course of teaching were embedded within the social, political, economic and cultural context of each student who produced them. From this material, I was able to gain an overall impression of what comprised the 'common knowledge' about the slippery notions of community and community work. I was able also to reflect on which pedagogical processes offered the greatest potential for gaining access to the classroom discourse on community. I concluded after reflection that isolated words and symbols, disconnected from their social, political and cultural context, threw little light on the concept. My pedagogical aim was to find bridges from the theoretical, often highly abstracted notions of community outlined in texts (e.g. Ife op. cit.; Pearson op. cit.), and the grounded embodied knowledge built on the students' lived experience. To this end I decided that I would seek to generate knowledge about sustainable community in three ways:

- by the material produced in the students'/participants' responses to research questions about their perceptions of 'sustainable community' and how it could be achieved

- by the stories the students/participants told which brought to life their understandings; and

- by reflection on the subject by the students and by me in the classroom.

I knew that I needed to prepare for my research in England by employing processes that would enable any differences in the social, political and cultural context to be acknowledged explicitly in the research process.

The summary provided in Figure 4.2 describes 'upstream' activities and how they contributed to the English research. Whilst the 'upstream' activities are 
largely self-explanatory, two warrant further discussion. Writing the thesis proposal enabled me to begin the difficult task of clarifying the focus of my research. I was not alone in struggling with this process (Rountree and Laing 1996:11), but I realised the very essence of my worldview contributed to this being problematic. There are warnings in the research literature about exploring global issues (eg. Silverman 1993:3), yet I believed this warning had to be tempered with a feminist "praxis-oriented advocacy approach which not only sought individual change but generated change-enhancing social theory" (Lather 1995:293). Such praxis involves personal, interpersonal and political dimensions. Investigating such a broad range of dimensions would have involved more than one research project. In my first proposal I had wanted to include an exploration not only of how an ecofeminist praxis could be used in the social work classroom but how students' actions, post-training, would be changed as a result. I decided to include in my research design an explicit reference to conscious empowerment as a research aim, but to focus largely on the implications of a change-oriented approach for me as the facilitator of learning. I learned during the research process that I could derive meanings that transcended the categories of personal, interpersonal and political change. After Lather, my aim was to “...empower through empirical research designs which maximise a dialogic, dialectically educative encounter between researcher and researched so that both become, in the words of feminist poetsinger Cris Williamson, 'the changer and the changed"' (Lather op. cit.:294).

The goals of change and empowerment, particularly within the classroom, have come under scrutiny for their potential to "reproduce the conceptual map of the teacher in the mind of the student" (Lather op. cit.:292). In action-oriented research within my teaching practice, therefore, I had to pay particular attention to the ethics of my research goals as they impinged on pedagogy. Gaining ethical approval from the Human Ethics Committee at my teaching university, as well as resubmitting it to a United Kingdom university, 
Figure 4.2 'UPSTREAM' ACTIVITIES AND CONTRIBUTIONS TO

THE RESEARCH

\begin{tabular}{|c|c|c|}
\hline & ACTIVITY & CONTRIBUTION TO RESEARCH \\
\hline 1 & $\begin{array}{l}\text { Maintained teaching journals on all } \\
\text { reading, teaching plans, conference } \\
\text { workshops and presentations }\end{array}$ & $\begin{array}{l}\text { Development of a reflective practitioner } \\
\text { stance; 'doing' action/reflection on my } \\
\text { own pedagogical practice }\end{array}$ \\
\hline 2 & $\begin{array}{l}\text { Integrated new learning from } \\
\text { personal research/reading into } \\
\text { teaching programme }\end{array}$ & $\begin{array}{l}\text { Practice gained in applying theory to } \\
\text { pedagogical practice }\end{array}$ \\
\hline 3 & $\begin{array}{l}\text { Tested new teaching techniques in } \\
\text { adult education classes and } \\
\text { conference workshops }\end{array}$ & $\begin{array}{l}\text { Refined Boal's theatre approach in } \\
\text { relation to classroom activities }\end{array}$ \\
\hline 4 & $\begin{array}{l}\text { Sought feedback from student } \\
\text { assessments and conference } \\
\text { participants about teaching content } \\
\text { and process }\end{array}$ & $\begin{array}{l}\text { Contributed to the development of } \\
\text { feedback loops as an integral part of } \\
\text { pedagogical research }\end{array}$ \\
\hline 5 & $\begin{array}{l}\text { Analysed student learning via essay } \\
\text { and oral presentations }\end{array}$ & $\begin{array}{l}\text { Contributed to changes made to } \\
\text { curriculum and teaching processes }\end{array}$ \\
\hline 6 & $\begin{array}{l}\text { Developed exploratory research } \\
\text { questions relating to sustainable } \\
\text { community for use in teaching } \\
\text { programme }\end{array}$ & $\begin{array}{l}\text { Analysis of student responses helped } \\
\text { shape the research questions }\end{array}$ \\
\hline 7 & $\begin{array}{l}\text { Prepared proposal. } \\
\text { Prepared consent forms and } \\
\text { information for research participants }\end{array}$ & $\begin{array}{l}\text { Established research design and } \\
\text { realistic parameters. Positioned } \\
\text { research subjectivity in } \\
\text { socio/historical/cultural context } \\
\text { Decided areas of literature to be } \\
\text { reviewed }\end{array}$ \\
\hline 8 & $\begin{array}{l}\text { Gained ethical approval and } \\
\text { compliance with VUW Human } \\
\text { Ethics Committee }\end{array}$ & $\begin{array}{l}\text { Raised the level of research } \\
\text { consciousness to importance of ethical } \\
\text { decisions as occurring throughout the } \\
\text { research process }\end{array}$ \\
\hline
\end{tabular}


was only the tip of the ethical iceberg. I refer later (see 5.2.1) to the ongoing ethical questions with which I wrestled during the research process itself.

Suffice to indicate that 'upstream' of the research I was aware of the tensions and ethical issues involved in conducting participatory, reflexive research where students had the right not to have my research goals interfere with their learning goals. The challenge was to make this a 'win-win' situation, to the benefit of both researcher and researched. Choosing to conduct some of my research in another country, in a university where I was a guest and where I was not in a position to assess the work of the student participants, was in part a result of keeping ethical considerations uppermost throughout the entire process (Glesne and Peshkin op. cit.:109). As Stanley and Wise point out, when as a researcher I claim feminist ethical positions, I am "concerned with far more than behaviours and activities". There are, in addition, concerns about "whose knowledge, seen in what terms, around whose definitions and standards, and judged by whose as well as what criteria, should count as "knowledge" itself" (Stanley and Wise 1993:202).

\section{4 'Midstream' activities and methodological choices}

In thinking about the research design during the 'upstream' phase of the research, I had concluded that a qualitative approach would facilitate my interest in "a dynamic process of becoming rather than a static state of being" (Olesen and Whittaker 1968:4, cited in Harre Hindmarsh 1992:75). I wanted congruence of purpose and methodology between the pedagogical agenda and the research aims (Laragy 1996:89). As I was using action approaches to pedagogy, this led me to explore the options available using an action research methodology. Action research is described as a "series of spiral steps composed of planning, acting, observing and evaluating" (Kurt Lewin cited in Laragy op. cit.:90). The process usually proceeds over a considerable period of time and the active agents in such a process are the research participants as well as the researcher (ibid).

I knew that for two reasons there would be limitations on how closely I would be able to adhere to the usual prescription for action research. The cycles of planning/action/reflection/planning and so on, normally spread over a considerable period of time, were limited by the two-month duration of my 
residency at the University of Lincolnshire and Humberside. I also knew that despite my considerable efforts to ensure the active involvement of the research participants at every phase of the cycles, my pedagogical intent influenced the research agenda. I had an explicit desire to interrogate the social structures surrounding social work pedagogy and to promote student empowerment through consciousness raising and critical thinking (Van den Berg 1995:xx1x). To action research methodology, therefore, I added elements of feminist standpoint theory.

In relating feminist standpoint theory to social work research, Swigonski (1994), makes several points relevant to my research epistemology, viz. ecofeminism. Feminist standpoint research selects issues for investigation that affect the lives of marginalised people; ecofeminism posits a link between the oppression of subjugated peoples and environmental destruction. Both aim to enable oppressed groups to become conscious of and be empowered to change aspects of their lives as a result of new knowledge gained by active reflection. Feminist standpoint research advocates the conscious, reflective participation of the researcher; in the case of ecofeminism, this pertains to the theorist/activist role being ideally performed by the same individual (Sturgeon 1997:196).

\subsubsection{Criteria for my choice of research methods}

From the range of research techniques available, I was concerned to choose methods which:

- enabled me to include myself in the research as an active agent

- attached the same significance to the subjectivity and critical agency of the research participants as it did to my own

- acknowledged that any phenomenon observed was not 'reality' but a version open to critical inquiry (Harre Hindmarsh 1992:75; Stanley and Wise 1993:189)

- were not only congruent with my ecofeminist epistemology, but honoured principles of 'best practice' within the classroom. 
Within social work education, best practice within the classroom needs to both reflect and inform best practice in the field (Dore 1994:102). Despite the rhetoric in social work literature about the links between classroom teaching and social work practice, it is only relatively recently that the dichotomised relationship has been researched as a broadly based issue. Harre Hindmarsh (op. cit.) argues that positivist paradigms in the profession are partially responsible for artificial divisions between theory, practice and research. A number of theorists have sought to develop paradigms that avoid false dichotomies. Variously described as ‘theory in action' (Argyris and Schon 1974 and Schon, op. cit.) or 'theorising' (Hopkin 1985:54), such practice paradigms enable social work educators to think systematically and critically about practice. In other words, both the educator and the social work practitioner become engaged in 'praxis'.

As a corollary to the connections between pedagogy, practice and research, it is possible to identify parallel principles between the practice of social work (Cournoyer 1991) and the activity of research. Thus,

- gaining access to the research sites parallels preparation for client involvement

- building research relationships parallels building social work relationships

- profiling research groups is akin to information gathering carried out at the beginning of social work engagement

- designing the pedagogical process with built-in research tools parallels casework or community planning

- building in participatory approaches to learning is similar to joint contracting with a client for desired outcomes

- using questionnaires and video feedback in the research design parallels reviewing social work activities to ensure intervention goals have been achieved. 
Recognising these parallel processes enabled me to strive for congruence between them as well as recognising the point at which tensions and oppositions arose (Harre Hindmarsh op. cit.).

\subsubsection{Identifying sites for critical reflection}

Rather than 'gathering research data', I sought in this research to identify sites within which critical reflection could occur. Seeking a variety of such sites is consistent with a qualitative approach that seeks to capture and reflect on the complexity of social worlds (Coffey and Atkinson 1996:5). It is congruent with an eclectic view of social work practice which legitimises the use of different approaches in different situations, based on an informed choice about which theory, approach or method is likely to achieve the best results in a given situation (Gleed 1996). It is also supported by an ecofeminist epistemology that encourages diversity. For these reasons I chose to exploit a number of potential sites.

Because the research activity was embedded in self-reflective pedagogy, it was appropriate that the approach to site identification and to research activity served a dual purpose, both research and pedagogy. I chose three ways to gain research information:

(i) two sets of open-ended questions;

(ii) audio and video recordings of the research activity; and

(iii) a simple rating scale.

The three-pronged approach, commonly called triangulation, is designed to increase the trustworthiness of the research material (Glesne and Peshkin 1992:24). However, the aim in this case was more to generate different perspectives on the complexity of the phenomena (Coffey and Atkinson op. cit.:14). 
The two sets of open-ended questions were chosen because from a research perspective they had the potential to allow students freedom to enunciate their perception of the concepts of sustainable community using their own preferred means - words, diagrams, drawings, colour. Experience 'upstream' had reinforced my belief that such an approach elicited a research opportunity rich in meaning for the students.

From a pedagogical perspective, this approach served to focus the students' attention on the fact that they already possessed a view of this phenomenon and that their social knowledge was a sound place on which to start building or expanding their knowledge about 'sustainable community'.

I chose to administer the two sets of open-ended questions at different times during the research. These moments were designed to capture critical reflection at two points: firstly before the students were initiated to the concept (sustainable community); and then after they had been exposed to deliberate pedagogical processes intended to expand and ultimately to change their grasp of the concept's complexity.

Whilst I had no intention of employing a full-scale quantitative approach by exploring a 'before and after' with certain factors held constant, I had several aims in mind in asking the same questions at different points in the process. Firstly, I was indeed interested in changed levels of awareness about the complex nature of the notion of sustainable community - whether there had been a change as a result of the reflective processes employed. My second reason for their introduction was to utilise best practice teaching by reviewing learning on a regular basis to determine whether learning goals were being reached. Regular review parallels best social work practice in which the worker keeps revisiting the focus of the activity to avoid loss of direction that can ensue if objectives are not frequently reviewed.

The manner in which I utilised the 'before and after' approach did not satisfy the conventional criteria of so-called 'scientific' enquiry since so much changed during the process. Rather than representing a linear progression of 
activity, these points represented 'critical moments' when the research issues were brought into focus.

\section{ii. Audio and video recordings of the research activity}

Many of the social sciences have been slow to exploit the opportunities afforded by the use of video-recording as a source of research material. There is, however, a long-standing though largely disregarded tradition in social anthropology of 'interaction analysis' using recorded data to record naturalistic activities (Heath 1997:183). Unlike many of the classical approaches utilising video recordings as a method of representation and documentation (op. cit.:190), my choice was influenced by a desire to use it as part of the activities of a reflective teacher engaged in participatory action research. I decided to exploit the potential of video to its fullest extent. I used it to enable research participants and me to view our interactions and engage in collaborative reflection. By also video-recording that activity I was able to deepen the reflective process. (The details of this technique are described in 4.4.4.) Heath suggests that:

"...the possibility of capturing aspects of the audible and visual elements of in situ human conduct as it arises within its natural habitats provides researchers with the unprecedented access to social actions and activities (op. cit.:198).

In addition to extending its potential as a tool for collaborative reflection in research, I chose to use video recordings of the research activity (backed up by audio recordings) because social work interviewing skills are frequently taught utilising video feedback. Students are therefore familiar with the technology and are not unduly threatened by its presence in the classroom.

Students of social work are aware that communication is more than the words that are spoken. So gaining access to accompanying non-verbal expressions such as gestures and body language is another feature of social work education that I carried over into the design of this research. It added another dimension 
to the meanings that can be derived from verbal expression and was therefore consistent with an ecofeminist approach that encourages diversity and plurality.

\section{iii. $\quad$ Rating scale}

Following the first two workshops, my reflections on the process of students' responses to the pedagogical processes led to my becoming curious about what particular aspects of the process impacted on their understanding of the concept of sustainable community, and to what degree. To this end, I developed a simple rating scale on the usefulness of each pedagogical activity. As part of the design of the second workshops, during which students viewed selected parts of the video-taped first workshop, I asked them to complete the rating scale about the usefulness of the introductions, the open-ended questions, the mini-lecture, the action (Boal-type theatre), the reflection at the end of the workshop and the reflection on the bigger (macro) picture of the theatrical scenario. The purpose of this research tool was to enrich my understanding, as well as the students', of the relative success of each process in bringing about increased understanding of sustainable community. After each section had been viewed on the video, I was able to discuss the results with students. On the basis of their responses to the rating scale I could immediately clarify any confusion and enrich the discussion by giving relevant examples. In addition, I was able to prepare for subsequent workshops using the information I gathered from the rating scale and discussion with the first group of participants. (The details of this process are described in 4.4.9.)

Grinnell suggests that social work research should be methodologically pluralistic (Grinnell 1993:38). This means that the full range of methodological approaches can be utilised. Any artificial separation of qualitative and quantitative approaches, particularly along gendered lines, reinforces a false oppositional stance which current researchers resist (Harre Hindmarsh op.cit.:83). I felt at liberty therefore, to utilise whatever approach seemed to best serve the research objectives. 
In order to illuminate the interweaving of the research and the pedagogical processes Figure 4.3(a) summarises the activities carried out in the "midstream' phase of the research. Each aspect of the process is then discussed in turn.

\section{Figure 4.3(a) NATURE AND SEQUENCE OF 'MID-STREAM' ACTIVITIES}

\begin{tabular}{|c|c|c|c|}
\hline & ACTIVITIES & & \\
\hline 1 & $\begin{array}{l}\text { Negotiated access to research sites } \\
\text { in University of Lincolnshire and } \\
\text { Humberside. } \\
\text { Gained institutional credibility } \\
\text { and ethical compliance. }\end{array}$ & & \\
\hline 2 & $\begin{array}{l}\text { Built research relationships with } \\
\text { teaching staff by discussion and } \\
\text { with tourism students by } \\
\text { attendance at regular class. }\end{array}$ & & \\
\hline 3 & $\begin{array}{l}\text { Designed Workshop One (see } \\
\text { Figure } 4.4 \text { ) for tourism students. }\end{array}$ & & \\
\hline 4 & $\begin{array}{l}\text { Arranged for room and technical } \\
\text { set-up. }\end{array}$ & & \\
\hline & TOURISM STUDENTS & & SOCIAL WORK GROUP \\
\hline 5 & $\begin{array}{l}\text { Conducted first workshop. } \\
\text { Gave students research questions } \\
1-4 \text { (see Figure } 4.4 \text { ) and videoed } \\
\text { workshop. }\end{array}$ & & \\
\hline 6 & $\begin{array}{l}\text { Reflected on workshop process in } \\
\text { teaching journal and summarised } \\
\text { research question responses. }\end{array}$ & 7 & $\begin{array}{l}\text { Modified first workshop design } \\
\text { on basis of reviewing the first } \\
\text { session. }\end{array}$ \\
\hline
\end{tabular}




\begin{tabular}{|c|c|c|c|}
\hline & TOURISM STUDENTS & & SOCIAL WORK GROUP \\
\hline & & 8 & $\begin{array}{l}\text { Conducted first workshop. } \\
\text { Gave students research } \\
\text { questions } 1 \text { and } 2 \text { (see Figure } \\
\text { 4.4). Videoed workshop. }\end{array}$ \\
\hline & & 9 & $\begin{array}{l}\text { Reviewed both videos; } \\
\text { reflected in journal. Analysed } \\
\text { research question responses. } \\
\text { Attended to technical } \\
\text { problems. }\end{array}$ \\
\hline \multirow[t]{2}{*}{10} & $\begin{array}{l}\text { Designed second workshop on } \\
\text { basis of reviewing both tourism } \\
\text { and social work videos and all } \\
\text { previous reflections. }\end{array}$ & & \\
\hline & & 11 & $\begin{array}{l}\text { Delivered lecture on } \\
\text { ecofeminism to social work } \\
\text { students. }\end{array}$ \\
\hline 12 & $\begin{array}{l}\text { Conducted second workshop. } \\
\text { Returned summaries of } 4 \text { research } \\
\text { questions. Gave students rating } \\
\text { scale response sheet to complete. }\end{array}$ & & \\
\hline \multirow[t]{4}{*}{13} & $\begin{array}{l}\text { Reflected on second workshop in } \\
\text { journal; summarised response } \\
\text { sheet }\end{array}$ & & \\
\hline & & 14 & $\begin{array}{l}\text { Modified second workshop on } \\
\text { basis of reflections. }\end{array}$ \\
\hline & & 15 & $\begin{array}{l}\text { Conducted second workshop. } \\
\text { Gave students summaries of } \\
\text { Questions } 1 \text { and } 2 \text {. } \\
\text { Gave students Questions } 3 \text { and } \\
4 \text { to answer. Gave students } \\
\text { response sheet to complete. }\end{array}$ \\
\hline & & 16 & $\begin{array}{l}\text { Reflected on process in } \\
\text { journal. }\end{array}$ \\
\hline
\end{tabular}

This table is numbered sequentially to indicate the flow of the action-based research activity between the two English research groups. Rather than a 
linear table, a spiral more accurately represents the process. To illustrate the relationship between designing, conducting, reflecting, modifying, and reviewing the activities with both groups a simplified version of the process is shown in Figure 4.3(b).

Figure 4.3(b)

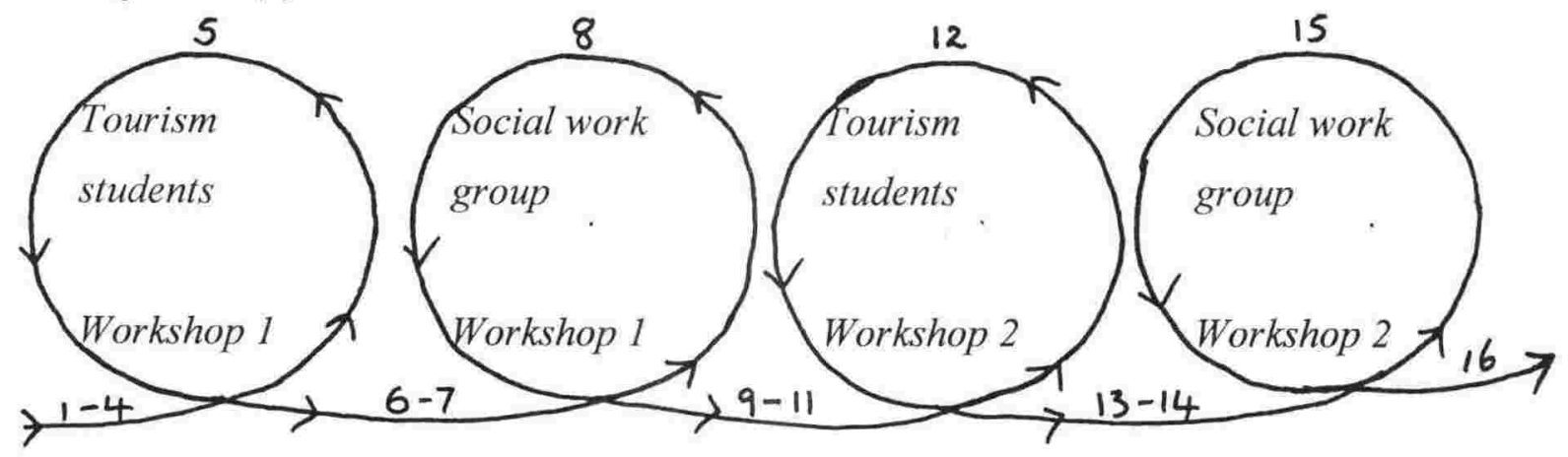

The last spiral represents the end of the research proper, the 'mid-stream' activities. In reality, the same spiralling processes continued in what I have described as the 'downstream' activities, where the focus was on my usual teaching in Aotearoa/New Zealand. These activities are described in detail in 4.5 .

\subsubsection{Gaining access to the United Kingdom research sites}

The first part of my fieldwork was carried out during a two-month period at the School of Policy Studies, University of Lincolnshire and Humberside, in 1997. My work was greatly assisted by the support I received from the Head of Policy Studies Research, Professor Gary Craig, who had arranged my residency in the department. Professor Craig established my credentials with the research committee of the university, accepted the ethical approval from Victoria University because it paralleled the British Social Science Ethical Standards, and was satisfied with the consent forms and information to research participants (see Appendices). 


\subsubsection{Building research relationships}

In meetings with departmental staff, I explained that I wished to set up workshops with a group of students who would be willing to meet twice. They would be video-taped during the first session and would take part in analysis of those recorded interactions in the second session, which would also be videotaped. I said that if possible I wanted to contribute to the current teaching programme in a 'natural' way rather than the research being an artificial project.

My desire to integrate the research project with the pedagogical one takes the emphasis in qualitative research on "watching people in their own territory" (Silverman op. cit.:29) several steps further. The reflective gaze is focused on the knowledge generated, on the students and on me, but also on the dynamic relationship between these elements as well as the contextual environment of the organisation in which teaching/learning occurs (Carr and Kemmis 1983:182). I considered it important, therefore, to interpret 'building research relationships' as meaning 'learning quietly, as a guest in someone else's home'. In this way I would learn about the nature of the course of study, the current climate of the university, and the interest the staff and students had in my topic.

I emphasised to staff my preference for a collaborative approach to this research, which was the reason for my wanting to involve the students in the analysis of their own interactions. I explained that the discussions would centre on the topic of sustainable community, that my approach would be an ecofeminist one, and that participants would be able to access the results of the research through the findings being sent to their tutors. Two lecturers, one in social work and the other in tourism, were immediately interested in finding students to take part in the project. I therefore decided to conduct the research with two different groups even though this meant there would almost certainly be greater complexity in the process as well as in the outcomes. 
I did not confine participation in the research to social work students for a number of reasons. At Victoria University I had for two years taught community development to recreation and leisure students. The curriculum was very similar to the tourism degree at the University of Lincolnshire and Humberside. I had enriched my own repertoire of teaching skills from this transdisciplinary experience and therefore believed that aspect of the research experience could similarly be enhanced.

At this stage of the research I was also aware that one of my aims was to make a contribution to pedagogy beyond the field of social work. Conducting some of the research in a different field, then, held the potential to contribute to an understanding of how different disciplinary contexts may influence the pedagogical process.

On a pragmatic level, I decided that interested and enthusiastic staff volunteers were most likely to bring to the project students whose participation in the research would be seen as part of a 'natural' curriculum-related activity.

\subsubsection{Recruiting the two groups to participate in the research}

The University of Lincolnshire and Humberside, formerly a polytechnic, is situated in Kingston-upon-Hull, East Yorkshire. In 1997 it was building a second campus 40 kilometres away in the city of Lincoln. The development of the Lincoln campus meant that some staff commuted between the two sites, and the whole environment of the organisation was one of rapid and farreaching change. The Lincoln campus hosted a three-year Bachelor of Tourism degree that included a paper on Tourism and the management of the natural environment. The learning outcomes included:

- familiarity with the key concepts of habitat, ecology, species and diversity, and how these relate to tourism

- understanding the diverse relationships between natural environments and human interventions, and 
- a critical examination of the implications of managing for sustainable economic, social and environmental futures.

Dr Alison Lewis, Senior Lecturer in Tourism, invited me to sit in on a seminar presentation on the development of a visitor centre on the Burren in Ireland. At the conclusion of this seminar I introduced myself as a New Zealander of English and Irish descent, teaching at an Aotearoa/New Zealand university. I consciously decided to use principles of engagement to build a research relationship with the tourism students. Specifically, I made links with their natural curiosity, as students interested in tourism, with a visitor from New Zealand; I connected with their seminar discussion about the Burren, which I had visited three years earlier; and I let them know I was interested in their views. In contrast with the building of a social work relationship with a client, building rapport with research participants has an acquisitive function in serving the interests of the researcher (Glesne and Peshkin op. cit.:94). In this instance, my belief was that in making connection with the students in their context as learners, I was not only establishing rapport for research purposes but building the foundation for a pedagogical milieu where student subjectivity and life experience would form the foundation of an active learning approach (Boud 1993:38).

I explained what the research project entailed, including the use of video. I asked for volunteers to take part in two workshops, both of which would be scheduled in normal seminar slots. Eleven students - approximately half the class - volunteered. Dr Lewis had indicated to students that participation in the research workshops would not mean their missing out on any essential information from the course work. As I had previously discussed at length with Dr Lewis the ideas I had for the workshop, she emphasised to students that the material presented would be of benefit to their own research goals.

Establishing a research relationship with the second group followed a different pattern. Ms Stephanie Petrie, Senior Lecturer in Social Work at the Humberside campus, volunteered after our initial discussion to recruit a group for me. She contributed to the diversity of research design by extending the 
group's membership to administrative staff, and she also included herself in the group of nine. The lecturer's initiative in participating so actively in the process resonates with feminist participatory or collaborative research protocols (Reinharz op. cit.:181). Rather than insisting on uniformity between the two groups, I was happy that research relationships in each case were initially mediated through staff members with good rapport with students. It did pose some difficulties, however, in that I did not brief the social work group directly. This meant that their expectations were different from those of the Lincoln group, with whom I had direct contact prior to the first session. The social work participants thought I would be giving them a lecture on ecofeminism, and that there was to be only one workshop. Ms Petrie had asked me to give a lecture on ecofeminism to the whole course at a later date, and mention of this caused the confusion with the research group.

Figure 4.4 documents the variety that developed as the research process proceeded with the two groups.

Figure 4.4 VARIETY IN THE TWO UK RESEARCH GROUPS

\begin{tabular}{|l|l|l|}
\hline & TOURISM STUDENTS & $\begin{array}{l}\text { SOCIAL WORK } \\
\text { GROUP }\end{array}$ \\
\hline Researcher contact: & $\begin{array}{l}\text { Participated in normal class } \\
\text { activity } \\
\text { Met research volunteers } \\
\text { before the workshop }\end{array}$ & $\begin{array}{l}\text { Had no contact prior to the } \\
\text { first workshop }\end{array}$ \\
\hline $\begin{array}{l}\text { Clarifying } \\
\text { expectations: }\end{array}$ & Briefed students directly & $\begin{array}{l}\text { Briefing about topic was via } \\
\text { their lecturer } \\
\text { They thought they would be } \\
\text { having a lecture about } \\
\text { ecofeminism } \\
\text { They were not told there } \\
\text { would be two sessions }\end{array}$ \\
\hline $\begin{array}{l}\text { Choice about } \\
\text { Participating: }\end{array}$ & Voluntary & $\begin{array}{l}\text { Handpicked by lecturer on } \\
\text { basis of perceived interest in } \\
\text { topic }\end{array}$ \\
\hline
\end{tabular}




\begin{tabular}{|l|l|l|}
\hline Group composition: & $\begin{array}{l}\text { All students from the same } \\
\text { course }\end{array}$ & $\begin{array}{l}\text { Some students, some admin. } \\
\text { staff and one lecturer, all } \\
\text { from social work } \\
\text { programme }\end{array}$ \\
\hline $\begin{array}{l}\text { Familiarity with } \\
\text { topic: }\end{array}$ & $\begin{array}{l}\text { Familiar with notions of } \\
\text { community, environmental } \\
\text { concerns and, to a lesser } \\
\text { extent, sustainability }\end{array}$ & $\begin{array}{l}\text { Not familiar with } \\
\text { environmental concerns, but } \\
\text { with community and social } \\
\text { concerns }\end{array}$ \\
\hline Composition: & $\begin{array}{l}\text { 4 female, 5 male Caucasian } \\
\text { students all able-bodied- } \\
\text { estimated age early 20s }\end{array}$ & $\begin{array}{l}\text { 9 females, 2 males; 1 black } \\
\text { female, rest Caucasian. 1 } \\
\text { female with a disability; } \\
\text { estimated age range 20 to } \\
\text { mid 40s }\end{array}$ \\
\hline
\end{tabular}

\subsubsection{Planning Workshop One}

My aim in preparing the first workshop for the Lincoln tourism group was twofold: firstly, to prepare an interesting and informative learning experience focused on an exploration of the notion of sustainable community; secondly, to employ pedagogical practices informed by ecofeminist praxis. To this end, I drafted a series of steps I intended to follow, identifying for myself the epistemological rationale upon which each action was based. I did not want to implant in the students' minds ideas and concepts simply of significance to me. Rather, I was consciously attempting to provide a learning experience that would contribute to an expansion of their consciousness about the nature of sustainable community.

I was aware of the contradictions inherent in this approach - my motive was to avoid 'depositing' information, while at the same time being committed to a political, conscientising process. Stanley and Wise write of this experience as working "with 'contradictory' elements because this is what social reality is like" (op. cit.:191). As I did not want to overload the students with theoretical input, I planned to keep my contribution to a minimum in the first workshop, thereby highlighting student experience in the process of knowledge 
generation. The outline I prepared for myself in preparation for the first workshop is reproduced as Figure 4.5.

\section{Figure 4.5 WORKSHOP ONE DESIGN ${ }^{3}$}

\begin{tabular}{|c|c|}
\hline ACTION & $\begin{array}{l}\text { ECOFEMINIST PEDAGOGICAL } \\
\text { PRINCIPLES }\end{array}$ \\
\hline $\begin{array}{l}\text { 1. Set the environment - comfort, fresh air, } \\
\text { flowers. Gain consent verbally. }\end{array}$ & $\begin{array}{l}\text { Co-operation as a feature of } \\
\text { sustainability. }\end{array}$ \\
\hline $\begin{array}{l}\text { 2. Introduction of self as facilitator of } \\
\text { learning: socially, culturally, economically, } \\
\text { historically and ecologically as member of } \\
\text { 'communities'. } \\
\text { Include personal motivation for doing it. }\end{array}$ & $\begin{array}{l}\text { Modelling identity as embodied \& } \\
\text { embedded in the natural world. } \\
\text { Illustrating interconnectedness. }\end{array}$ \\
\hline $\begin{array}{l}\text { 3. Invite student introductions of } \\
\text { themselves in a way that describes who they } \\
\text { are 'in community', plus anything they } \\
\text { know about the physical environment in } \\
\text { which they live. Link to own learning } \\
\text { outcome to understand diverse relationship } \\
\text { between human-natural. }\end{array}$ & $\begin{array}{l}\text { Establishing human-human and } \\
\text { human-nature connections. }\end{array}$ \\
\hline $\begin{array}{l}\text { 4. Outline purpose of workshop - research } \\
\text {-collaborative. Outline the } 2 \text { hour process - } \\
\text { exploration of notion of sustainable } \\
\text { community . } \\
\text { Invite students to answer Research } \\
\text { Questions } 1 \text { and } 2 \text { : } \\
\text { 1. As you think about the notion of } \\
\text { 'sustainable communities', what comes } \\
\text { into your mind? what images? what } \\
\text { ideas? what words? what activities? } \\
\text { 2. As you think about how to bring } \\
\text { about sustainable communities as you } \\
\text { understand them, what comes to } \\
\text { mind? what images? what ideas? } \\
\text { what words? what actions or activities? } \\
\text { Give mini-lecture with key points: } \\
\text { Community as a construct we use to }\end{array}$ & $\begin{array}{l}\text { Share notion of expanded } \\
\text { consciousness to include all in the } \\
\text { natural world. } \\
\text { Giving priority to social knowledge } \\
\text { of students - i.e. foreground their } \\
\text { knowledge. } \\
\text { Establish connection and diversity } \\
\text { (clarify). }\end{array}$ \\
\hline
\end{tabular}

\footnotetext{
${ }^{3}$ This plan has not been edited and therefore represents the teaching plan as I recorded it in my teaching journal. Text in italics indicates where I modified the plan for the initial social work workshop, having watched the video of the first workshop held with the tourism students.
} 
describe relationships that imply some
mutual benefit or interaction:
- recognisable grouping either
geographical, ideological or interest eg
family, neighbourhood, village, work,
leisure, natural environment
- sense of inter-connection
- notion of addictions - expand
- our restricted sense of community partly
responsible for our unsustainability.

Sustainable: Would not need to discuss this if we lived sustainably-our current actions in the world are just not sustainable. We are facing the wall -drip feed numbs us. Term first popularised when it became clear that Western industrialised nations were reaching the limits of the notion of growth that could extend beyond the next decade; set off debate about what needed to change to make human activity sustainable - could mean exploiting all the remaining resources of the $2^{\text {nd }}$ and $3^{\text {rd }}$ world countries; when linked with development could be an oxymoron; built-in contradictions and conflicts as resources become more scarce. May include the following elements:

- revisioning the concept of 'community" to include the non-human world

- accepting the limits to growth

- living with diversity

- facilitating learning communities

- ending "human chauvinism"

- dismantling dualisms

- counting what matters

- foregrounding indigenous peoples

- integrating practicality with spirituality

- amplifying the voices seldom heard in futures visioning.

5. Explain that knowledge is generated on the intersections between learner, facilitator of learning and the bodies of knowledge. Most of us will have more experience of unsustainability than of sustainability so discuss briefly some examples that you are personally part of that illustrate unsustainability in community. Decide on one and the person who knows it
Addiction to progress.

Be aware of the existence of dualistic thinking underlying even the most supposedly innovative and conserving notion- so development/sustainability linked with economic/social, human/nature, man/woman, etc.
Using Patti Lather's (Lusted 1986) feminist pedagogy - intersections of teacher, student and knowledge plus context.

Keep in mind the notion of dismantling dualisms that I have developed from Val Plumwood by foregrounding what has been backgrounded: 


\begin{tabular}{|c|c|}
\hline $\begin{array}{l}\text { well shapes it into a story with beginning, } \\
\text { middle and an end. } \\
\text { Who are the 'actors'? what is the crunch } \\
\text { issue? what are the conflicts? who is } \\
\text { benefiting from the status quo? who/what is } \\
\text { hurting, being damaged? what is the nature } \\
\text { of the relationship between the actors? (If } \\
\text { the story doesn't need all } 11 \text { people, specify } \\
\text { some as spect/actors). } \\
\text { Run the story without interruption } \\
\text { Re-run the story with opportunity for } \\
\text { spect/actors to interrupt to offer alternative } \\
\text { words and actions which would lead } \\
\text { towards a sustainable outcome. }\end{array}$ & $\begin{array}{l}\text { - affirm continuity and overlap } \\
\text { - reclaim positive, independent } \\
\text { sources of identity for the } \\
\text { underside } \\
\text { - reject objectification of the } \\
\text { underside } \\
\text { - recognise complexity of the } \\
\text { underside. }\end{array}$ \\
\hline $\begin{array}{l}\text { 6. While people still in role, identify any } \\
\text { principles of transforming unsustainability } \\
\text { into sustainability. } \\
\text { De-role anyone if necessary. }\end{array}$ & $\begin{array}{l}\text { Consciously exposing the colonised } \\
\text { consciousness within a safe and fun } \\
\text { context in order to deconstruct it, then } \\
\text { reconstruct using members of the } \\
\text { 'underside's' raised level of } \\
\text { conscientisation. } \\
\text { Re-establishing connection with the } \\
\text { disconnected elements of community. }\end{array}$ \\
\hline $\begin{array}{l}\text { 7. Explain next week's task: to watch } \\
\text { selected portions of today's activity in order } \\
\text { to reflect on it together. }\end{array}$ & $\begin{array}{l}\text { Engaging students in their own } \\
\text { development of knowledge by praxis. }\end{array}$ \\
\hline $\begin{array}{l}\text { 8. Ask students to answer Questions } 3 \text { and } 4 \\
\text { as part of the info to be woven into the } \\
\text { lecture: } \\
\text { 3. You have participated in a } \\
\text { workshop/discussion/lecture exploring } \\
\text { the notion of sustainable communities. } \\
\text { Are there any new images, ideas, words } \\
\text { or activities you would like to use to } \\
\text { describe this notion? } \\
\text { 4. Can you describe how these changes } \\
\text { happened? What actions, activities, } \\
\text { images, words, ideas, contributed? } \\
\text { (These could be your own, other } \\
\text { participants', or the facilitator's) }\end{array}$ & \\
\hline THANK THE STUDENTS & \\
\hline
\end{tabular}




\subsubsection{Conducting Workshop One - Lincoln tourism students}

I set up the room as a comfortable learning environment, with semi-circular seating arrangements, comfortable room temperature and a bowl of fresh flowers to enrich the sterile surroundings of the classroom with something from the natural world. I had checked technical details like microphone sensitivity with the video technician and we together set up the camera with wide-angle lens in one corner of the room. The students arrived late, which meant the workshop started half an hour behind schedule, with nine of the eleven volunteers present. The late start meant that I was worried about how to fit my two-hour plan into an hour and a half. I decided at that stage I would shorten the mini-lecture, rather than reduce the student participation. This aspect of research being conducted in a 'normal' education situation - with delays and 'no-shows' included - reflects the reality of action research being carried out in everyday situations (Stanley and Wise op. cit.:115).

I followed the plan of the workshop by commencing with a welcome, introducing myself with a brief sketch of the geography of my birthplace, Nelson, Aotearoa/New Zealand, the origins of the name Nelson, and a brief comment about the colonisation of my country. I then invited the students to introduce themselves. After that I outlined the research process and reconfirmed their understanding that participation in the research was voluntary, that the second workshop would involve them in the analysis of the initial workshop, that they would be sent a copy of the completed research findings via their lecturer, and that the video-tape would be erased once the research was complete. They then gave oral consent for the process to proceed. I made a spontaneous decision to make up some time lost to the pedagogical focus of the workshop by obtaining oral rather than written consent to the conditions of the research. The oral consent included those points outlined in the consent form.

I then got students to answer the research questions as set out in the workshop outline (see Figure 4.5, step 4). Although I had explained this as an individual exercise, some conferred with neighbours, so I encouraged them to assist each other if they wished. A departure from an individualistic approach was 
justified because my aim was to use pedagogical approaches that were congruent with the content of the workshop (sustainable community) and the process (ecofeminism). Co-operation and collaboration are principles consistent with both. I explained that I would summarise the content of their responses and give them the summary at the second workshop. This inclusive aspect of feedback and participation further demonstrated collaboration within the classroom and in participatory research. I then gave a much-abbreviated mini-lecture on community, sustainability and sustainable community.

Moving to step 5 of the workshop plan, I prepared the context for the Boalstyle theatre (see 3.4.4) by describing the interaction between theory and experience. I said that we would then attempt to understand some of the notions of sustainable community by drawing on their experience of personal involvement in a situation that for them was unsustainable. I then described the process of deciding on an incident - that the person would need to shape it into a story with a beginning, a middle and an end, identifying the key participants and the main issues. The students seemed to struggle with this idea initially, but after some prompting from me two examples were offered, one involving a student in her employment situation and the other a less well defined example to do with the university community.

With more time available, I would have followed my usual teaching practice of asking each student who volunteered an incident to describe it and getting the group to decide which would be chosen for the dramatic presentation. Because of the limited time, I gained the group's approval to opt for the employment scenario, which, when described, had potential to be more readily shaped into a story with a critical incident. My hope was that some common threads in the two scenarios would be identified. I established that students were familiar with role-playing, and then I reminded them of how to warm up to the roles, to choose names other than their own and to avoid caricature or over-dramatic performance. While the group of actors met outside the room, I explained to the others the tasks of the 'spect/actors', according to a Boalian approach to the dramatic presentation. 
The story played out concerned one of their number, a young woman student who had been, in her opinion, unjustly admonished by her male manager for being late for work at her part-time job. This student, Alice (not her real name), who became the protagonist, identified her work situation as unsustainable because if she could not be believed and trusted by her manager their future work relationship could not be sustained.

Alice rehearsed her story with the other actors, who self-selected their roles and 'warmed up' to them outside the classroom. The scenario opened with Alice's manager delegating work to a senior worker. When Alice and her sister (who also worked at the business) arrived, they were challenged about being late, even though the two young women had actually arrived five minutes before the official starting time. The scene concluded with the manager insisting they arrive earlier and the young women turning to their work feeling disgruntled and aggrieved.

The incident was played out without interruption. I then asked them to 'replay' the incident and explained the process of interrupting the action in order to offer alternatives in the search for sustainability. There was time for only one intervention, which did not achieve for the protagonist any transformation of the situation towards sustainability. A male student, Ben (not his real name, suggested a trade-off - that if the manager insisted that 'the girls' (as he referred to them) show up to work earlier than agreed, Ben would spread around the workplace pictures of the manager at a party. Alice was unable to accept that option, so was replaced in the protagonist role by Ben. Amidst much laughter, the two males engaged in a word battle. During this exchange, the emotional intensity increased and voices were raised.

Only a few moments were available to reflect on this process before the session ended. In the last few moments students were de-roled and asked to complete research questions 3 and 4 (see Figure 4.5, step 8). It was also explained that in the second workshop they would watch parts of the video of this day's activity, to draw out meanings of sustainable community. I thanked the 
students and checked that they would all be able to attend the next session - at which point two indicated that they would not be able to come.

\subsubsection{Conducting Workshop One - Humberside social work group}

The first session with the social work group at the Humberside campus was held on the day following that with the Lincoln tourism students. After the experience of the day before, I decided to modify the workshop design for Humberside social work participants by:

- giving more personal context and connection to the notion of sustainable community

- explaining more clearly my specific interest in the processes of bringing about sustainable community

- strengthening the mini-lecture considerably, including highlighting the social and environmental crises of the local area

- highlighting that I was interested in processes for "learning our way out" (Milbrath 1989) of unsustainability.

Because I was anxious that sound quality could be reduced by air conditioning noise, I arranged for the session to be audio-taped as well as video-taped. Again lateness was an issue. They all arrived at least ten minutes late, with two arriving twenty minutes late. Having gone through the consent process, I gave a much fuller explanation of the research process and my motivation for doing the study than I had with the tourism students. I had also learned from the previous workshop that I needed more explanation as to why contextual introductions were appropriate. In addition, unlike the tourism group, these students had not met me before the workshop. So in setting the context for the introductions I explained the purpose of sharing backgrounds as being to develop trust and a sense of what had shaped each individual's perception of the world. My own introduction included my name, how I got it, my birthplace and its topography, what influenced my sense of identity, my job at university, my family and personal interests, and a brief summary of my rationale for using this research as a way of understand better how I could employ processes 
which could prepare students to live and work in a very different world from the one which shaped me.

I invited the students to introduce themselves to me and to the group by asking them "What has helped shape how you perceive the world?". To this request, the students' responses were rich with references that included specifics of name, place of birth, family influences, present concerns and interests. Several noted explicitly how "different" they were both from me and from their peers.

They then filled in responses to research questions 1 and 2, and there was a great deal of interaction among the group as they discussed the questions. I then gave the mini-lecture, with much more detail about global social and environmental imperatives. I drew on local examples evolved from the participants themselves to illustrate notions of sustainability and unsustainability, particularly in relation to community.

I was conscious that for the social work students, the task of adding environmental to social dimensions in a notion of sustainable community possibly posed a greater challenge than had adding the social to the environmental for tourism students. This was because tourism students did have background knowledge about community and social issues. Social work participants had no professional knowledge about environmental issues. Some had a personal interest. I therefore spent much longer laying the foundation for connections to be made before I asked for an example of a situation of unsustainability to act out. I built the pattern in carefully linked steps:

- reference to the insidious nature of incremental social and environmental change resulting in a failure to respond until crisis conditions develop

- questioning students about whether they had any local examples of such crises

- exploration of possible responses once the awareness of the critical social and environmental issues is raised, viz. despair, as in "the problem is too big, so eat, drink and be merry for tomorrow we die", or alternatively, incentive to action 
- linking to social work's focus on social change, 'making a difference'.

This process prepared the intellectual ground for the introduction of a mode of knowledge generation to which they were largely unaccustomed. The students were asked to tell each other stories in which they had experienced unsustainability. These stories could be small incidents, ordinary accounts of everyday experiences about which they could ask questions, such as:

- What actions did the incident involve which, if carried on for a long time, would lead to social and environmental crises?

- Did the situation limit participation to a privileged few, to the harmful exclusion of others?

- Did the actions artificially simplify a complex and multi-faceted 'reality'?

- Did processes used for decision-making or problem-solving rely on an assumption of there being only one 'right way' to achieve desired goals?

- Did the desired goals, as well as the processes used, take into account long-term viability as well as short-term utility?

- Were the social goals of the action reliant on processes which depleted natural resources, contributing to environmental unsustainability?

- Alternatively, were the environmental goals reliant on processes which depleted or diminished social sustainability?

When it came to the theatre exercise, I spent more time shaping the participants' identification of an example because of my disappointment that the tourism students had not included an incident that covered both social and environmental aspects of unsustainability. I rationalised my reason for having suggested they identify an experience that included both social and environmental impacts as needing to create an opportunity where notions of community could be expanded. In that sense, I was conscious of the degree to which the pedagogical goal of bringing about change in students' perceptions overrode the research goal.

I asked the group to choose one story they could all relate to. A student who had been involved in collecting birds washed up ill or dying on the beach near 
Scarborough, a popular Yorkshire seaside resort, came up with the story which inspired the most enthusiastic response from the group.

Kerry (not his real name) described how an environmental group was convinced that raw sewage discharged into the sea near the town was responsible for a number of damaging social and environmental impacts: the local children, who played on the beach, had a higher than normal incidence of bronchial and eye infections; residents in expensive cliff-top housing were complaining of very unpleasant smells influencing property values and personal enjoyment; local fishermen were going out of business because fish stocks were depleted and fish caught (and used in local fish and chips) were often diseased or deformed. Encouraged to shape the situation into a story with a beginning, a middle and an end, Kerry as the protagonist talked with those students who had volunteered to play the parts of the story's characters: an employee of Yorkshire Water, responsible for the city's water and waste disposal systems; a local general practitioner; a local fisherman; and a wealthy property owner.

The scenario was a public meeting chaired by Yorkshire Water, to which all the 'characters' were invited. The participant playing Yorkshire Water outlined the purpose of the meeting, establishing at the outset her organisation's concern for the wellbeing of the whole community. All the actors challenged this claim. The General Practitioner claimed that a large proportion of the community she represented was adversely affected not only by the direct health problems attributable to the sewage but because the "bag of money assigned to deal with the health problems was too small". One of the 'spect/actors' reminded the actors that Yorkshire Water had been recently privatised and now had a mandate to make profits for the shareholders, not just perform a community service. The environmental pressure group presented forceful evidence of the detrimental effects of Yorkshire Water's failure to take the advice of their group and of the local fishermen as to where the sewage outfall should be relocated. Faced with competing pressures to supply clean water and dispose of waste appropriately, Yorkshire Water appealed to the complainants to come up with solutions. At this point, the wealthy resident 
expressed her view that the fate of the environment was irrelevant, because she could afford to avoid local seafood - her concern was with the "smell from the sewage". She would throw money at the environmental group, not in support of its cause, but because they were challenging Yorkshire Water's inaction.

As the situation became more complex, an additional element was introduced. The environmental group claimed that the person testing Scarborough's seawater quality had a conflict of interest, because he also served on the Board of Yorkshire Water. Unfortunately, because of the late start to the session, the action had to be curtailed at this point, with Yorkshire Water inviting one-toone discussion with the aim of producing a solution to the problem. As an aside, she added "a cheap solution".

Because of the time constraint, the normal Boalian process of re-running the dramatic presentation to allow interventions for alternative solutions was not possible. All that could be done in order not to leave the session at an unsatisfactory point was to invite each participant in the role play to describe how, in the role they played, the idea of a sustainable community would be described.

I decided on the spot to change the priority in this workshop, by postponing the completion of research questions 3 and 4 until the second session. I was more concerned to have the group exposed to further discussion on the conceptual foundation for the ideas than I was on gauging their responses at this early stage.

I explained that at the second session we would review the video as well as explicitly use ecofeminist thought to shed light on the ideas and the process. I did this because it would enable them to understand how theory from my lecture on ecofeminism, which I was scheduled to give before the next workshop, could be applied. 


\subsubsection{Reflection on Workshop One - Lincoln tourism students and Humberside social work group}

Immediately following the initial workshops with each group, I wrote a journal reflection and summarised the responses to the written questions. When I attempted to view the videos, I discovered that both were faulty. The Lincoln video had a faulty spool, which meant it had to be rewound onto a new spool, with subsequent damage to part of the tape. In addition, the sound quality of the Lincoln tape was very poor. Because of this, I arranged to have an extension microphone to video record the second session in Lincoln.

With the first Humberside video-tape, the sound quality was totally unacceptable, with total disappearance of sound for most of the tape. Fortunately, because I had arranged for a separate sound recording, the technicians were able to dub the audio recording of the session onto the videotape, with, of course, some loss of synchronisation. To obviate this occurring for the second social work workshop, I arranged to have a technician present, to ensure better quality recording. Given such a problematic technical situation, I was tempted to abandon the use of video. Despite the irony of one of the video tapes being 'silent', I decided to persist with the use of this technology because it seemed to offer, in the short time span available to me, enhanced opportunity for increased reflexive participation by the students and by me. It also appealed to what Fonow and Cook (1991:13) refer to as a survival mechanism, used by technocrats in transforming barriers into opportunities. Apart from anything else, I refused be beaten by a technical problem and chose rather to see it as a challenge.

I had planned to choose selected clips of the video to play back to the students during the second workshops. The process was made very difficult because neither of the video players was equipped with counters. Faced with the difficulty presented by the inadequacy of the technology to accurately identify the sections of the video for replay, I needed to structure the second workshops in such a way that students could be engaged constructively while I was fastforwarding the video to the appropriate places. I therefore identified six activities that captured the essence of the workshop process. These were: 
- Introductions

- Answering the research questions

- Mini-lecture

- Dramatic activity (divided into actors and spect/actors)

- Reflection on the dramatic activity

- Extending the reflection from micro to macro.

I decided to ask the students to rate each of these activities on a scale from 1 to 5 , with 1 being 'Not useful' and 5 being 'Useful' in terms of increasing their understanding of the notion of sustainable community and of the processes for achieving it (see Appendices). This was to focus the reflection of the students, as well as myself, on these significant 'moments' in the workshop process. I planned to ask the students what they thought was going on, as well as to share my interpretation and to draw in an ecofeminist perspective. This rating exercise was to be carried out while I was finding the next section on the video-tapes for students to view.

What was originally a challenge presented by a technological problem became a question of utilising the available teaching opportunity creatively. Research concerns ran parallel to pedagogical ones. The introduction of a small, simple, semi-quantitative method was designed to achieve some measure of the students' perceptions of the relative usefulness of various teaching strategies and concepts. Rather than remaining wedded solely to qualitative methods, I felt it was more important to remain true to the overarching aim of research to "transform the present to produce a different future" (Carr and Kemmis op. cit.:183).

In addition, I was anxious not to reproduce a binary, oppositional stance towards quantitative/qualitative research methodologies by avoiding quantitative methods simply because they are usually less highly valued in feminist research (Kelly, Regan and Burton 1995:235). I wanted to have access to whatever would assist me in making sense of the research activity, bringing "a feminist standpoint to a range of methods" (op. cit.:246). In so doing, I was placing more emphasis on the feminist intent of the research than on the particular methods employed (Reinharz op. cit.:197). 


\subsubsection{Conducting Workshop Two - Lincoln tourism students}

I opened this workshop, carried out a week after the first, with a brief discussion of an action/reflection process of knowledge generation. I explained that I had summarised the responses to the questions about sustainable community and had viewed the first video, making notes on what I believed were significant moments in the workshop. The present workshop was an opportunity for them to view their own responses to the first one, to discuss it together and to make further responses to the material, with my contributing additional ideas and questions about each key theme. I returned the summary of their responses from the previous week and also explained the use of the rating response form they were given that day.

I played the parts of the video-tape that focused on the six activities (see above), asking the students to think about the usefulness of each in developing an understanding of the notion of sustainable community and how it could be developed or brought about. I revisited the introduction by specifically interrogating the many variables that comprise our expression of identity. So where we live, our family, our sexual identity, our connection to other social groupings, our socio-economic position, our gender, and our connection to the land were all included. Faced with students from a highly urbanised and densely populated area, I sought to make a relevant and practical example of making connection to their place. I asked students if they knew where the ingredients of their breakfast that morning had come from. Bread and other food containing wheat was a common ingredient. As wheat had historically been grown extensively in Lincolnshire, they were able instantly to explore this aspect, several commenting that they used to cover these sorts of things in geography, but that such knowledge was not part of the present curriculum. The workshop concluded with a discussion on the usefulness of the whole process.

As I had been invited by Dr Lewis to give a lecture on sustainable community to the rest of the Tourism course who had not participated in this workshop, I 
invited the research students to make a collaborative presentation with me. This would enable them to become learner/teachers with their own colleagues, with the aim of extending their understanding of the notion of sustainable community as they thought about how to articulate it to their peers. Time did not permit detailed planning for that session, but one of the students offered to coordinate the presentation. I thanked the students for their participation and reiterated that the research findings would be available to them.

\subsubsection{Conducting Workshop Two - Humberside social work group}

I repeated the process used at Lincoln with the social work group at Humberside. In the time between the first and second workshop, there was an opportunity for some of the members to attend a guest lecture I gave to the entire first-year social work cohort on 'Ecofeminism for social workers: the potential for radical action'. In this lecture, I talked about why the environment must be included in our concept of community and how social work can either support our present unsustainable systems or challenge them and work for change. Attendance at this lecture meant that the students in this research group were exposed to a more in-depth account of sustainability and ecofeminist issues.

A further difference with the social work group was that in the second session I supplied them with environmental and social indicators for the region. I had learned from the second workshop with the Lincoln students that their knowledge of local social and environmental profiles was sketchy. The aim of introducing this material to the social work participants was to draw attention to the practical impacts of unsustainability on their own community. Anecdotal evidence of social and ecological unsustainability was thus reinforced by statistics. 


\subsubsection{Reflection on Workshop Two - Lincoln tourism students and Humberside social work group}

Following both workshop sessions, I completed journal entries, summarised participants' response sheets and viewed the videos. Despite the attendance of a technician in charge of the video camera, the tape of the second workshop at Humberside had no sound track. Again, I had arranged sound recording also, but technicians were unable to dub the sound from the tape recorder to the video because it was too complicated to match the on/off periods of video recording with the continuous audiotape. It would be difficult for me to express in appropriate language my level of frustration at the technical failure affecting three of the four workshops. ${ }^{4}$

\subsection{Planning the 'downstream' activities in Aotearoa/New Zealand}

As a result of the interaction I had had with the students in Humberside and Lincoln, reading more extensively on the subject, and my own reflections as I viewed myself on video in the teaching role, I had more clearly refined processes for integrating the ideas gleaned from the English research into the teaching which followed my return home to New Zealand.

This teaching involved week-long modules on Working with Communities and constituted one part of a two-module, 2nd-year paper, Principles and Practice of Social Work within the Diploma and MA (Applied) in Social Work at Victoria University. The first of these modules was conducted in Wellington, Aotearoa/New Zealand's capital city, and the second in Nelson, a provincial city where the Victoria University Social Work Department had set up a distance-learning programme. (See course outline in the Appendices) I planned to integrate the same four research questions I had used 'upstream' before I left New Zealand, and 'midstream' in the United Kingdom, into the course curriculum as well as explicitly using them as part of the research process.

\footnotetext{
${ }^{4}$ I had taken every precaution I knew against technical failures, yet they still occurred because the equipment was poorly maintained. I used the opportunity to reflect on the wider socioeconomic implications. The University of Lincolnshire and Humberside was originally a College of Further Education that became a Polytechnic and then a University. To my outsider's eye, comparing it with the neighbouring University of Hull, these changes had occurred without an appropriate level of increase in resources. There was a marked disparity between the two institutions in terms of buildings, campus and libraries, for example.
} 
I told New Zealand students that I wanted to integrate my learning from the overseas experience into the present course and enable them also to become involved in the ongoing action/reflection/action process. I hoped that as I modelled being a reflective teacher, the students might see the benefit of reflective practitioners to the communities with which they would work (Fook op. cit.). I explained that I had ethical approval for the research and that the questions I was asking would function as a 'warm-up' to the assignment topic, which focused on community sustainability. The aim was to allow the topic to 'brew' so that by the end of the week they should be able to draft their assignment essay outline. I pointed out that while completion of the question forms was compulsory, as that formed part of the learning for the course, return of their responses to me for analysis, i.e. to participate in my research, was voluntary. I explained that in acknowledgment of their contribution to my research, I would summarise and return the completed responses to them so they could use them as a resource for the assignment.

Aware that my request held the potential for coercion, I reiterated that all students would receive the summary, whether or not they had returned their answers to the questions. This was to reinforce the use of collective gathering and sharing of knowledge that I was attempting to model as an appropriate community work principle. As I taught with a colleague, I was able to ask her to verify that my incorporation of a research activity into the teaching programme was explicit, its aims were transparent and the methods of data collection ethically sound.

I did not repeat in New Zealand all the research activities that I had used in the United Kingdom, for several reasons. The study was not intended to be comparative. Nor was it ethically appropriate to replicate during regular teaching - when facilitating a prescribed curriculum had primacy - what I had done in workshops where research was the primary aim. As I designed the course curriculum in Aotearoa/New Zealand, I modified pedagogical processes that I had previously used and in particular focused on importing my learning about seven main areas: 
- establishing ground rules and context for the learning environment;

- making explicit the need to 'make room' for difference within the classroom;

- embedding the discussion about the meaning of sustainability and community within a thoroughly supported theoretical framework and within student experience

- anticipating resistance to a changed way of conceptualising community

- encouraging all expressions of such resistance as evidence of engagement in a process of change

- giving full expression to my own passionate commitment to the notion of sustainable community while encouraging equally passionate different perceptions

- encouraging students to articulate, argue, justify and debate these different views both in class and via their written assignments.

In the next chapter, the focus moves from the research activity to what meaning I derived from it. I have already alluded to the linear division of the research activity as problematic when describing cycles of planning/action/reflection/ further planning/action/further reflection. Just as what I learned from the 'upstream' activities was carried into the 'midstream' research, where learning from one workshop to the next was integrated, so the learning from both 'upstream' and 'midstream' flowed on to cumulatively influence the 'downstream' activity. Highlights from this learning are identified and synthesised in the chapter that follows.

In addition, the interpretive practice of 'making sense of the data' or the process of analysis cannot in a feminist action research methodology be seen as a distinct stage of the research. As I have described in this chapter, the reflexive activity informed and shaped how further opportunities for research activity could be generated as the process proceeded. I include in the next chapter detail about the "artful and political" interpretive process of making sense of the research outcomes (Denzin and Lincoln op. cit.:15). 


\section{CHAPTER 5}

\section{RESEARCH OUTCOMES AND WAYS OF MAKING MEANING}

\subsection{Introduction}

In this chapter I describe the talk, activity, visual expressions, ideas and dilemmas that flowed from the research activity, and how I have attached meaning to those outcomes. My learning occurred throughout the process, contributing constantly to the ongoing design and the choice of methods of inquiry. 'Research outcomes' became negotiated ways of attributing meaning to the ideas being explored. I use the term 'outcome' rather than 'output' or 'result' to describe what emerged from the research activity. 'Outcome' implies interaction between what emerges and the context in which it appears. I was not searching so much for results as 'answers' to research questions. I was turning a reflective research gaze onto a particular arena of educational life. I was not investigating problems or even 'making problems' (Silverman 1993:19), so much as gaining 'scenic understanding' of the pedagogical processes.

'Scenic understanding' is a term used by geographer Steven Pile to describe a process which "establishes an equivalence of significance (both meaning and importance) between the three dimensions of the lived experience of everyday life: the semantic scene (language), the socio-spatial scene (behaviour) and the socio-historical scene (social structure)" (Pile 1991:466). This is another way of enunciating what feminist researchers have long advocated by way of accentuating knowledge derived from the personal and political aspects of everyday experience (Stanley 1992:15). In feminist research this principle translates to who is establishing meaning and importance to the research outcomes. 
If no explicit agency is attached to the activities described as 'data analysis', the usual assumption is that it is the researcher making sense of the data, and doing so "... in order to capture the complexities of the social worlds we seek to understand" (Coffey and Atkinson 1996:3). In this research I sought to move the locus of control of the interpretation of the outcomes as close as possible towards the participants. On a continuum which has at one end participants having no influence and at the other has them being in partnership, feminist participatory research aims towards the latter end (Lather 1992b:95). The closest I got to this was in forming an alliance with research participants as often as possible for the duration of the research (Pile op. cit.). Just as qualitative and quantitative methodologies are not inherently good, bad or 'feminist' (Stanley and Wise 1983:159), so no one approach to making meaning from the research activity is inherently better or worse than others. As Dupuis and Neale (1998:122) suggest, the focus in the methodology literature has moved to the way methods are used, how research participants are treated and how data is handled.

I have already alluded to the linear division of the research activities as problematic when describing the action research cycles of planning/action/ reflection/further planning/action and further reflection. In recognition of the dynamic cyclical nature of all the research moments, this chapter weaves together outcomes, reflection (processes of making meaning), and the teaching activities resulting from the research learning. It includes my reflections on:

- responses by research participants to the four research questions

- the four videotaped workshops conducted in the United Kingdom

- the ratings responses of the two United Kingdom groups

- selected parts of the planning and teaching of the community modules with two Aotearoa/New Zealand groups.

It therefore constitutes the 'downstream' activities, which are summarised in more detail in Figure 5.1. 
Figure 5.1 THE NATURE AND SEQUENCE OF' 'DOWNSTREAM'

ACTIVITIES

\begin{tabular}{|c|c|c|c|}
\hline & RESEARCH & & $T E A C H I N G$ \\
\hline 1 & $\begin{array}{l}\text { Read all question summaries. } \\
\text { Read own journal entries. } \\
\text { Read and summarised rating } \\
\text { scale response sheets from } \\
\text { both groups. }\end{array}$ & 2 & $\begin{array}{l}\text { Integrated learning from the } \\
\text { previous activities/reflections } \\
\text { and designed teaching module } \\
\text { on community. }\end{array}$ \\
\hline 3 & $\begin{array}{l}\text { Analysed all } 4 \text { video-tapes. } \\
\text { Administered } 4 \text { research } \\
\text { questions to first community } \\
\text { work class at Victoria } \\
\text { University. } \\
\text { Summarised responses. }\end{array}$ & 4 & $\begin{array}{l}\text { Integrated insights and } \\
\text { feedback from all previous } \\
\text { sources into curriculum } \\
\text { development for week's module } \\
\text { on community at Victoria } \\
\text { University. } \\
\text { Returned responses to students } \\
\text { for them to utilise in essays. }\end{array}$ \\
\hline 7 & $\begin{array}{l}\text { Reflected on differences in } \\
\text { teaching/researching in } \\
\text { UK/NZ on basis of essays, } \\
\text { journal entries and student } \\
\text { feedback. }\end{array}$ & 8 & $\begin{array}{l}\text { Modified community course } \\
\text { curriculum for the second } \\
\text { Victoria University module. }\end{array}$ \\
\hline \multirow[t]{2}{*}{9} & $\begin{array}{l}\text { Gave out research questions } \\
1 \text { and } 2 \text { to second Victoria } \\
\text { University class. }\end{array}$ & & \\
\hline & & 10 & $\begin{array}{l}\text { Gave mini-lecture on } \\
\text { sustainable community using } \\
\text { ecofeminist approach. } \\
\text { Video-taped this lecture. }\end{array}$ \\
\hline \multirow[t]{2}{*}{11} & $\begin{array}{l}\text { Gave students in second } \\
\text { community class results of } \\
\text { response sheets for Qs } 1 \text { and } \\
\text { 2. Gave out Qs } 3 \text { and } 4 \text {. }\end{array}$ & & \\
\hline & & 12 & $\begin{array}{l}\text { Reviewed the tape of myself in } \\
\text { action giving the mini-lecture } \\
\text { during the second class. }\end{array}$ \\
\hline
\end{tabular}




\subsection{Choosing how to 'hear', 'read' and 'view' the research outcomes}

Just as I had striven for congruence between how I conducted the research activity and ecofeminist epistemology, when it came to managing the procedures for handling the empirical material ('data') and the process of making sense of it ('analysis'), I sought to achieve a similar consistency. The empirical material, which included:

- participant responses to four questions about sustainable community;

- the stories told and enacted during Boal-type theatre performances;

- the participant rating scale response sheets on the usefulness of various pedagogical activities; and

- reflections (both mine and research participants') on the research topic as collected via written text (including my teaching journals) and video/audio recordings,

produced a large volume of rich images, words, ideas and insights. I was faced, therefore, with the task of constructing a qualitative interpretive framework that would achieve the research aims as well as maintain the integrity of the researcher and the research participants.

Consistent with an ecofeminist epistemology, I chose from amongst the array of different approaches to 'analysis' (Coffey and Atkinson 1996:6) those most frequently used by feminist qualitative researchers as well as those from critical and participatory action frameworks. Dealing with the data for feminist researchers goes beyond procedures for data manipulation or even the imaginative work of interpretation (Coffey and Atkinson ibid) and includes:

"an emphasis on researcher and textual reflexivity; an action and praxis orientation; an attention to the affective, emotional components of research; and concrete grounding in immediate situations" (Fonow and Cook op. cit.:2-13).

In addition, feminist perspectives pay attention to the political nature of versions of 'reality' represented in research writing. Lather suggests, for 
example, that "the social text becomes a stage, or a site where power and knowledge are presented" (Lather 1991b:91).

As I 'listened' for recurrent themes in the participants' responses to questions and in the theatrical performances, and as I 'looked' for significant images in the drawings and the video-taped workshops, I developed a process which wove into the fabric of the research activity. It did not follow the research in a linear, sequential manner (Coffey and Atkinson op. cit.:6) but evolved in much the same way as an actor in an impromptu performance is moved by the audience's responses and her own creativity.

Within this dynamic dance, I did follow a rigorous pattern of recording and responding to the research materials. This pattern closely emulated the steps described by Joan Pennell during a research seminar I attended at Victoria University in 1996 and which she later refined in her co-authored book (Ristock and Pennell 1996). These included:

- listening to/watching closely what the research participants said, and writing down their actual words

- comparing their statements

- noticing interesting and recurring themes, particularly generative ones accompanied by heightened gestures and raised voice levels, indicating some emotion

- naming each theme and categorising it

- checking out each category against more statements

- clarifying each category against other categories being developed

- reshaping the categories to better fit their statements (op. cit.:86).

The last two steps were considerably extended by the use of students' feedback on their own responses, thereby enhancing the authenticity of the theoretical formulations that grew out of my reflections. 
How I chose to 'read' the research material and translate that into useable ecofeminist praxis within social work pedagogy was shaped in three major ways.

\subsubsection{Involving the research participants}

As already indicated, and consistent with a praxis-oriented participatory feminist approach, I wanted to involve the research participants in identifying research outcomes as much as possible (Lather 1992b). This approach is also consistent with a pedagogical stance which values students' contribution to knowledge generation. There were some limitations on this ideal. In the 'upstream' phase, participants were not exposed to as much theoretical material on sustainability and community as a basis for knowledge generation, since my own knowledge base on the topic was less well developed at that stage. 'Midstream', the brief time span within which the research activity was confined imposed a limitation on participants' involvement in reflection on the second workshops. 'Downstream', in New Zealand, research was not the primary aim of my activity and the curriculum for the week-long modules on working with communities needed to cover a broader range of topics than did the workshops in England. In addition, I had to be acutely aware in my New Zealand teaching of the possibility for me to be pre-occupied, albeit unconsciously, with my research agenda and exploit students' vulnerability as a captive audience in the classroom. I managed this risk by explicitly outlining my thesis topic, the processes it had already involved and how it was contributing to the knowledge I could share.

\subsubsection{Focusing on change}

Even in the United Kingdom, where research was my primary aim, I was aware that I was part of the students' learning process, where my role was to facilitate an interesting, scholarly pedagogical experience. Within that experience I had a praxis-oriented feminist eye to student learning which leads to action and change, and to a large extent my focus was still on outcomes that had relevance for the classroom. I deliberately paid attention to comments, 
ideas and images that did not fit the common emergent categories. I chose as well the "changeable, marginal, deviant aspects - anything not integrated which might suggest fermentation, resistance, protest, alternatives - all the 'facts' unfit to fit" (Gebhardt 1982:405, cited in Holland, Blair and Sheldon 1995:301). I was conscious, though, of needing to avoid falling into the twin traps of tourism (looking for the novel and imposing difference, rather than commonality) or of romanticism (confusing authentic with "culturally defined') (Silverman op. cit.:3-4).

\subsubsection{Utilising ecofeminist praxis principles}

What helped me to avoid these interpretive pitfalls while remaining true to a change-oriented focus was to concentrate deliberately on the six elements of an ecofeminist praxis that I had drawn from the literature. These elements are ecofeminism's:

- theoretical location on the intersections of a number of disciplinary boundaries and its contested status within the academy

- focus on multiple injustices and its attention to privileging marginalised voices

- focus on identity as embodied and embedded

- identification as diversified global movements and personal, political agendas

- parallel discourses of commonality/unity and difference/diversity

- emphasis on indigenous and spiritual dimensions.

The ecofeminist framework not only influenced how I chose to frame the research outcomes, but also had practical implications for how I utilised the visual, auditory and written material. The use of video with audio back-up enabled me to repeatedly watch and listen to the diverse forms of communication from all the participants. So on one viewing I could look exclusively at the way the bodies of the participants occupied the pedagogical space (hooks 1994:140). On another I could focus on the speakers and record their exact words. My reflections were deepened because I had access not 
only to my responses as I viewed and heard them, but also to the participants'. Figure 5.2 summarises the methods I used to systematically reflect on all the interactions of the research participants and on my own activities.

\section{Figure 5.2 SYSTEMATIC RECORDING OF THE CONTENT AND PROCESS OF RESEARCH WORKSHOPS USING THE AUDIO/VIDEO RECORDINGS}

\begin{tabular}{|l|l|l|l|}
\hline $\begin{array}{l}\text { Audio/video } \\
\text { tape counter } \\
\text { reading } \\
\text { (on playback } \\
\text { machine) }\end{array}$ & WORDS & ACTIONS & REFLECTIONS \\
\hline & Teacher/students & Teacher/students & Teacher/students \\
\cline { 2 - 4 } &
\end{tabular}

Shaped by the interaction and involvement of research participants, focused on change and utilising ecofeminist praxis principles, I consciously applied the interpretative template that evolved to all research material and process. What emerged began to take shape as my version of the 'world' that the research participants and I had been exploring together. From this emerged the outcomes and the process of making meaning.

\subsection{Outcomes and process of making meaning}

"Men and women are human beings because they are historically constituted as beings of praxis, and in the process they have become capable of transforming the world - of giving it meaning."

(hooks 1994:48)

To an important extent, this research aimed to enable participants to engage in a small but significant process of transforming their world. The process of describing the outcomes of the research and giving them meaning is seen as part of the dynamic relationship between pedagogy and research within the

\footnotetext{
${ }^{1}$ Where I had problems with video soundtracks, I played the videos with the audio-tapes of the sessions and synchronised them as best I could.
} 
classroom. There is always the hope that in a creative learning environment there will be elements of surprise and tension, leading to new levels of understanding and knowledge. I was conscious throughout this process that the learning and teaching occurred on both sides of the pedagogical equation the students' and mine (as in the Maori concept of 'ako' referred to in 3.6.1).

The results of my application of an emergent ecofeminist praxis to the workshops conducted around the topic, 'sustainable community' are considered under three headings:

- identity of the teacher and students

- generation of knowledge about sustainable community

- the role of self-reflective pedagogy.

\subsubsection{Identity of teacher/students in the pedagogical process}

Levels of understanding depend on active engagement of subjects in the learning/teaching process (Freire 1973:125). Interrogation of identity is a crucial part of the beginning phase of active learning. Ecofeminist praxis extends the interrogation to an exploration of identity as connected - to other human beings and to the natural world. In the classroom the presentation of self is complex (Ellsworth 1992). In this research, I utilise the practice of exchanging personal introductions of teacher and students - developed at the commencement of the workshops and routine modular teaching - as one window on identity in the classroom.

\subsubsection{1 'Introductions' as a window on identity}

My encounters with the research participants began with my paying attention to introductions of myself that went beyond name and where I come from (described in 4.4.7 and 4.4.8). My aim was to make conscious and explicit some of the multiple facets of my identity in the hope that students would become more conscious of identity as a significant ingredient in the teaching/learning process. 
The Lincoln students in my first workshop chose in the main not to emulate my pattern when they introduced themselves. Some in expressing their reticence,

"I don't know what to say",

chose simply to give their name and where they were from. Despite studying a tourism course which included material on the significance of place and identity, the Lincoln students did not seem familiar with the process of describing their identity within the context of the classroom. They may have assumed it irrelevant because they were already familiar with each other and I was the 'outsider'. It was clear from the ratings and comments made during the second workshop and recorded on their response sheets (See Appendices) that these students felt that introductions were irrelevant to the subject being studied - sustainable community - until an explicit connection had been made during the second workshop. All of them rated introductions as 'not useful' or of little use and one suggested introductions were,

" not totally relevant to sustainability (at first)".

I learned from viewing the videos and listening to the audio tapes of the first Lincoln workshop that I configured my identity in a way which consciously located me, and which made connections to the students' place (historically, geographically and culturally) and to my own. In addition, I suggested they were part of a community, albeit a temporary one, as members of the Lincoln student body. I likened my presence in their classroom to a transient visit of a migratory bird to Spurn Head (a local bird sanctuary with which they were familiar). What I realised on reflection was that such multiple connections did not immediately hold significance for the students in the classroom discourse on sustainable communities. This discourse includes the exposure of a disconnected consciousness such that identity is seen only in relationship to other human beings (Sylvan and Bennett op. cit.). Such human chauvinism in turn leads to disconnection from a broadly inclusive understanding of community. On reflection, I realised I had failed to appreciate that the inclusive nature of my introduction, about which I had thought a great deal, 
would not of itself facilitate the expansion of students' perception of their identity as embodied and embedded.

The student feedback and my own reflections forced me to revisit the ecofeminist focus on identity as embodied and embedded and to experiment further with its translation into pedagogical practice. As described in 4.4.10, I expanded the expression of identity by including references to where the Lincoln students' daily food had come from. I used a process of questioning to demonstrate the human-human and human-nature connections. Starting with inviting discussion on how gender differences may influence how we viewed the world and related to it, I moved gradually to the basics of what goes to sustain our bodies - food, and a discussion about the role of food production in the rural land surrounding Lincoln. The students shared their knowledge of the history of the surrounding rural land as a grain growing area and the influence that had on formulating the identity of their forebears as farmers and bakers, for example. We then compared that history with the modern reality of food production, purchase and consumption and how that influenced how they experienced a connection to the natural world. By more carefully crafting the discourse to begin with the students' own personal knowledge about physical sustenance, local social conditions, landscape and land use, and then moving to the knowledge we were together developing in the classroom, they were more readily able to grasp the ecofeminist notion that human beings are embedded in the natural environment in very tangible ways.

As I translated ecofeminist principles into pedagogical practice, I became aware of the need to pay close attention to the language and metaphors I chose, and the starting points, flow of questions and discussion patterns that I developed. Such attention to the linguistic patterns as well as the activities of teaching parallels the focus in social work practice on language use, metaphor and story-telling as empowering processes. Post-structural feminist approaches have also contributed to this focus.

I incorporated into my preparation for the first Humberside workshop what I learned from the Lincoln one. I knew that I needed to make explicit 
connections between everything I did and the notion of sustainable community. My introduction not only made explicit links with the discourse of sustainability and community, but also encouraged participants to disclose whatever aspects of their identify they felt comfortable expressing, using an expanded repertoire of elements. Rather than functioning as a prescription for students to follow, an expanded profile of my identity appeared to provide an expanded discursive space in which they could frame their own diverse identities (Solas op. cit.:83). A parallel can be drawn here between the greater sustainability of biodiversity in natural communities (Capra 1993, cited in Bowers 1995:207) and the enrichment of the classroom community by the explicit expression of diversity and difference. It is clear to me that my expanded expression of identity was encouraged by the greater visible diversity present in the Humberside social work group. In contrast to the Lincoln tourism students, the social work participants were not all students, were not all in the same age range, were not all Caucasian and were not all able-bodied.

Not surprisingly, in contrast to the tourism students, a number of social work participants rated the introductions as 'highly or moderately useful' in expanding their understanding of sustainable community. Where ratings were more neutral, they were accompanied by comments indicating an uncertainty about what and how much of themselves to disclose. Like the tourism students, the social work participants may have been uncomfortable with the degree of disclosure I had come to expect in social work courses in Aotearoa/New Zealand, where reticence about self-disclosure is not generally an issue.

A positive aspect of my conducting the research in another country was that I was able to exploit my being in a different cultural setting to facilitate a deeper exploration of the notion of identity as significant to understanding sustainable community. I had noted in my teaching journal just how much I 'tuned in' or 'tuned out' of my own expression of identity, depending on the context and purpose. When sharing this idea with the Humberside group, I used the metaphor of a sound mixer on an amplifier as representing the way group 
participants disclosed a variety of aspects of themselves according to such factors as personal safety and group knowledge and purpose. People presenting themselves in different social environments 'turn up' aspects of themselves they think appropriate and 'tune out' others. I could more appropriately have chosen to use a natural metaphor such as how many insects change their colouring to blend in with their environment.

Just as social communities are healthier when diversity is expressed and valued, so environmental and social communities are more sustainable when the full range of diversity is allowed to flourish. After the critical analysis of the contextual nature of identity was discussed, members of both groups seemed able to recognise more readily a connection between who they are and what they do in their work in communities. One social work student volunteered:

"who we are and where you are affects what you're doing".

\subsubsection{The complexity of elucidating identity within the classroom}

Establishing identity in the Victoria University social work programme is a normal part of student/teacher interchange, influenced by Maori and Pacific Island presence and custom. From an indigenous perspective, understanding and knowledge does not begin with an introduction to the topic, but with the rituals of personal encounter which locate the speaker in time, place and in genealogy. 'Ko wai au?' (Who am I?) is a question which when answered in a formal Maori introduction locates the speaker in their spiritual, social and cultural space (Pere 1979:23). The speaker is also located in geographical space - mountains, rivers, lakes and even significant trees and animals, actual or mythological, are included.

I observed, however, that cultural difference is not the only factor in the Aotearoa/New Zealand context to influence how identity is named in the social work classroom. Students at both Victoria University teaching sites had spent 18 months together, not only in the modular-type teaching but also in residential marae-based teaching. Mindful of these factors, I incorporated 
introductions into the content of the course in a very different way from how I had utilised them before conducting my research. Because I had been overseas when these classes first formed, and was relatively new to them, I used an expanded version of my own identity, as in Humberside, though excluding explicit mention of the colonial history of Aotearoa/New Zealand. This introduction specifically included my experiences as a pakeha, lesbian, older woman with Irish and English ancestry, living in Aotearoa/New Zealand and having worked for twenty years in a variety of social work/community contexts.

In applying what I had learned from the research in the United Kingdom about contextualising introductions I divided the process of 'naming ourselves' into two parts. Because the New Zealand students had already been together for over a year and it was I who was new to them, I asked them to give a brief introduction for my benefit. I explained that more detailed introductions would be invited later.

The second part of the 'introductions' linked not only to the significance for the topic, working with communities, but also with the pedagogical aim of fostering a learning community within the classroom. I invited the students to introduce themselves again, this time locating themselves in relation to their past experience of living and working in 'community', whatever they understood that to mean. This sharing of information had a practical rationale. Students had already been briefed that on the basis of such shared information they were to form learning partnerships with fellow students whose previous experience in living and working with communities had potential to contribute to their own learning goals. Cooperation as a feature of an ecofeminist praxis was thus translated explicitly into the fostering of a sustainable learning community.

Some aspects of the use of inclusive descriptions of identity were of particular significance to women students. My embodiment as a woman made way for women in the class to 'count as something' their unpaid work in the community (Waring 1988). Including aspects of everyday activity as an 
ingredient of identity is one of the factors that from an ecofeminist perspective contribute to 'flourishing' (Cuomo 1998). In addition to the references to family/whanau membership, place of birth, place in family and a wide variety of paid work experiences, many women in the class made specific reference to their child-rearing and a large variety of unpaid caring and physical activities as experience of community they were willing to share. This outcome is reflected in the literature that describes the divergent paths taken by women compared to men in gaining knowledge (Dore 1994:99). The process of identity description and recognition derived from an application of ecofeminist praxis assisted women to construct their identities in a non-dualistic way. It valued their subjective experience as well as their academic knowledge. Embodied identity is, after all, "ordinary bodies doing ordinary things" (Mellor 1997b).

My attempts to translate to classroom praxis the ecofeminist emphasis on identity as embodied were not totally unproblematic. Whilst I learned that some women gained from the recognition of their identities as embodied, there were young women in the New Zealand classrooms who struggled to 'match' the richness and diversity of the mature women. Employing a process that proved empowering for one group of students had the unintended consequence of disempowering another (Kramer-Dahl 1996:253). I was not able to verify whether the tourism students, who were mostly young, may have been similarly reduced to silence by my 'impressive' introduction. What was 'ordinary' for me may have appeared extraordinary for them.

In reviewing the video-taped material of the introduction process, I was likewise 'suspicious' in a post-modern sense (Lather 1992b:95) about how much my own commitment to identity as 'embedded' in the natural world had been foist on the students in a way which denied them independent agency in the pedagogical equation. In Aotearoa/New Zealand, where the indigenous practice of establishing one's identity in relation to mountains, rivers, plants and animals as well as to other human beings, either living or dead, was already established, it was possible to dismantle the human-nature dualism more successfully. 
In applying an ecofeminist praxis to the establishment of identity in the classroom, I had aspired to do so in terms of a non-hierarchical concept of difference (Plumwood 1993). To do this I had included my own cultural origins, including my connections to the land, my academic achievements, and my sexual orientation, alongside what had shaped my understanding and actions within the notion of community. Students were more readily able to follow this example and to see its usefulness in relation to their learning only in those situations where there was already an established protocol for such self-disclosure.

Where no such foundation existed, as with the research participants in the United Kingdom, especially the tourism students, the pedagogical task needed to be much more explicitly focused on exploring the relationship between identity formation and sustainable community. In modelling that knowledge of community derived from experience (which in my case connected me to minority groups - lesbian - and to physical activity - gardening - for example) was as accessible and valued in the classroom context as academic knowledge, I provided an opportunity for students to experiment with the use of personal aspects of identity not always included in the academic classroom. I was aware from the literature that there are inherent dangers in relying on the uncritical use of experience as the basis of knowledge on the one hand (Luke 1992:37; Weiner 1994:11) and on the other of abandoning the centrality of experiential learning so firmly established in both feminist and social work literature (Stanley and Wise 1993:67; Yelloly and Henkel 1995:8).

Despite the limitations described, an ecofeminist praxis that acknowledges identity as embodied and embedded provided the impetus for me to disrupt the hegemonic discourse in the classroom in relation to identity. By utilising the simple notion of introductions as a window on identity, I was able to expand a perfunctory "Hello, this is me" to a situated, diverse expression of identity. Expanded introductions enabled students and teacher to access enriched meanings of what it is to occupy a body within time and space, in relation to others within the learning community and in connection to the natural world. 
My aim was not to provide a prescription for the expression of identity. Yet I discovered how influential my own introductions were in contributing to the extent to which students revealed themselves and how relevant it seemed to their grasp of the knowledge they sought.

An ecofeminist praxis highlights the process of gaining knowledge derived from the expression of how our 'selves' are inserted into social and ecological spaces. This is perhaps a particular strength of the 'feminist' contribution. An ecofeminist position goes further. It requires that the outcome of learning results in a changed view of the world - in this research, an expanded view of 'sustainability' and 'community' as practical processes.

\subsubsection{Generation of knowledge about sustainable community}

What is being learned, therefore, as well as the identities of the learners/teacher, formed a significant preoccupation in this action-based research within learning communities. In particular, I was interested in what contribution an ecofeminist praxis could make to generation of useable knowledge. Within social work education, preparing students for practice is the highest priority (Mattaini 1995:62). Practice involves both process and content. I was interested firstly in this research with how students enunciated the concept of sustainable community.

\subsubsection{Enunciating the concept in the United Kingdom}

The goal of an ecofeminist pedagogy is to facilitate change. I wanted to ascertain whether there were any changes in the way research participants enunciated their understanding of the complex notion of 'sustainable community' within the classroom processes I facilitated. I was interested in the generation of knowledge about a process, sustainable community, within another process, ecofeminist praxis. Rather like momentarily 'freezing' the motion of dancers in order to focus on their steps, I introduced questions to sample research participants' views. These views represented 'moments' in 
the complex dance between teacher, students and the knowledge we were together generating.

The Lincoln tourism students' responses to Question one, given at the start of the first workshop, about what images, ideas, words and activities came to mind about their understanding of sustainable community, fell basically into three categories:

\section{Nature of social relationships}

Relationships within sustainable communities were seen to be co-operative and close-knit, with certain bonds or connections:

"where people can work together for the good of that community". A number specified family and old family friends living in:

"a dependable background, slow moving and little development - if any...".

These relationships were not only close, but also maintained into the future. They were communities whose members were actively involved in their planning. Understandably, since we had already identified their current living environments as 'transient', none of the references were in the present.

\section{$\underline{\text { Physical/structural characteristics }}$}

Sustainable communities were seen to have historic sites, to be located usually in rural settings and with old traditional buildings. There was a strong emphasis on these communities being planned:

"...communities that are planned to accommodate all the people living in it, e.g. planned infrastructure, industry...".

\section{Environmental characteristics}

Consistent with their tourism background, these students saw sustainable community as designed both environmentally and socially to:

"...prevent decline/degradation in the future".

Others saw such communities as places that were "unspoilt". Several tussled with the idea of 'development' in relation to sustainable community: 
“... with the chance of development occurring, yet development schemes will not ruin the community/environment to any great extent." “... taking old strategies for management and improving them so the future of an area is rich both environmentally and socially."

Given their focus on tourism and the impact of human activity on natural places it ic not curnricino that thev olco had a clear nercention of the 
It is diverse and hypothetical in some senses, but very relevant and close to the heart."

- involved more problem-solving, not just planning

"A community resolving problems in the present, rather than just planning for the future".

Like the Lincoln tourism students, the social work participants at Humberside in their first workshop thought of sustainable communities in largely cohesive, harmonious terms. I grouped their responses using the same three headings:

\section{Nature of social relationships}

Consistent with a social work orientation, the social work participants responded to Question one with adjectives such as:

"empowering", "supportive", "compassionate", "accepting",

" non-oppressive", "fair", and "respectful".

In addition, they expected such communities to be:

"peaceful", "fun", "creative", "without prejudice", and "happy".

\section{Physical/structural characteristics}

The social work participants most consistently characterised sustainable communities as sharing resources, being diverse and highly interactive. Like tourism students, their first thoughts were of communities that were traditional, geographically identifiable, cohesive human groups. There was a common theme of self-reliance:

"... a community that is self-sufficient to some degree... that takes an interest in infrastructure, e.g. railways, roads, airport".

Predictably, other structural features included:

"full employment", "equality", "no crime", and "free from restrictions". 


\section{Environmental characteristics}

The social work participants' responses included only two references to the natural environment:

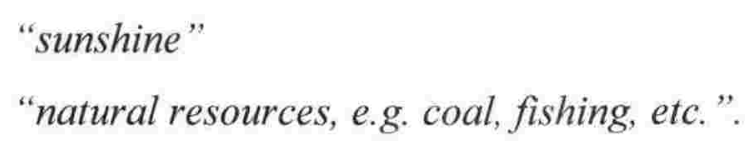

After they had been exposed to an introductory lecture on the meaning of sustainable community, followed by participation in a Boal-type theatre (see 4.4.8), the social work participants' understanding of the concept recorded as their responses to Question three appeared much less idealistic and included greater complexity and appreciation of the inherent conflicts surrounding an application of the ideas to a 'real-life' scenario. Rather than monosyllabic, relatively simplistic words their descriptions were thoughtful and reflective:

“ Working together as one and not fighting each other's ideas but coming together to solve problems. You have to be part of the solution here to start to change your own life styles."

Not only were respondents more aware of the contested nature of the concept but they also imported their ideas about what could be done to bring about sustainable community into this question in a way they had not done when answering Question one. This could be interpreted to mean that participants were confused about the question, but taken together with a viewing of their later comments made on the video, I argue that it is more likely an indication that they were beginning to integrate knowledge about the ideas and concepts of sustainable community with options for how to bring it about. This is a small but significant example in the social work classroom of the ecofeminist project of dismantling a theory/practice dualism. One student concluded:

"It makes me more aware on a personal level, therefore makes me want to change my own way of life to improve the environment".

Responses to the rating scale on the usefulness of the mini-lecture and the Boal-type theatre were disappointingly small (see Appendices). Those who did respond, however, made some interesting comments. The respondents 
from both groups rated both activities either highly or neutrally. One suggested that:

"[The mini-lecture] allowed people to gain a knowledge of what sustainability really means - noting if their own definitions were relevant or not".

The mini-lecture seemed to increase awareness of the issues and prompted interaction and feedback on the information given. For one student the material was not new, but prompted him to:

"remember past facts".

For both groups of participants, initial perceptions of 'sustainable community' were nostalgic, somewhat simplistic and generally 'out there', something they were not part of. After participants acted out scenarios from their own lives, playing roles they could identify with, their perceptions of sustainable community were complex, diverse and certainly less nostalgic. Ecofeminism claims that a disconnected consciousness results in identity that is not embodied or embedded. I argue that experiencing embodiment as participants 'used' their own bodies to enact real-life scenarios contributed to a beginning awareness that 'sustainable community' could be something they were a part of, embodied and embedded.

\subsubsection{Enunciating the concept in Aotearoa/New Zealand}

Consistent with a reflective model of pedagogy, I decided on my return to Aotearoa/New Zealand to enrich the pedagogical process by utilising the insights I had gained from the research in the United Kingdom. While teaching the Working with Communities module in the two Victoria University sites, I asked the research questions about the notion of sustainable community explicitly as part of the pedagogical process. I asked the questions after considerable discussion around the students' understanding of sustainable community and following the introductions which had served to link their own experiences to their interpretation of the concepts (Boud 1993). Based on my reflections on how the English research participants had enunciated the concepts, I presented the historical, cultural, social, economic, political and 
ecological elements using the metaphor of a window. I suggested each element was a window through which the concepts could be viewed. I invited student dialogue, debate and discussion of reference material with the aim of facilitating appreciation of the breadth, complexity and contestability of the notion.

The Aotearoa/New Zealand students had, therefore, the benefit of a brief but focused discussion on the notion before they responded to the research questions. I had learned from the way the United Kingdom participants had responded to the mini-lecture on sustainable community that I needed to raise critical questions about the human-human and human-nature connections so that the awareness of 'disconnected consciousness' would begin to dawn. Like their counterparts in England, the students shared at the beginning of the teaching week a somewhat idealised notion of sustainable community, but were notably more conscious of a wider range of elements even though this was after a very brief discussion about the topic. Their responses to Question one included:

$$
\begin{aligned}
& \text { " power (who has it and why - is there a balance?)"; " economics"; } \\
& \text { " spiritual emphasis"; "access to plentiful resources"; "changing } \\
& \text { and adapting"; " a strong sense of history and future". }
\end{aligned}
$$

In addition to the breadth of the elements included in the groups' conceptual understanding of sustainable community, the presence of Maori and Pacific Island students in the Aotearoa/New Zealand classrooms greatly increased the emphasis on words, images and activities associating human-nature connections. Such evidence of the degree to which cultures traditionally less alienated from close association with the natural world include human-nature images is consistent with the ecofeminist view that indigenous voices demand greater recognition in current local and global dialogues (Sturgeon 1997:165). Within the classroom, cultural diversity enriches the potential for all students to expand their awareness of the breadth and complexity of sustainable community. 
While I was not engaged in a comparative study between the United Kingdom participants' responses and those of the New Zealand students, there was sufficient similarity between the responses to the research questions to enable me to utilise the same categories in my analysis. What follows is an analysis of responses to the first research question about the words, images, ideas and activities that the notion of 'sustainable community' prompted.

\section{Nature of relationships}

As well as images and ideas conveying the sorts of relationships that typify cohesive, close-knit communities, the New Zealand students included more diversity and consciousness of the practical complexity of the notion:

"... equal contribution to a collective and common interests, where needs are identified and met collectively, protocols to allow equity in distribution and contributions."

“... people...share benefits although not necessarily equally.”

“... an equally interdependent community where some members are not advantaged over others to the detriment of others. "

In addition there was a stronger emphasis on acceptance of difference:

“... [sustainable community] needs to have flexibility to allow difference and change"

"... appreciates differences"

"...changing and adapting".

\section{Physical/structural characteristics}

The students in Aotearoa/New Zealand were very comfortable with representing their ideas symbolically, so there were a number of culturally significant contributions. Some, for example, drew traditional house shapes (fale a Samoan word meaning house, or wharenui), flowers with deep roots, a coconut tree and a time-line disappearing gradually into the mists of the future. In addition to elements the English students had also identified, these students added:

"common boundaries"

"links with other communities" 


\begin{abstract}
"balanced inputs and outputs"
"the whole is greater than the sum of the parts".
\end{abstract}

\title{
Environmental characteristics
}

There was little awareness of a notion of community that expanded to include the natural world even though some of the student's drawings showed sensitivity to it. Where the natural world was included it was - as with the English participants - a peripheral preoccupation:

"People living in harmony with environment and each other, having shared goals/working to similar outcomes".

However, when describing activities associated with the notion, there was a marked increase in references to the natural environment:

"Community gardens, community spaces, people's centre, parks, centres, festivals, green dollar systems".

At the end of the modules, both groups of Aotearoa/New Zealand students, like their English counterparts, answered Question three, which invited them to revisit their notion of 'sustainable community' and to describe what words, images, ideas and activities were evoked. They demonstrated an increased awareness of the complexity of the notion and were already enunciating ideas linked to action strategies in relation to their own communities/workplaces:

"The realisation that to be effective within a community there is nothing wrong with an individual being driven by passion, as long as judgement and knowledge are also part of the equation".

It is important to acknowledge that some of the richness of the responses may be attributable to a number of variables apart from the pedagogical focus on ecofeminist praxis. These variables include:

- the influence of a modular teaching format which encourages high student participation with accompanying heightened learning 
- the fact that students knew the 'deal' was that their collaborative contributions were to be distributed and would be a useful resource for the preparation of their assessed work

- the high proportion (overall $40 \%$ ) of Maori and Pacific Islands students for whom the notion of sustainable community is embedded in their cultural knowledge base (Durie 1997:149)

- the presence of older, mature students who had spent longer actually living in communities

- the presence of some students from rural areas, where the traditional geographically based perception at least is more readily accepted

- the degree of comfort I felt in my familiar teaching environment and how this affected the clarity with which I communicated as a facilitator of learning.

Further evidence of the greater sophistication with which many Aotearoa/New Zealand students were able to enunciate the concept of sustainable community was in the essays they wrote as part of the course assessment. They wrote creatively of social issues intimately connected to global and local environmental ones. Maori students wrote of the connections between illhealth and loss of land, used rich metaphors of trees as symbolising the strength of local kohanga reo, and described sustainable communities as those which had a chain of connection from the wisdom of nga tupuna (the ancestors) through whanau (family and kin) to the future.

The greatest weakness, illustrative of the addiction to old paradigms of thought described earlier (see 1.7.3), was that many still failed to make the connections between local and global issues. They fell into the common social work habit of focusing on the interpersonal problems and ignoring their macro connections. Clearly, since attachment to old paradigms is strong, and generally supported by social work hegemony, sustained effort would be required across all subject areas for greater change to occur in how the concept of sustainable community was understood. 
The window on identity expressed through classroom introductions served the pedagogical objective of awakening an awareness of participants' embodiment and embeddedness. The questions asked at critical points in the pedagogical process served to focus on the possibility of conceptual changes in participants' understanding of a concept which is itself capable of straddling aspects that are usually dualistically related. In my efforts to explore the potential of an ecofeminist praxis, I employed a process which relied on moving from the individual and conceptual to the social and affective. To develop this approach, I adapted the theatre work of Augusto Boal for use in the classroom.

\subsubsection{3 'Performing' knowledge in the classroom}

Whilst role-playing is a technique of classroom pedagogy familiar to many students, particularly in applied fields, its use needed to be linked to rigorous academic processes to avoid student resistance to 'playing' in the classroom. Students were reminded that 'play' is the process used by children to rehearse living. Theatre is adult 'play', but the problem is that in conventional theatre the spectators are passive and the outcomes for the protagonist are fixed. Since the playwright decides the outcomes, they cannot be transformed by the spectators, or indeed by the actors. In 'playing Boal' (see 3.4.4) students were engaging in a form of theatre in which their stories were told and retold, with the opportunity to experiment with changing the outcomes.

During the discussion that followed the Lincoln tourism students' theatre performance (see 4.4.7), it was agreed that no satisfactory option had been found for the protagonist to effect a change towards sustainability in the microcosm of a workplace community. The protagonist rejected outright the 'trading' option (a kind of blackmail, in threatening to display potentially embarrassing photographs) - it was not at all attractive to her. The 'manager' indicated that he became more entrenched in his position because the personal/work boundary had been broken by the suggestion. This made him call on his authority over the worker even more. 
It had emerged during the scenario that the manager was newly employed in the position. I chose to link the idea of a newly appointed authority figure needing to make his or her presence felt with the idea that this phenomenon had parallels in the relationship between the human-natural worlds. I introduced the idea that the assertion of power that the new manager felt he had to exert over his staff could be similar to the way human beings often assume a stance of domination over any land, especially when they first inhabit it. In both situations such power leads to a breakdown in the relationships necessary for sustainability. In the social situation, the one over whom power is exerted can seek to reverse the power imbalance, leading to destructive power struggles (Freire 1972). In the natural world, domination often results in loss of biodiversity, exhaustion of resources and destruction of life-sustaining ecosystems (Park 1995:280).

Reflection about the performance of a personal scenario of unsustainability provided an opportunity to extend the discourse of power from the individual to the community, from the social to the ecological. Unlike socio-drama, where a skilled facilitator conducts the role reversals and exploratory interactions, Boal-type theatre facilitates the exercise of power by the participants themselves as they explore provocative options for change.

For the tourism students, knowledge of human impact on the natural world was familiar territory. The discussion around this issue moved back and forth from the micro situation that had just been performed to the macro - of what occurs in the wider community. Rather than arriving at any 'pat' solution, students were left with a number of questions about the particular scenario and made thoughtful comments about how the ideas linked with sustainable community. The 'manager' observed:

"You need to have a sense that things have been there and will be there for you in the future...You can go back and family will still be there...trees you planted will still be there. This may not feel sustainable to the people who live there now, but it will to you." The protagonist concluded: 
"If you want to change things to be better, you'd need to get more support from other workers".

What had started as an individual 'problem' had been transformed by involvement in the 'community' of the theatrical classroom into an opportunity for collective action.

Interestingly, the scenario presented by the Humberside social work participants already had elements of collective community action. This group enacted a drama regarding the pollution of the sea at Scarborough (see 4.4.8). In the discussion that followed, I invited each participant to speak from their performed roles about what the notion of a sustainable community meant in this scenario. What emerged was a description of the complex, intersecting nature of competing community issues. Whose notion of sustainability would be adopted depended largely on how much power/wealth/influence they were perceived to hold. The protagonist was seen as speaking on behalf of the 'natural' community largely left out of consideration by the others - the fisherman, the General Practitioner and the wealthy resident - who were all reacting to direct human impacts of the issue. One student observed that in situations like this, awareness of broader impacts, for example of detrimental environmental impacts, only 'touched' them when there was a personal involvement. 'Spect/actors' observed that people in the scenario did not, in fact, share the same community or the same goals.

The participants suggested that had the whole 'community' group, which had met with Yorkshire Water, introduced themselves to each other as we had done at the beginning of Workshop One, they may have discovered some commonality. One participant suggested:

"If each had come out of their corners, they may have been able to point in the same direction."

This comment was important from a pedagogical perspective. It meant that learning was happening at a number of levels: processes used to establish connection within the classroom group were seen as appropriate ones to use in 
a community group. Participants agreed that ridding Scarborough of pollution from sewage disposal was a goal shared by all. Had they taken the time to divulge more about themselves and their concerns, a foundation may have been laid for collaborative problem-solving. It was observed that once a scenario develops where deeply entrenched positions are taken up, moving from conflict towards cooperation is more difficult. Achieving sustainability involved recognition of the power imbalances present when any community issues are debated.

I introduced the idea that power can be simply, but never willingly, wrested from the particular power-holders at the time and vested in new stakeholders. This reversal simply sets up different but equally unsustainable struggles (Freire 1972). An ecofeminist perspective on the issue would acknowledge which stakeholders had been 'backgrounded' in the issue and provide extra incentives for them to participate in decision-making, at the same time aiming to achieve mutuality of purpose for all those affected by the issue. We discussed what this would mean for the scenario of Scarborough's sewage pollution. It would have meant listening to the concerns of the least powerful in relation to this issue, and relating them to the larger issue. Once some commitment to the larger issue had been achieved, participants considered the problem should have been broken down into parts and the skills and knowledge of all present focused on a step-by-step approach to each part of the problem. Additional environmental information would also be needed to enable movement towards a sustainable situation.

In concluding this workshop, I noted that an ecofeminist perspective would honour the diversity and complexity present in communities like the one described. It would especially bring to the foreground those 'voices' that were often silenced - those of women, children, and the natural world.

A common outcome of both the initial workshops at Lincoln and Humberside was that attempts at moving situations from unsustainability towards sustainability involved a deepening of the complexity of the conflicts. 
Differences in perceptions of the nature of the issues and of power imbalances between participants were all increased by participation in the scenario.

For students expecting to find 'answers' to perplexing social and environmental concerns, this outcome was predictably disturbing. Had there been no follow-up workshop, the pedagogical experience could have contributed to an increased sense of powerlessness for students facing practical challenges in their application of theory to practice. ${ }^{2}$

What the Boal-type theatre did was bring research participants face to face with the complexity of enacting sustainability in a scenario that had relevance for their own lives. Research participants temporarily 'tried on' the identities of the stakeholders and engaged in the power struggles and practical implications of holding different conceptual understandings of sustainability. The outcomes suggest that the Boal-type theatre had considerable potential as a pedagogical tool for translating ecofeminist principles into an ecofeminist praxis.

For both groups, the Boal-type theatre (described as 'role play' in the rating response sheet) was rated either neutrally or highly, and it was the interactive nature of the activity that drew comment:

"Everybody got extremely involved in their role".

The most significant response came from the social work participants, who all rated 'reflection on the action' and 'reflection from micro to macro' on the 'high' end of the rating scale in relation to their understanding of sustainable community.

This outcome illustrates well the ecofeminist focus on the importance of a strengthened connection between personal/political agendas and more global issues. The tourism students had enacted a very personal scenario, the social

\footnotetext{
${ }^{2}$ Experience from 1970 s feminist consciousness-raising demonstrated that heightened awareness without the exploration of appropriate strategies for change leads to feelings of powerlessness. In that context, political activism transformed such feelings.
} 
work participants a more global, community issue. It did not seem to matter what the focus was so long as the reflective process facilitated connection between the micro and the macro, the personal and the global. The strength of translating an ecofeminist focus on commonality/unity and difference/diversity into an affective, collective pedagogical process was illustrated by the way both groups' enunciation of 'sustainable community' was enhanced by their engagement with the Boal-type theatre.

Although I was convinced from the two experiences in the United Kingdom that 'playing Boal' was a powerful and effective pedagogical tool for translating ecofeminist principles into classroom learning, I did not use this approach in the Aotearoa/New Zealand classrooms on my return. There were several reasons for this decision, which in hindsight I believe was an unfortunate one. I had learned that to utilise its full potential, the performance of the Boal-type theatre would require at least half a day in total, a higher proportion of the available teaching time than I considered was justified. Secondly, I was conscious of my institutional context, the university, where my department had just come through an unfavourable review. While I knew I could justify on professional grounds my use of an interactive, innovative learning approach in an applied course, I was unnerved by the negativity expressed in the official academic review. In so clipping my "pedagogical wings", I substantiated the claim by a number of writers that the practice of pedagogy is often performed in a context of opposition to the principle of engaged pedagogy (see 3.4.2).

I had to reflect then on why, given the significance of the Boal-type theatre in increasing the United Kingdom participants' enunciation of the concept of 'sustainable community', the Aotearoa/New Zealand students clearly gained similar increased understanding without participating in the theatre. I searched for those aspects of the theatre that had contributed to the increased awareness. I then looked for what had contributed to a similar result in the Aotearoa/New Zealand classroom. 
On reviewing my journal records of the two teaching modules in Aotearoa/New Zealand, I realised that I had employed a number of approaches that, over the week, did what the Boal-type theatre had condensed into little more than an hour. The activities I identified all involved maximising the use of student experience in active engagement with the topic, providing local and international examples of human-nature connections as intrinsic to the understanding of sustainable community (for example, showing the video Trading Futures, which highlights unsustainable as well as sustainable scenarios around the world) and utilising small group discussion around local issues where collective action held the greatest possibility of effecting change.

\subsubsection{The role of self-reflective pedagogy in finding change options}

Engaged pedagogy seeks to extend the reflexive gaze as far as possible in the interests of achieving positive change. In this research, change in my teaching and change in students' understanding were the dual foci. The aim of the second workshops conducted with the two groups in England was to enable students to reflect on the learning gained from the first workshops and to give feedback on what pedagogical processes were most successful in enriching their understanding of the notion of sustainable community. Firstly, excerpts from the video-recording of the first session were replayed for the students to view. Secondly, students were asked to record ratings about the usefulness of specific parts of the first workshop (see Appendices). The aim of this dual process was to visually prompt the memory of the experience of the first workshop as well as to refocus the goal of both sessions - viz. to enhance their understanding of the notion of 'sustainable community'. A third element of this triangulated approach was for the students to be given copies of the responses to the four research questions and to reflect on them. Due to the dynamic nature of workshops at each site, there was some variation in the order and detail of these three aspects of the process. The aim was to extend the reflection to involve the research participants as well as me in deriving new levels of understanding about the notion of sustainable community and how it could be brought about. The first and third questions, dealing with the 
students' enunciation of 'sustainable community', have been discussed in 5.3.2.1 and 5.3.2.2. The second and fourth questions concerned their perceptions of how sustainable community could be brought about.

\subsubsection{Bringing about sustainable community}

Question two was designed to ascertain what images, ideas, words, actions, and activities came to mind as research participants thought about how to bring about sustainable community. It was answered by research participants in the United Kingdom and by the two Aotearoa/New Zealand classes.

Question four was designed to ascertain whether the process and content of the workshops/teaching had changed participants' perceptions about 'how' changes happened; what actions, activities, images, words, ideas, contributed. (These could be their own, other participants' or the facilitator's.) When I came to analyse the responses to these two questions I realised that the meaning in Question four was ambiguous. It was most likely to be interpreted as how changes during the workshop or the teaching took place, not how sustainable community could be achieved. The latter was the meaning I had intended. For this reason, as well as because the responses opened up a whole new level of enquiry (see 4.3), I have not included a detailed analysis of the responses.

Before the workshops, research participants thought of bringing about sustainable community in the following ways:

"Working together to solve problems."

"It involves activities which start with changing personal life styles."

"Notice and try to change the smallest wrongs and make them right"

"Getting to know what goes on in your community... not waiting to help until it hits your 'bubble?."

In addition they believed that local participation and cooperation, good management, education, not restricting the spirit and changing attitudes were all also pre-requisites for bringing about sustainable community. 
During the Boal-type theatre activities, the two research groups in the United Kingdom had had the opportunity to 'take on' a variety of roles in the search for alternative strategies for bringing about a change from unsustainability to sustainability. They were able to 'enact' different embodiments and from within these roles seek provocative options (de Bono 1993:145) for change. Despite the ambiguity of whether the question referred to micro- or macroscale change, both groups in the United Kingdom thought that the process of connecting the personal and the global was a significant change strategy in bringing about sustainable community. The 'playful' nature of the Boal-type theatre encouraged participants to practise change strategies without risk of making fools of themselves or 'being wrong'. In identifying how they perceived that their new or changed ideas had come about, participants spoke of:

"... being unafraid to change routines"

"...learning by cooperation"

“... increased awareness".

Such enactment of diverse change strategies in the social work classroom has potential to equip students to deal with the oppositional social work discourse encountered by new graduates leaving the university and entering social work. In the Aotearoa/New Zealand context, the students were able to engage with a variety of options for change strategy by writing an essay specifically designed to elicit a variety of responses (see course outline in Appendices).

Utilising reflective practice in pedagogy not only serves the ecofeminist aim of increasing diversity of options for change. It also enables a deepening of the levels of understanding about the topic being studied. Following the Boaltype theatre, both groups interpreted the ambiguous question to refer to either the micro or the macro situations. Whatever the starting point, both groups, particularly the social work group, made connections between the personal and the global. 


\subsubsection{Deepening the levels of understanding}

The process of consciousness-raising involves increasing awareness at both conceptual and affective levels. Having learned from the second workshop with the Lincoln students how little they knew about the social and environmental configuration of their locality, I did not then assume the Humberside participants possessed such knowledge about their communities either. When it came to the second workshop at Humberside, therefore, I had prepared a brief social and environmental profile of the city and its hinterland. I was relying on the assertion that one of the first steps in movement towards change is a raised level of consciousness about the issues (Ife 1995:210 ff). Initially, a raised consciousness elicits feelings of helplessness and even disempowerment (ibid). One participant from the social work group said it made her feel vulnerable when all the factors were put together. Some participants observed that raised consciousness about the issues provided a strong incentive for action. As a guest in their class and their country, I was aware of the potential, in addition to consciousness-raising, to evoke defensiveness. So I complemented the socio-environmental profile of Hull with some similar statistics about Wellington, Aotearoa/New Zealand.

Gaining an intellectual understanding of the 'facts' of unsustainability was observed by the participants to be one precursor to taking action for change. One participant in the Humberside group commented that:

"action was only possible when you moved from an 'idealistic society' to one that you entered".

Another described it as a process of being:

"lifted up and transported into a different society" when some socio/environmental impact was felt personally.

In summary, Humberside participants considered they had gained many useful ideas from not only being involved in the theatre, as either actors or spect/actors, but in intensifying and extending the reflection by viewing and reflecting on their activities at the second workshop. No-one wanted to end 
the discussion and one participant became very animated about everyone getting involved in their own communities in a more positive way.

One student summed up how she now felt about the notion of sustainable community:

"You've got to be part of the solution, not just part of the problem".

\subsection{What about the 'feminist' in ecofeminist praxis?}

In Chapter 2 I gave an extensive explanation of how ecofeminism combines concerns about the treatment of women and of the earth. In the brief time I was able to spend with my research participants, I discussed this notion in a tightly compressed fashion, but was unable to explore it in great detail.

In reflecting upon the research results, I realised that I concentrated in the research exercises almost entirely on the environmental issues, to the virtual exclusion of gender. In discussing the notion of 'sustainable community' I certainly included such factors as equity and inclusivity, but I did not make a point of discussing feminism as such.

In wondering how this came about, I have deduced that such was my sense of urgency about raising the consciousness of students regarding the environment that I subconsciously chose to spend the limited time available almost exclusively on this issue. It could be asked, therefore, whether my research would have had the same results if a liberal environmentalist with no feminist consciousness had carried it out. I do not believe so. My feminist perspective profoundly influenced the process of pedagogy I practised - its attention to holism, to inclusive language, to gendered power relations, to the discursive space given to marginalised voices, to the valuing of knowledge derived from everyday experience, to the equal valuing of diversity and commonality and to change potential inherent in collective political action. It was as though I needed to 'foreground' the aspect of knowledge that had been 'backgrounded' in my own teaching experience in a social work programme. It was not as though I had "hidden my light under a bushel" as a feminist academic. In 
Aotearoa/New Zealand I had introduced a paper on feminist social work practice. I also felt well established in my feminist reputation. It was more a case of employing a feminist perspective that transcended the simplistic focus on gender. However, what is more significant is that my experience demonstrated the relative ease with which the two contributing elements of ecofeminist praxis hold together 'on the page' compared with the difficulty with which that integration translates into pedagogical practice. It illustrated to me that much more time is needed to thoroughly interrogate two such highly contested and complex philosophies in the classroom.

\subsection{Conclusion}

Despite the above limitation, the outcomes are a rich response to the engagement of students, teacher and ideas about sustainable community using an ecofeminist praxis. In order to make meaning of the research, I listened to students, reflected on my own practice and creatively experimented with ways of translating ecofeminist principles into classroom practice. I learned that far from being a prescription for teaching, ecofeminist praxis enabled both research participants and me to interrogate the many meanings of 'sustainable community'. The outcomes demonstrated that who we are is deeply influenced by where we come from, where we are, who is with us and why we are there; identity is situated. Our physical bodies and what those bodies do also shape it - it is embodied and it is inseparably linked to the natural world on which we as human beings depend - it is embedded.

I learned that one way of dismantling the activity/knowledge dualism in the classroom is to enact the knowledge development process in a way that reflects global issues in personal stories and vice versa. Reflective practice makes - not perfect, but - engaged students. 


\title{
CHAPTER 6
}

\section{WEAVING NEW PATTERNS: ECOFEMINIST PRAXIS IN SOCIAL WORK PEDAGOGY - AND BEYOND}

\begin{abstract}
"Tane, manifest in the tall trees of the dry sand ridges, is locked in a reciprocal embrace with the swampy arms of the lake, feminine in its flows. Imbued with the female mauri, or life force, Niwareka, daughter of the union between Papatuanuku and Ranginui, made possible the plants like harakeke, nikau and kie kie that bind people to the landand gave people the skills to weave them." (Park 1995:179)
\end{abstract}

Imbued with the energy of my active engagement with students, I have learned the skills of weaving threads of ecology and feminism into the fabric of ecofeminist praxis. In this chapter, I use the themes I derived from the literature on ecofeminism to show how the ecofeminist praxis I developed can apply new patterns of thought and action within social work education. I suggest some of the challenges such an application implies. I also examine the broader implications of an ecofeminist praxis for other disciplines and for the wider community.

\subsection{Ecofeminism on theoretical intersections and academic margins}

Ecofeminism draws on theoretical positions and activities that are at the heart of two of the most significant social movements of the post-modern age feminism and ecology. I have referred elsewhere (2.2) to the complex conceptual and political permutations that result when strands from these two bodies of knowledge combine to form ecofeminism. It follows that developing an ecofeminist praxis potentially includes weaving together many different shades of ecofeminist thought and action. For example, combining liberal feminism with an ecological stance which views women as essentially closer to nature results in an ecofeminist position that holds women more capable of, and certainly more responsible for, caring for the earth. 
Combining feminist and ecological interpretations at the more radical end of the spectrum results in a different ecofeminist position. Nature is viewed as sentient and worthy of respect for its own sake and hierarchically connected human-human and human-nature relationships are unsettled. Such an ecofeminist position seeks to reframe these relationships as partnerships not based on subjugated perceptions of women, people of colour or nature. I agree with those ecofeminist writers who consider it unhelpful to pigeonhole ecofeminists according to which strand of feminism or ecology they prefer (refer 2.2). However, given my commitment to a social work pedagogy which seeks to prepare students to challenge social and environmental unsustainability in working with communities, some ecofeminist positions proved more attractive to me than others: those which transcended dualistic connections between the human and natural world (Plumwood 1993), proposed an ethic of flourishing rather than an ethic of care (Cuomo 1998), and that focused on the links and patterns amongst the treatment of oppressed, exploited or undervalued entities rather than focusing on the objects of such oppression (Cuomo op. cit.).

In meeting the challenge of translating ecofeminist thought and action into ecofeminist praxis, I was mindful of the danger of slipping into unhelpful dualisms. For example, at the purely theoretical level, my preference for focusing on the links and patterns connecting various undervalued entities seemed defensible. However, when practising engaged pedagogy, plurality of identity and experience - my own and that of the students - required that I held both the objects and the links and patterns together in creative tension.

The metaphor of 'intersections' adequately illuminates the theoretical richness ecofeminism contributes in the classroom. The challenge for me was to identify a metaphor that also accurately reflected the practical issues which pedagogy demanded. I opted for the image of 'windows' (as in computer programmes) facilitating multiple viewing of a number of conceptual and practice perspectives. In the classroom, 'keeping open' several different windows enabled students to gain diverse perspectives on the notion under study, in this case 'sustainable community'. Once learned and practised, the 
skill of keeping open a number of viable options for creative problem-solving has the potential to equip social work students to become practitioners capable of responding creatively and flexibly to a number of complex societal and interpersonal issues. In this research I was able to translate ecofeminist plurality into pedagogical practice in a number of ways.

In introducing myself prior to the students doing so, I modelled a presentation of self that located identity on the intersections of gender, culture, geographical origins and spiritual connection. Initially this process did not appear to have much impact on some of the research participants. I refined my introductions and made explicit reference to the relationship between identity and conscious connection to the natural world and our physical presence within it. After that, the awareness of most students to their embodiment and embeddedness increased. Insight into the need to make certain changes would have been very difficult, even impossible, without my use of a reflexive technique that not only included my recall but also made a visual and auditory record for researcher and researched to use.

The window on identity as embodied and embedded which introductions afforded remained 'open' very briefly. A deepening of awareness was facilitated by my choice of a pedagogical process drawn from the theatrical world. Students' participation in the Boal-type theatre about unsustainability lasted little more than an hour but included sustained engagement of their bodies as well as their minds. Students were able to linger rather than pausing momentarily at open windows. They could, like hikers exploring a new landscape, move back and forth along the contours, experiencing different vistas from each vantage point.

As well as impacting on the pedagogical processes I used as a teacher, multiple ecofeminist perspectives had implications for me as the researcher. I extended my literature review and research activity well beyond the current boundaries of my own discipline. In order to gain an understanding of the components of ecofeminist theory and what might be included in an ecofeminist praxis, I drew from and made connections between a wide range 
of theory and practice. Such a journey into unexplored and 'foreign' territory on the one hand excited and challenged me. On the other hand, researching a topic that seemed marginal left me at times feeling like a stranger amongst my fellow social work teachers in the university.

Ecofeminist scholars and activists alike attest to the precarious foothold ecofeminism has within academic institutions (Cuomo 1998; Sturgeon 1997). Interestingly, there are some parallels between the status of social work and ecofeminism. Like ecofeminism, social work places issues of oppression and justice high on its agenda. Such identification with oppression often locates both on the edges of institutions where higher status accrues from association with economic and social power. Radical social work has a tradition of ambivalence towards its own status as a profession. Yet, through the efforts of many dedicated practitioner/academics social work education has gained a recognised place in the academy. Despite its demonstrable relevance within academia its foothold there still seems precarious. In some cases, as in my university, it has been lost, at least for the immediate future. Ecofeminist scholars, who are not usually confined to any one discipline, can also face marginality, no matter where they are (Sturgeon 1997:167).

Another reason for the marginality of ecofeminism and social work within the academy is that both have an applied or activist focus. When ecofeminism or social work in the academy form alliances with 'pure' social or natural sciences they have many theoretical commonalities. It is when the applied focus of ecofeminism and social work come to the fore that tensions and conflicts can arise. Whilst the explicit concerns may revolve around student/teacher ratios and resource allocation generally, these only thinly disguise the deeply imbedded hierarchy of 'pure' over 'applied' knowledge.

I argue that the considerable energy consumed by debating or avoiding the marginality of these two areas in the academy is misplaced, because it reinforces dualistic relationships. Instead, ecofeminist and social work educators should focus on developing vital, rigorous theory in tandem with radical activism. Applying ecofeminist praxis within disciplines such as 
economics and political science, for example, would cement ecofeminist theory and practice into mainstream academic activity as well as into highly relevant political and commercial pre-occupations. The dualistic relationship between the academy and the community would be dismantled. That way, fruitful interaction between activism and theorising, both in the community and in the university, would make the notions of 'centre' and 'margins' redundant. One of the keys to breaking down the false separation between theory and action is to focus on how identity includes the body as well as the mind of the learner.

\subsection{Ecofeminism's focus on identity as embodied and embedded}

I have argued that ecofeminist praxis seeks to facilitate recognition that human identity is embodied. An equal emphasis on the body and the mind in the process of knowledge generation derives from the feminist contributions to ecofeminism. Critical pedagogy highlights the centrality of the identity of the learner. In the classroom, disclosure of aspects of the self in making introductions provides one window on identity. In this research I exploited 'introductions' to highlight the presence of the embodied self in the pedagogical process. Whilst many research participants were able to identify as embodied, their acceptance of such a notion was initially at an individual, intellectual level. It was not until they 'used' their bodies in the theatre process to stand in the role of another self and to be relationally connected to other people that the experience moved to a collective, affective level. Awareness of an embodied identity cannot emerge until there is recognition of the significance of the physical sphere at both cognitive and affective level.

In a similar way, disconnected consciousness that results in separation of the human world from the natural world, and its elevation above it, has to be challenged at both cognitive and affective levels. Ecology's interpretation of systems thinking contributes to ecofeminism a focus on the interconnectedness of all living things, which form complex self-regulating systems in a constant state of change. What flows from this is the notion of identity as embedded in the natural world. Translation as ecofeminist praxis in the classroom requires 
the use of pedagogical processes that focus on exploring parallels between membership of human communities and natural ones. Such processes privilege neither the individual nor the collective, neither conceptual activities nor affective ones. Thus they model the dismantling of dualistic relationships between the human and the natural worlds.

An expansion of social work students' identity as not only socially embodied but also embedded in the natural world clearly involves a paradigm shift. Such major change is typically resisted (Bateson 1979; Beare and Slaughter 1993; Handy 1995). Despite the fact that the social work profession has a tradition of accepting the importance of radical change, apathy at best, or outright resistance, characterises the challenge to extending its focus to include justice for the planet. It is social work education that must address this reluctance. Approaches that impose theory on students or force particular strategies for action on them achieve little. There must be a pedagogical process that ensures a person's change threshold is exceeded. In the absence of this component it is unlikely that significant paradigm shifts will occur. When the participants in this research became 'conscious' of their embodiment and embeddedness, they were able to contemplate making some personal changes. In 'playing out' the various strategies for bringing about change, research participants were able to view their own interactions and the practical implications of their embodiment and embeddedness in everyday life situations. The multi-layered action/reflection process I devised during the research included collective physical participation complemented by intellectual engagement with issues of unsustainability. The knowledge derived from the interactions of teacher and students, and the mix of experiential and intellectual activity, did result in providing solutions to particular unsustainable situations. A more significant result, from an educational perspective, was that elements of a transformative process for achieving sustainability were identified and developed.

Consciousness-raising, paradigm shifts and the development of change strategies all take considerable time. It is not surprising that given the time it has taken for an alienated, disconnected consciousness to develop in Western 
culture, 'conscientisation' to embodiment and embeddedness in this study could be considered 'first level'. The creative use of technology to 'speed up' the process was used in this research and there is considerable potential to explore this medium further. Despite the limitations, the outcomes show that many participants were able to make meaningful connections between their personal lives and issues of more global importance. In order to transcend a dualistic separation of the personal from the political, an ecofeminist praxis must provide students with the opportunity to reflect not only on their own lives but on the larger political and economic arrangements which contribute to social and environmental justice. Critical reflection on the impacts of globalisation on people and the planet is a crucial aspect of an ecofeminist praxis.

\subsection{Ecofeminism's parallel discourses of commonality/unity and difference/diversity}

Recognition of the commonality of human embodiment and embeddedness provides impetus for action, both personal and global. The research was conducted in two countries and with participants from a variety of cultural and social backgrounds. There were ways in which their responses revealed the common threads needed for the activism that is a feature of ecofeminism. Concurrently, the research exposed significant contextual differences. Rather than obscuring the different ways identity was expressed and meanings attached to knowledge (in this case about sustainable community), an ecofeminist praxis utilised the participants' differences, contributing to a climate of acceptance and enrichment within the classroom. Acknowledging the rich diversity within the classroom context meant that I could not universally apply any one pedagogical prescription. Nor could the exact nature of the educational outcome be predicted. What this research demonstrates is that the classroom is a complex milieu for translation of theoretical and activist ecofeminist principles into pedagogical practice. Ecofeminism affirms the complexity inherent in all social and natural systems. This research utilised the potential for creativity in knowledge generation by deliberately choosing methodologies that enabled complexity of interactions 
and ideas to escalate. To this extent, it honoured the ecological principle of diversity and a feminist focus on difference.

In the classroom, there is a fine line between complexity and confusion. There were times during the research workshops in the United Kingdom and in the teaching modules in New Zealand when students were confused. Rather than succumb to the temptation to 'clarify' the ideas and actions, I chose to develop the reflective process more deeply, sometimes on the spot, with the aim of holding in creative tension the potential for confusion on the one hand and changed consciousness on the other. Without these measures, students could have become despondent or disengaged. At these moments it was clear that the pedagogical purpose overrode the research goals.

My teaching approaches were, however, by no means the only variables in achieving heightened levels of consciousness. Many of the participants were students with extensive life experience, who brought their own ways of managing complexity and difference to the classroom activities (refer 5.3.2.2).

\subsection{Ecofeminism's focus on indigenous and spiritual dimensions and on 'voices from the margins'}

Ecofeminism honours the unique place of indigenous knowledge and practice and the voices from the margins. Wisdom for change most often resides in alienated and disrupted sites (Bowers 1995; Mellor 1997), because those retaining the essence of that connection are the ones able to mediate across the gap. Women, people of colour and those most affected by social and ecological disruption can be expected to make the most useful contributions to useable knowledge. Such a claim is supported by the outcomes of this research. Many of the richest images and metaphors for change towards a sustainable community came from Maori and mature women students. Such knowledge will not, however, be universally endorsed by all people, nor indeed should it be. The environmental values of indigenous Maori culture are very different from those, for example, of pakeha Aotearoa/New Zealand environmentalists. Maori put greater value on protection of places of ancestral 
and mythological significance and conservation for human use, particularly for food provision. Non-Maori tend, on the other hand, to highlight the intrinsic and aesthetic value of particular places (Ministry for the Environment 1997:2.9-2.11). These differences are potentially divisive. An ecofeminist praxis encourages explicit acknowledgement of these differences and accords equal value to subjugated views.

The significance of indigenous or subjugated people's knowledge lies particularly in the spiritual dimensions that often accompany their world views. In this research, a spiritual dimension is only hinted at - in the metaphors and symbols the research participants used to describe 'sustainable community'. The notion of 'sustainable community' can itself be thought of as embodying the spirituality of an increasingly globalised society.

'Sustainable community' embraces principles which, while notoriously elusive to 'define', provide the basis for increased citizen participation, responsible social and ecological planning with future generations in mind, and consciousness that there are limits to human use of non-renewable natural resources. While many ecofeminists have avoided a spiritual dimension or have only seen its significance in relation to indigenous cultures or small rural communities, my position is different. Although I was not able to pursue it in this study, a search for models of spirituality relevant for industrialised, urban people is needed. However, based on personal reflection and on the research outcomes, I claim that a spiritual dimension forms an essential ingredient of living sustainably in community. Yet any notion of community struggles to retain currency as long as competitive, market-driven principles dominate the global consciousness.

Writers at the cutting edge of social work pedagogy have suggested that globalisation and its concomitant impact on social work education are issues for urgent debate and research (Dominelli 1997a; Ife 1995). A corollary of the competitive nature of the global market is the increasing emphasis on technology. Mechanisation of human interactions requires social work educators to deliver measurable outcomes. This leaves little room for the kind of self-reflective practice to which this research has subscribed. The costs of 
social work education satisfying the demands of a technocratic philosophy will, in my view, be high. Short-term, tangibly measurable goals leave out context and the ability to engage all the facets of students' learning theoretical, practical and personal.

Spretnak suggests that our inability to take the time to reflect on the larger reality has "turned us into the Earth's walking wounded" (Spretnak 1995:51). As a reflective teacher, my commitment in this research was to provide a discursive space for all involved to engage with the larger reality of the earth's finite capacity and the impact of such limits. These limits affect global decisions but also impact daily on our own lives and on our social arrangements. The effect of becoming conscious of these limits is often deeply disturbing. I learned that the pedagogical process, in order to move students beyond the first reactions of fear and paralysis, must engage participants' courage, integrity and ability to strategise. I modelled a 'sustainable community' in the classroom by developing a particular version of engaged pedagogy. I believe I identified principles of a praxis that could be applied wherever the critical issues of sustainability are addressed within the academy and beyond.

\subsection{Extending the ecofeminist canvas: within and beyond the academy}

The boundaries between academic disciplines are becoming more permeable. Indeed, if we mimic nature and accept that strength lies in diversity and interconnectedness, then applications of ecofeminist praxis should not be confined to social work pedagogy. Wherever professions are looking to educate across boundaries, in ways which equip students to face exponential change and in particular where new ways of conceptualising connections are needed, techniques and processes I have developed could be appropriately applied.

I have argued already that ecofeminist praxis transcends academic/community boundaries. Such is the urgency of the need to promote sustainable social and ecological practices that the educational project must also extend beyond 
academia. From the ecofeminist praxis I developed within social work pedagogy have arisen elements of a pedagogy of sustainability. I propose firstly an application of ecofeminist principles that may be useful for many other disciplines within the academy. This application is intended to provoke critical appraisal and creative application by educators wishing to develop pedagogies within their discipline or practice that can promote sustainability.

The educational project I propose applies a pedagogy of sustainability both within the academy and within the community. Where possible, I include examples of how such a pedagogy may be applied in both settings..

\subsubsection{From ecofeminist praxis towards a pedagogy of sustainability}

In the history of human settlement on the planet, we have never before had to face a combination of diminishing natural resources and expanding social demands. As a civilisation, we do not know definitively what 'sustainability' will look like. The common goal of sustainable futures for all (the earth and its people) is essential. However, no single, universally applicable pedagogy will enable us to meet the complex challenge we face. For this reason, then, I propose that a pedagogy of sustainability must build an inclusive learning community, engage expanded identities, employ community as a mediating process, and engage in appropriate knowledge exchange and generation.

\subsubsection{Building an inclusive learning community}

Translating the ecofeminist principle of diversity into the learning context means including as wide a range of differences as possible into any learning community. In the academy, this means enabling students from diverse socioeconomic and cultural backgrounds, and from different disciplines, to collaborate on joint projects. In community settings where local authorities plan social, cultural and environmental services and structures, it would mean bringing together sectors currently separated by organisational barriers. For example, land developers seeking resource consent under the Resource Management Act (1991) and environmentalists seeking to protect landscapes 
could be brought together much earlier than at present. If meaningful conversations could occur before parties adopt entrenched positions, the possibility of reaching decisions that are sustainable for people and the environment could be greatly increased.

The pragmatist may well wonder how a learning context built out of such diverse and potentially oppositional components could feasibly avoid descending into unmanageable conflict. Classrooms, community groups and businesses all need to develop explicit ground rules for their successful operation. Skills learned from group facilitation can be applied to any learning context to ensure that the processes and systems imitate the cooperative, whole system modes of operating demonstrated in the natural world. Instead of polarising conflict generated by difference, such protocols would establish discursive spaces in which human potential and energy are directed to achieving sustainability, not to amassing power or status for individual members. As Berry contends:

"All human professions, institutions and activities must be integral with the earth as the primary self-nourishing, self-governing and selffulfilling community. To integrate our human activities with this context is our way to the future." (Berry 1988:88)

Inclusive learning communities need specific protocols that ensure emotional and cultural safety, especially for those whose voices have in the past been largely disregarded and devalued. Such pro-active spaces need to manage power, gender, class and racial issues transparently. Without adequate safeguards, the degree of self-disclosure and vulnerability essential for paradigm shift will not be fostered. It must be acknowledged, however, that even with the measures I have described, the struggle for a share in the diminishing supply of the earth's natural resources will inevitably result in conflicts which challenge the best devised facilitative processes. 


\subsubsection{Expanding identity - lived-in bodies and bodies in living systems}

Pedagogy aimed at transforming an alienated consciousness into a connected one involves an exploration of identity as a vital step in the development of new paradigms. In an exploration of the 'lived-in body', students of sustainability interrogate their location as selves made 'of the earth'. Highlighting both conceptual and physical processes within pedagogy avoids the artificial separation of mind and body. It makes way for an expanded identity where human beings experience their identity as intimately interconnected with other living systems.

Perhaps no experience grounds human identity more directly than involvement with food production, preparation or consumption. Many ecofeminist actions have revolved around the promotion of sustainable food production - for example Vandana Shiva's seed-saving projects in India (Shiva and Moser 1995:199). A pedagogy using ecofeminist principles has wide application within home and commercial food production. I have suggested elsewhere that "As competition for control of the technology surrounding commercial horticulture and agriculture increases, the home garden becomes a microcosm of such battles for supremacy" (Anderton 1999). Gardening practices that imitate nature, instead of trying to control it, form the basis of the permaculture approach to sustainable agriculture. The ethical foundations of permaculture include "care of the earth, care of people, distribution of goods surplus to individual need and setting limits to population and consumption" (Morrow 1997:12). Instead of artificially separating off wild remnants of socalled natural ecosystems (for example as national parks or wildlife sanctuaries) and destroying them everywhere else (for example in home gardens and on farms), a permaculture approach uses principles which work to restore and maintain natural ecosystems while at the same time supporting human dwelling and food production. There is evidence to suggest that some conservation approaches which rely on separation and isolation of remnant places or species at best delay, at worst speed up, the demise of healthy ecosystems (Nabhan 1997). I am, of course, aware of the important function wildlife sanctuaries perform in protecting endangered plant and animal species 
and habitats. But if whatever happens outside these havens is destructive of ecosystems all we are doing is establishing museums for the casualties of human development. Learning from nature how to live sustainably in ecosystems is an enormous educational challenge. The practical component of such a project would include enacting sustainability principles in every setting. In Aotearoa/New Zealand, farming still plays a very significant role in our economy, with land-based products providing 53 per cent of our export income in 1996 (Le Heron and Pawson 1996:136). Pressure to increase productivity and efficiency to meet global market requirements often puts farmers and environmentalists on a collision course. In an address to the Federated Farmers of New Zealand conference in 1994, Frederick Turner suggested that:

"The polluter and the ecology freak are two faces of the same coin; they both perpetuate a theory about nature that allows no alternative to raping it or tying it up in a plastic bag to prevent it from contamination. A landscape without people would be as unnatural as a landscape with only people" (Turner 1994).

A pedagogy of sustainability seeks to dismantle the dualistic separation of land for people and land for plants and animals. Rather, it would assist protagonists from both camps to identify fundamental principles and tangible strategies for sustaining ecosystems in which all species, including human beings, can flourish.

The Boal-type theatre that I used is one example of a process that would facilitate changes in the deeply held value systems underlying the approaches to farming and gardening. Avoiding the paralysis and guilt that sometimes characterises environmental education, a pedagogy of sustainability devises processes which promote joy, playfulness and experimentation. In addition, such processes are conducted in community, not in isolation. 


\subsubsection{Community as mediating process between unsustainability and sustainability}

A pedagogy of sustainability views community not as an entity but as a process by which the beliefs, attitudes and behaviours that lie at the heart of unsustainability can be challenged and expunged. I maintain that starting with an exploration of unsustainability in community is justified from a pedagogical perspective because it involves starting where experience is known and felt - conceptually and physically. Social injustice and ecological degradation impact on people's minds and bodies. It affects how we live and do business.

Interestingly, it is in the business community that one model for achieving sustainability, The Natural Step, has arisen (Nattrass and Altomare 1999; Robert 1991). The Natural Step is a non-profit environmental education organization that originated in Sweden in 1989. Founded by Karl-Henrik Robert, a cancer researcher and physician, it grew out of his frustration with the short-term conflicts taking place over the details of environmental problems, and lack of recognition of the increasing impact of environmental issues on society. In collaboration with 50 other scientists, he and John Holmberg developed four system conditions that must be met if the cyclical processes of nature, which are the keys to sustainability, are to remain intact:

'In order for a society to be sustainable, nature's functions and diversity are not systematically:

1... subject to increasing concentrations of substances extracted from the Earth's crust;

2...subject to increasing concentrations of substances produced by society; or

3 ...impoverished by overharvesting or other forms of ecosystem manipulation.

And,

4...resources are used fairly and efficiently in order to meet basic human needs worldwide' (Nattrass and Altomare op. cit.:23). 
Immutable laws, even scientific ones, find little appeal in a society strongly influenced by post-modern relativity and technological supremacy. The Natural Step approach, however, is gaining acceptance in the business world by demonstrating that people, business and the environment all profit from adherence to the four systems conditions. The model first presents business with evidence of the inevitable collision course between current business practice and diminishing natural resources. The facilitation of such business learning communities could be enhanced by employment of some of the ecofeminist principles I have incorporated into a pedagogy of sustainability. For example, resistance to 'following laws' may be more readily broken down by involvement in theatrical scenarios that extend participant engagement beyond the cognitive to the affective.

The recent innovation of sustainability education in the commercial sector has been paralleled by increasing pressure for local authorities to involve communities in their environmental planning. A recent Community Development Journal article noted the lack of expertise amongst environment planning departments in engaging communities. It suggested that threads could be woven between community development practitioners and environmentalists utilising the skills and knowledge of both (Downie and Elrick 2000). This was the first article I had seen making such connections and, while welcome, it fell short of enunciating how such threads could be woven. Resistance to community development is likely to be strong given the prevailing ethos of competition between sectorial interest groups.

Competition rather than cooperation can become entrenched when groups compete not only for credibility but also for limited funding.

I claim that movement towards sustainability is most likely to occur when community as process is engaged. What I further contend is that whilst the emphasis in any pedagogical process aimed at sustainability focuses on processes which raise awareness of unsustainability, the project cannot stop there. A pedagogy of sustainability actively engages students in the "What?" as well as the "How?" in the exchange and generation of useable knowledge. 


\subsubsection{Engaging in appropriate knowledge exchange and generation}

Possible areas of knowledge for a sustainability agenda have emerged from the research. These include:

- knowledge of the history of "people and place" and the dynamic relationship between the two;

- knowledge of the forces - social, historical, economic, cultural, ecological and spiritual - which have shaped a community or locality;

- knowledge of the ecological laws which govern the natural world and of the indicators which show when natural limits are being reached;

- knowledge of community development principles which nurture processes of empowerment;

- knowledge of alternative mental models including, in particular, indigenous and non-Western paradigms.

In addition to identifying what knowledge is useful for the transition towards sustainability, I have devised the following steps for the generation and exchange of such knowledge in the classroom or community:

- Recognition and use of the wisdom and knowledge that students/participants already have

This principle is equivalent to recording a species list in an ecological community in order to establish a baseline for future assessment of changes in ecosystem health.

\section{- Use of multiple methods of knowledge generation}

Multiple methods acknowledge the social construction of knowledge. These are necessary not only to accommodate diverse student knowledge and experience but also to plumb the depths of knowledge derived from affective and spiritual as well as cognitive and secular 
sources. The range of approaches includes reading of texts and novels, engaging in Boal-type or other participatory theatre, field observations, watching film and video, story-telling and listening to guest teachers and visitors. I have described earlier (see 3.6.3) how I experimented with a variety of pedagogical approaches that included taking a social work tutorial group to visit a remnant wetland area. As the group moved to various vantage points, we read excerpts from a book describing the human and ecological history of the place and reflected on what we could learn from what we saw and experienced as well as from what we read.

At that time I was not aware of 'biomimicry', ${ }^{1}$ an approach that specifically identifies the process of sustainability exemplified by nature and develops processes to imitate them. Biomimicry may seem an alien concept to people with a Western world-view. Yet even people more removed from nature retain, I suggest, memories of connections to nature. After all, human-nature connections were intrinsic to Celtic cultures from which many Western cultures derive. Evidence that such memories lie close to the surface is in the frequent use of natural metaphors. In Aotearoa/New Zealand, for example, people of Anglo-Saxon and Celtic cultures say that young adults leaving home are "leaving the nest", that feelings "ebb and flow" or "wax and wane", and that "it never rains but it pours".

\footnotetext{
${ }^{1}$ Biomimicry is the practical outcome of a changed human-nature relationship. Instead of dominating and controlling natural processes, human activity is so designed as to learn from nature and mimic natural processes. Such processes typically avoid human manufacturing systems' use of heavy metals, combustion and petroleum and employ minimal inputs, lower temperatures and enzymatic reactions. Engineers are currently using the approach to design more efficient cyclical production systems that imitate nature by producing no waste products (Hawken, Lovins and Lovins 1999:15). Designers in many fields are looking at nature through new eyes in an effort to learn "the benign chemistry of its processes" (op.cit.:16).
} 
To indigenous people, learning directly from nature is part of their world view. For Maori, the life force, mauri, which flows through creation, binds it together and establishes a universal kinship. Each natural object has a kaitiaki or spirit guardian to sustain its mauri. The human use of resources is regulated by temporary sanctions (rahui) and more lasting ones (tapu). We are fortunate in Aotearoa/New Zealand that we have so close at hand sustainable ways of viewing connections to nature that can be woven into pedagogies of sustainability. Sadly, to date the dominant world view has largely forced Maori to resort to legal means of exercising guardianship (kaitiakitanga) over natural treasures (taonga).

- Use of strategic questioning and debate around the issues raised

In reviewing the video-tapes of the research workshops I observed that I had been employing this technique without conscious awareness.

Strategic questioning involves asking open-ended questions which start with acknowledging the students' knowledge base; it expands awareness by asking about gaps and contradictions and invites creative contributions that are then woven into the context of the topic under discussion.

- Employing a mix of small and large group activities, as well as individual ones

This practice recognises cultural diversity and the different degree of ease with which students participate in group activities. Even though varying group size is considered part of educational best practice, the reality of large class sizes in many learning institutions makes this a difficult goal to realise. 
- Use of assessment protocols which value affective as well as cognitive expression, and group as well as individual performance

Employing a pedagogy of sustainability but using assessment methods which favour "old paradigms" models unhelpful dissonance between what is claimed and what is done. Instead, assessment protocols that enable learners to demonstrate their cognitive and affective learning models congruence between pedagogical processes and assessment of learning.

Similarly, encouraging students to learn cooperatively needs to be reflected by including assessment of group activity. During my teaching career I developed a variety of assessment protocols that included video-taped role plays which were jointly assessed by students and me; and oral presentations in addition to the more traditional written assignments. Such practices are not new to social work education, where fieldwork practice is assessed using nontraditional approaches.

- Ongoing collaborative, cross-disciplinary research

Whilst collaborative research between allied disciplines is relatively common, research involving the social and natural sciences is less so. I was gratified to see this trend reversed at a recent seminar bringing social and environmental research issues together. The seminar was designed to canvas comment about how Aotearoa/New Zealand had progressed towards attaining the underlying goals of the World Earth Summit and the World Summit on Social Development (Davey 1999). One of the conclusions was that despite all the evidence about our alarmingly unsustainable state, human beings seem collectively unable 
to change the behaviour that leads to such a condition. Many of the relevant research questions raised could profitably be worked on collaboratively, across disciplines, in order to make contributions to the complex task of bringing about sustainable social and environmental development.

Within academia such interdisciplinary research collaboration faces some significant difficulties. The dialectic between traditional philosophical and epistemological bases for research within the natural and social sciences could undermine collaborative projects. I argue, however, that disciplinary separation is often reinforced more by institutional organisational arrangements, such as funding for research, than by academic arguments. It may be that if governmental and university funding arrangements offered incentives for collaborative interdisciplinary research projects, many of the ideological differences that appear to inhibit such endeavours would be found to be illusory. I am not arguing for denial of disciplinary identity but for a search for a research basis which truly reflects a sustainability ethic. Such an ethic would view disciplines as members of a knowledge community and as such, like ecological communities, mutually interdependent.

In this section I have focussed my attention outside social work, on areas where ecofeminist praxis could contribute to pedagogies of sustainability. I now turn to my own discipline, hold the mirror up to social work education, asking:

\subsection{Can social work education accept ecofeminist challenges?}

Social work as a profession already struggles with the oppositional nature of its activity. It performs its roles in organisations either wholly run by the state or almost certainly funded by it. Yet its advocacy role requires that it challenge the authority by which the state constrains people's lives. Feminist renderings of non-oppressive ways of working with people across the personal/structural dichotomy include the use of holistic approaches which 
recognise interdependency between people and seek the interconnection between different parts of social reality (Dominelli 1997b:80).

The ecofeminist praxis I propose challenges social work to add further complexity to the equation for empowering practice by including the environment as part of the 'interconnections'. If current social work education falls short of preparing students to deal with value and practice oppositions (Harre Hindmarsh 1992), how could adding another potentially oppositional dimension possibly be justified?

In order to make a positive response to the ecofeminist call to add further complexity to its educational agenda, social work education must adopt a much more radical approach to pedagogy. It must expose the unsustainability of the paradigm on which social work and its educational project is currently based. Western social work's origins within capitalism commit it to social and economic arrangements that use human capital, financial capital and manufactured capital to transform natural capital into the stuff of everyday life. Capitalism does not assign value to the largest stocks of capital it employs - natural resources, living systems and social and cultural systems (Hawken, Lovins and Lovins op.cit.:5). I argue that it is only possible to educate social workers to be champions of social and environmental justice and alleviators of suffering when the methods employed to educate them are derived from outside the mind-set that created that injustice and suffering.

A familiar metaphor in social work favours putting a fence at the top of the cliff rather than an ambulance at the bottom. If falling over the cliff means descent into poverty, ill-health, abusive relationships, uncaring neighbourhoods and lack of meaningful employment, a new paradigm would in every situation include the inter-relationship between the natural world and the socio-economic realities. For example, abuse of children by parents or caregivers and destruction of natural ecosystems are both logical outcomes of an alienative consciousness that perpetuates domination and subjugation. Whether the objects of that misuse of power are small children or other small creatures, the mind-set that enables it to happen is the same. In my experience 
as a social worker in a child and family psychiatric service it was quite common for children presenting as abused to have a history of cruelty to animals. 'Breaking the cycle' in relation to abuse prevention and management needs to include the natural world.

How might learning how natural systems have survived assist us in facing social challenges? For example, might working with families 'at risk' be informed by exploring principles of ecosystem health? In the quest for ecological and social sustainability, both the conservation ethic and the ethic of care have been found wanting. An ecofeminist ethic of flourishing focuses on averting scarcity and perpetuating abundance. With abundance as an ethical base, the areas of innovation for social work educators willing to translate ethics into praxis are limitless. Our imaginations, and our willingness or otherwise to challenge the dominant unsustainable paradigms by which many of us practise our profession, are what stand between us and realisation of new possibilities in social work pedagogy.

Divesting ourselves of a limiting paradigm would open the way for us to teach how human communities might be strengthened by learning what principles enhance the health and wellbeing of ecological ecosystems. It is not as though we would be breaking entirely new theoretical ground. Some of our colleagues in social policy have recognised the need to evolve approaches to social justice that are compatible with ecological sustainability, and vice versa (Cahill 1994; Fitzpatrick 1998). The debates in social policy tend to concentrate on the ethical and ideological nature of the challenge to add ecological concerns to its social agenda. My contribution to enabling social work education to take up a similar challenge is to focus on the practice of pedagogy, as well as the ethical, ideological and theoretical frameworks on which practice rests. This focus opens up new possibilities for the practical component of social work courses.

Fieldwork practice could move to a different plane if students from the natural and social sciences and commerce were to work collaboratively on real-life issues. If social work education were to join forces with related natural sciences, such as ecology, environmental studies and human geography, a 
curriculum of sustainability could be devised which would expand the horizons of research and teaching. Joint research projects could focus on some of the most urgent and vexed problems of our time - such as how to maintain reasonable standards of living and meaningful work for communities historically reliant on industries which have destroyed whole ecosystems and which are no longer sustainable. I could imagine social work students working in multi-disciplinary teams aimed at overcoming the loss of forestry employment when logging of native timbers is halted. Combining ecofeminist praxis, community development principles and knowledge of how natural systems respond could see creative options generated where solutions have eluded social scientists or ecological researchers working in isolation.

In a post-welfare state, social work as a profession is increasingly under pressure to promote self-reliance and decrease state dependency. The corollary is that social work education is expected to provide social work graduates able to function in highly competitive, technologically sophisticated, contested environments. I have identified the negative aspects of this expectation (see 6.4), but there are positive ones as well.

Social work education, if it educates its workers for a relevant, radical profession, can contribute to a total rethink of the impacts of globalisation and market economies on people and on the planet. I argue that social work education has two choices: continue to educate for an agenda of dealing with the 'fallout' of unsustainable social, economic and environmental policies; or contribute to nurturing the development of new paradigms aimed at sustainability. It is no longer sufficient to focus on social justice - that which is desirable for the human inhabitants of the earth - without addressing what is feasible from an ecological perspective.

The social justice imperative alone poses a daunting challenge. Add the ecological to the agenda and the result can be overwhelming. Yet at points in history where the dominant cultural narrative begins to falter it is often the lot of youthful and dissident movements to illuminate new pathways. This research has demonstrated how ecofeminism as a relatively new and contested 
epistemology offers possibilities of moving towards a path that is "socially and naturally viable" (Oelschlaeger 1995:217). As Susan George has claimed, "In order to bring about change everywhere, we need to bring about change somewhere" (George 1993).

My research has shown that an ecofeminist praxis can extend the change agenda of social work education. The challenge I issue is to other teachers, researchers and activists to extend this to every field likewise dedicated to bringing about change. 


\section{GLOSSARY OF MAORI WORDS}

The Maori language is intensely rich and full of spiritual and symbolic meanings which can never be adequately expressed in a simple translation. Technical limitations have prevented the display of the macron to indicate long vowels. Dictionaries used were Williams, H. W. A dictionary of the Maori language. Wellington, Government Printer, 1975 and Reed, A.W. The concise Maori handbook. Wellington, Reed, 1978

\begin{tabular}{|c|c|}
\hline ako & learn, teach, instruct, advise \\
\hline hapu & clan or section of tribe \\
\hline$i w i$ & nation, people \\
\hline kaitiaki & guardian \\
\hline kaitiakitanga & guardianship \\
\hline karakia & charm, spell, incantation; modern meaning: prayer \\
\hline kaupapa & floor, platform; modern meaning: values, philosophy \\
\hline kohanga reo & $\begin{array}{l}\text { language nest, applied to total immersion Maori language } \\
\text { pre-schools }\end{array}$ \\
\hline marae & enclosed ground used as a meeting place \\
\hline mauri & life principle \\
\hline nga & the (plural) \\
\hline pakeha & foreigner; usually applied to white Europeans \\
\hline Papatuanuku & the Earth Mother \\
\hline rahui & $\begin{array}{c}\text { sign or mark of warning to trespassers, especially against } \\
\text { infringement of tapu }\end{array}$ \\
\hline Ranginui & the Sky Father \\
\hline taonga & treasures, valuables, possessions, property \\
\hline tapu & sacred; forbidden, inaccessible, not to be defiled \\
\hline tupuna & ancestors \\
\hline whanau & family (in broad sense) \\
\hline whare & house, shed \\
\hline wharenui & large meeting house on a marae \\
\hline
\end{tabular}




\section{BIBLIOGRAPHY}

Abramovitz, Mimi (1993) "Should all social work students be educated for social change? Pro". Journal of Social Work Education, 29 (1) 6-13, 17-18.

Adams, Robert, Dominelli, Lena and Payne, Malcolm (eds.)(1998) Social work: themes, issues and critical debates. Basingstoke, Macmillan.

Adams, Carol (ed.)(1993) Ecofeminism and the sacred. New York, Continuum Press.

Ahmed, Iftikhar and Doeleman, Jacobus A.(eds.)(1995) Beyond Rio: the environmental crisis and sustainable livelihoods in the Third World. New York, St Martin's Press.

Alaimo, Stacy (1994) "Cyborg and ecofeminist interventions: challenges for an environmental feminism". Feminist Studies, 20 (1) 133-152.

Albert, Michael, Cagan, Leslie, Chomsky, Noam, Nahnel, Robin, King, Mel, Sargent, Lydia, and Sklar, Holly (1986) Liberating theory. Boston, South End Press.

Anderton, Joy (1999) "How does your garden grow? The garden as an ecofeminist site", in Hui raranga wahine: Women's Studies Association (NZ) conference papers 1999. Wellington, Women's Studies Association, 47-52.

Anderton, Joy (1997) "The sustainability imperative for social work education". Social Work Review, 9 (3) 24-27.

Argyle, M. (1991) Cooperation: the basis of sociability. London, Routledge.

Argyris, C. and Schon, D. (1974) Theory in practice: increasing professional effectiveness. San Francisco, Jossey-Bass.

Awatere, Donna (1984) Maori sovereignty. Auckland, Broadsheet Magazine Ltd

Bardill, D.Ray (1993) "Should all social work students be educated for social change? Con". Journal of Social Work Education, 29 (1) 13-17.

Barndt, D. (1989) Naming the moment: political analysis for action. Toronto, Jesuit Centre for Social Faith and Justice.

Bartlett, M., Tebb, S., and Chadha, J. (1995) "Teaching feminist practice:

support, transition, change". Afilia, 10 (4) 442-457.

Bateson, Gregory (1979) Mind and nature: a necessary unity. London, Wildwood House. 
Batsleer, J., Davis, T., O'Rourke, R. and Weedon, C. (1985) Rewriting English. New York, Methuen.

Batten, Juliet (1995) Celebrating the southern seasons: rituals for Aotearoa. North Shore, Tandem Press.

Beare, Hedley and Slaughter, Richard (1993) Education for the twenty-first century. London, Routledge.

Belenky, M., Clinchy, B., Goldberger, N. and Tarule, J. (1986) Women's ways of knowing: the development of self, voice and mind. New York, Basic Books.

Bell, Diane and Klein, Renate (eds.)(1996) Radically speaking: feminism reclaimed. Melbourne, Spinifex.

Belotti, Elena Gianini (1975) Little girls. London, Writers and Readers Publishing Cooperative.

Berry, Thomas (1988) The dream of the earth. San Francisco, Sierra Club.

Beyer, L. and Zeichner, K. (1987) "Teacher education in cultural context: beyond reproduction" in Popkewitz, T. S. (ed.) Critical studies in teacher education: its folklore, theory and practice. London, Falmer Press.

Biehl, Janet (1991) Finding our way: rethinking ecofeminist politics Montreal, Black Rose Books.

Boal, Augusto (1995) The rainbow of desire: the Boal method of theatre and therapy. London, Routledge.

Boal, Augusto (1979) Theatre of the oppressed. New York, Urizen Books.

Bosselmann, Klaus (1995) When two worlds collide: society and ecology. Auckland, RSVP.

Boud, David (1988) "A facilitator's view of adult learning" in Boud, D. and Griffin, V. (eds.) Appreciating adult learning: from the learners' perspective. London, Kogan Page, 222-239.

Boud, David (1993) "Experience as the base for learning". Higher Education Research and Development, 12 (1) 33-44.

Bowers, C.A. (1995) Educating for an ecologically sustainable culture. Albany, State University of New York Press.

Brookfield, S.D. (1995) Becoming a critically reflective teacher. San Francisco, Jossey-Bass. 
Brown, Valerie, Ingle Smith, David, Wiseman, Rob and Handmer, John (1995) Risks and opportunities: managing environmental conflict and change. London, Earthscan.

Buege, Douglas J. (1994) "Rethinking again: a defense of ecofeminist philosophy" in Karen J. Warren (ed.) Ecological feminism. London, Routledge, 42-63.

Burstow, B. (1991) "Freirian codifications and social work education". Journal of Social Work Education, 27 (2) 196-207.

Cahill, M. (1994) The new social policy. Oxford, Basil Blackwell.

Cairns, Tamati, Fulcher, Leon, Kereopa, Hohepa, Nia Nia, Pare and TaitRolleston, Waereti (1997) Maori self-determination in the education and training of social workers. Paper presented at the Learned Societies Conference of the Canadian Schools of Social Work, 11-14 June, Memorial University of Newfoundland.

Cameron, Julia (1995) The artist's way: a spiritual path to higher creativity. London, Pan Books.

Cannan, C. (1994) "Enterprise culture, professional socialisation and social work education in Britain. Critical Social Policy, 2,5-18". Reviewed by Imogen Taylor in British Journal of Social Work, 1995, 25, 817-827.

Capra, Fritjof (1993) Guide to ecological literacy, Berkeley, The Elmwood Institute.

Carr, W. and Kemmis, S. (1986) Becoming critical: education, knowledge and action research. London, Falmer Press.

Carr, W. and Kemmis, S. (1983) Becoming critical: knowing through action research. Melbourne, Deakin University.

Cheney, Jim (1994) "Nature/theory/difference: ecofeminism and the reconstruction of environmental ethics" in Warren, Karen J. (ed.) Ecological feminism. London, Routledge, 158-178.

Christ, Carol P. (1990) "Rethinking theology and nature" in Diamond, Irene. and Orenstein, Gloria Feman.(eds.)(1990) Reweaving the world: the emergence of ecofeminism. San Francisco, Sierra Club Books, 58-72.

Clark, Linda, Ronan, Marion and Walker, Eleanor (1981) Imagebreaking/image-building: a handbook of creative worship with women of Christian tradition. New York, The Pilgrim Press.

Coffey, Amanda and Atkinson, Paul (1996) Making sense of qualitative data: complementary research strategies. Thousand Oaks, Sage Publications. 
Cohen, Anthony P. (1989) The symbolic construction of community. London, Routledge.

Collins, Sheila D. (1974) A different heaven and earth. Valley Forge, Judson Press.

Concise Oxford dictionary of current English (1982). $7^{\text {th }}$ ed., reprinted with corrections 1983. Oxford, Clarendon Press.

Cournoyer, Barry (1991) The social work skills workbook. Belmont, Calif., Wadsworth.

Cox, Cat (1992) "Eco-feminism" in Kirkup, G. and Keller, L.S. (eds.) Inventing women: science, technology and gender. Cambridge, Polity Press, 282-293.

Craig, Gary (1998) "Community development in a global context". Community Development Journal, 33 (1) 2-17.

Craig, Wendy (1987) A community work perspective. Palmerston North, Massey University.

Crotty, Michael (1998) The foundations of social research: meanings and perspectives in the research process. Sydney, Allen and Unwin.

Crowley, Helen and Himmelweit, Susan (eds.)(1992) Knowing women: feminism and knowledge. Cambridge, Polity Press.

Cuomo, Chris J. (1998) Feminism and ecological communities: an ethic of flourishing. London, Routledge.

Cuomo, Christine J .(1994) "Ecofeminism, deep ecology, and human population" in Warren, Karen J. (ed.) Ecological feminism. London, Routledge, 88-105.

Curtin, Deane (1996) "Toward an ecological ethic of care" in Warren, Karen J. (ed.) Ecological feminist philosophies. Bloomington, Indiana University Press, 66-81.

Daly, Mary (1987) Webster's first new intergalactic wickedary of the English language. Boston, Beacon Press.

Daly, Mary (1980) Pure lust. London, Women's Press.

Daly, Mary (1978) Gyn/ecology: the metathics of radical feminism. London, Women's Press.

Daly, Mary (1973) Beyond God the father: toward a philosophy of women's liberation. Boston, Beacon Press. 
Dann, Christine (1992) "Ecofeminism, women, and nature" in Du Plessis, Rosemary (ed.) Feminist voices: women's studies texts for Aotearoa/New Zealand. Auckland, Oxford University Press, 338-353.

Dann, Christine (1985) Up from under: women and liberation in New Zealand 1970-1985. Wellington, Allen \& Unwin/Port Nicholson Press.

Dann, Christine (1979) "Daughters of earth - women and the environment". Broadsheet, 66, 15-19.

Davey, Judith A. (1999) "Forging links - social and environmental sustainability and social science research". Summary of proceedings of seminar Forging links - social and environmental sustainability and social science research, Foundation for Research, Science and Technology and The Royal Society of New Zealand, Wellington, 91-102.

Davion, Victoria (1994) "Is ecofeminism feminist?" in Warren, Karen J. (ed.) Ecological feminism. London, Routledge, 8-28.

d'Eaubonne, Francoise (1974) "Feminism or death" in Elaine Marks and Isabelle de Courtivron (eds.)(1980) New French feminisms: an anthology. Amherst, University of Massachusetts Press, 25, 64-7.

de Bono, Edward (1994) Parallel thinking. London, Viking.

de Bono, Edward (1993) Serious creativity. London, Fontana.

De Lauretis, Teresa (1994) The practice of love: lesbian sexuality and perverse desire. Bloomington, Indiana University Press.

Denzin, Norman K. and Lincoln, Yvonna S. (eds.)(1994) Handbook of qualitative research. Thousand Oaks, Sage Publications.

Department of Social Welfare (1984, revised 1985) Institutional racism in the Department of Social Welfare. [Tamaki-makau-rau] Department of Social Welfare.

Derksen, L.D .(1996) Dialogues on women: images of women in the history of philosophy. Amsterdam, VU University Press.

Diamond, Irene and Orenstein, Gloria Feman (eds.)(1990) Reweaving the world: the emergence of ecofeminism. San Francisco, Sierra Club Books.

Diamond, Irene (1990) "Babies, heroic experts, and a poisoned earth" in Diamond, Irene and Orenstein, Gloria Feman (eds.) Reweaving the world: the emergence of ecofeminism. San Francisco, Sierra Club Books, 201-210.

Dobson, Andrew (1990) Green political thought. London, Unwin Hyman. 
Doel, Mark and Shadlow, S. (1996) Practice learning and teaching. London, MacMillan.

Dominelli, Lena (1998) "Anti-oppressive practice in context" in Adams, Robert, Dominelli, Lena and Payne, Malcolm (eds) Social work: themes, issues and critical debates. Basingstoke, Macmillan, 3-22.

Dominelli, Lena (1997a) "Educating social workers in a changing cultural context: social work under globalisation". Social Work Review, IX (4) 3-8.

Dominelli, Lena (1997b) Sociology for social work. Basingstoke, Macmillan.

Dominelli, Lena (1997c) Anti-racist social work: a challenge for white practitioners and educators. Basingstoke, Macmillan.

Dominelli, Lena (1996) "Deprofessionalizing social work: anti-oppressive practice, competencies and postmodernism". British Journal of Social Work, 26, 153-175.

Dore, Martha M (1994) "Feminist pedagogy and the teaching of social work practice". Journal of Social Work Education, 30 (1) 97-106.

Downie, Alex and Elrick, Deirdre (2000) "Weaving the threads: community development and organizing around the environment - a Scottish perspective". Community Development Journal, 35 (3) 245-254.

Dupuis, Ann and Neale, Jenny (1998) "Numbers and talk: doing feminist research" in Du Plessis, Rosemary and Alice, Lynne (eds) Feminist thought in Aotearoa/New Zealand: differences and connections. Auckland, Oxford University Press, 120-126.

Durie, Arohia (1997) "Te aka Matua: keeping a Maori identity" in Te Whaiti, P, McCarthy, M and Durie, A (eds.) Mai i Rangiatea. Auckland, Auckland University Press/Bridget Williams Books, 142-162.

Eisler, Riane (1988) The chalice and the blade: our history, our future. San Francisco, Harper \& Row.

Elden, M. (1981) "Sharing the research work: participative research and its role demands" in Reason, $\mathrm{P}$ and Rowan, J (eds.) Human inquiry:a sourcebook of new paradigm research. Chichester, Wiley and Sons.

Ellen, R.F. (1984) Ethnographic research: a guide to general conduct. New York, Academic Press.

Ellsworth, Elizabeth (1992) "Why doesn't this feel empowering? Working through the repressive myths of critical pedagogy" in Luke, Carmen and Gore, Jennifer (eds.) Feminism and critical pedagogy. New York, Routledge, 90119. 
Everitt, Angela. "Research and development in social work" in Adams, Robert, Dominelli, Lena and Payne, Malcolm (eds.) Social work: themes, issues and critical debates. Basingstoke, Macmillan Press, 104-115.

Fay, B. (1987) Critical social science: liberation and its limits. Cambridge, Polity Press, in association with Basil Blackwell.

Featherstone, Brid and Fawcett, Barbara (1995a) "Power, difference and social work: an exploration". Issues in Social Work Education, 15 (1) 3-19.

Featherstone, Brid and Fawcett, Barbara (1995b) "Oh no! Not more isms: feminism, postmodernism, poststructuralism and social work education". Social Work Education, 14 (3) 25-43.

Feldhendler, Daniel (1994) "Augusto Boal and Jacob L. Moreno: theatre and therapy" in Schutzman, M. and Cohen-Cruz, J. (eds.) Playing Boal: theatre, therapy, activism. London, Routledge, 87-109.

Firestone, Shulamith (1979) The dialectic of sex: the case for feminist revolution. London, The Women's Press.

Fitzpatrick, Tony (1998) "The implications of ecological thought for social welfare". Critical Social Policy, 18 (1) 5-26.

Flannery, Tim (1994) The future eaters. Sydney, Reed New Holland.

Fonow, Mary Margaret and Cook, Judith A. (eds.)(1991) Beyond methodology - feminist scholarship as lived research. Bloomington, Indiana University Press.

Fook, Jan (1999) "Critical reflectivity in education and practice" in Pease, Bob and Fook, Jan (eds.) Transforming social work practice: postmodern critical perspectives. St Leonards, NSW, Allen \& Unwin, 195-210.

Fook, Jan and Pease, Bob (1999) "Emancipatory social work for a postmodern age" in Pease, Bob and Fook, Jan (eds) Transforming social work practice: postmodern critical perspectives. St Leonards, N.S.W., Allen \& Unwin, 224-229.

Fook, Jan (1997) "Educating social workers in a changing cultural context. Response: an Australian perspective". Social Work Review, IX (4) 9-11. Fook, Jan (ed.) (1996) The reflective researcher: social workers' theories of practice research. St Leonards, N.S.W., Allen \& Unwin.

Foucault, Michel (1980) Power/knowledge: selected interviews and other writings 1972-1977. New York, Pantheon.

Freire, P. and Shor, I. (1987) A pedagogy for liberation: dialogues on transforming education. London, Macmillan. 
Freire, Paulo (1973) Education for critical consciousness. New York, Seabury Press.

Freire, Paulo (1972) Pedagogy of the oppressed. Harmondsworth, Penguin.

Fuss, Diana (1989) Essentially speaking: feminism, nature and difference. New York, Routledge.

Gaard, Greta (ed.)(1993) Ecofeminism: women, animals and nature. Philadelphia, Temple University Press.

Gardiner, Derek W.G. (1984) "Learning for transfer". Issues in Social Work Education, 4 (2) 95-105.

Gebhardt, E. (1982) Introduction to Part 111: a critique of methodology in Arato, A. and Gebhardt, E. (eds.) The essential Frankfurt school reader pp 371-406. New York Continuum, in Holland, Janet, Blair, Maud, with Sheldon, Sue. (eds.) Debates and issues in feminist research and pedagogy. Clevedon, Multilingual Matters/Open University.

George, Susan (1993) Comment in Trading futures: living in the global economy. Video produced by Canadian Broadcasting Corporation.

Germain, C. and Gitterman, A. (1980) The life model of social work practice. New York, Columbia University Press.

Giddens, Anthony (1984) The social construction of society. Cambridge, Polity Press.

Gilligan (1982) In a different voice. Cambridge, Harvard University Press.

Giroux, H (1983) Theory and resistance in education: a pedagogy for the opposition. South Hadley, MA: Bergin and Garvey.

Giroux, H (1988) Schooling and the struggle for public life: critical pedagogy in the modern age. Minneapolis, MN: University of Minnesota Press.

Gleed, Sue (1996) "A first attempt at research: surveying rural social work practice" in Fook, Jan (ed) The reflective researcher: social workers' theories of practice research. St Leonards, N.S.W., Allen \& Unwin, 11-20.

Glesne, C. and Peshkin, A. (1992) Becoming qualitative researchers. New York, Longman.

Gore, Jennifer (1992) "What we can do for you! What can we do for you? Struggling over empowerment in critical and feminist pedagogy" in Luke, Carmen and Gore, Jennifer (eds.), Feminisms and critical pedagogy. New York, Routledge, 54-73. 
Gould, N. (1989) "Reflective learning for social work practice". Social Work Education, 8 (2) 9-19.

Gould, N. and Taylor, I. (eds.)(1996) Reflective learning for social work: research theory and practice. Aldershot, Arena.

Gray, Elizabeth Dodson (1979) Why the green nigger: re-mything Genesis. (Republished as Green paradise lost, 1981) Wellesley, Mass., Roundtable Press.

Griffin, Susan (1997) "Ecofeminism and meaning" in Warren Karen J. (ed.) (1997) Ecofeminism: women, culture, nature. Bloomington, Indiana University Press, 213-226.

Griffin, Susan (1989) "Split culture" in Plant, J. (ed.) Healing the Wounds: the promise of ecofeminism. Philadelphia, New Society Publishers.

Griffin, Susan (1978) Woman and nature: the roaring inside her. New York, Harper \& Row.

Grinnell, R. (1993) Social work research and evaluation. Itasca, F. E. Peacock.

Gross, Elizabeth (1992) "What is feminist theory?" in Crowley, H. and Himmelweit, S. (eds) Knowing women: feminism and knowledge, Cambridge, Polity Press, 355-369.

Grove, R. (1990) "The origins of environmentalism". Nature, 345,11-14.

Gruen, Lori (1997) "Revaluing nature" in Warren, Karen J. (ed.)(1997) Ecofeminism: women, culture, nature. Bloomington, Indiana University Press, 356-374.

Gruen, Lori (1994) "Toward an ecofeminist moral epistemology" in Warren, Karen J. (ed.) Ecological feminism. London, Routledge, 120-138.

Handy, Charles (1995) The empty raincoat: making sense of the future. London, Arrow Business Books.

Haraway, Donna (1991) Simians, cyborgs, and women: the reinvention of nature. New York, Routledge.

Haraway, Donna (1988) "Situated knowledge: the science question in feminism and the privilege of partial perspective". Feminist Studies, 14 (3) 575-599.

Harcourt, Wendy (ed.)(1994) Feminist perspectives on sustainable development. London, Zed Books. 
Harding, Sandra (1993) "Rethinking standpoint epistemology: what is "strong objectivity"?" in Alcoff, L. and Potter, E. (eds) Feminist epistemologies. New York, Routledge.

Harding, Sandra and Hintikka, Merrill (eds.)(1983) Discovering reality: feminist perspectives on epistemology, metaphysics, methodology and the philosophy of science. Dordrecht, Reidel Publishing Co.

Harper, Douglas (1994) "On the authority of the image: visual methods at the crossroads" in Denzin, Norman K. and Lincoln, Yvonna S. Handbook of qualitative research. Thousand Oaks, Sage Publications, 403-412.

Harre Hindmarsh, Jennie (1992) Social work oppositions: new graduates' experiences. Aldershot, Avebury.

Harris, Robert J. (1983) "Social work education and the transfer of learning". Issues in Social Work Education, 3 (2) 103-117.

Hawken, Paul (1998) Natural Step Seminar held in Wellington.

Hawken, Paul (1993) The ecology of commerce. New York, HarperCollins.

Hawken, Paul, Lovins, Amory and Lovins, L. Hunter (1999) Natural capitalism: creating the next industrial revolution. Boston, Little, Brown and Company.

Heap, Elizabeth (1975) "The supervisor as reflector". Social Work Today, 5 (22) 677-679

Heath, Christian (1997) "The analysis of activities in face to face interaction using video" in Silverman, David (ed.) Qualitative research: theory, method and practice. London, Sage Publications.

Henderson, Hazel (1996) Creating alternative futures: the end of economics. West Hartford, Kumarian Press.

Hollis, F.H. (1972) Casework: a psychosocial therapy. 2nd edition. New York, Random House.

hooks, bell (1994) Teaching to transgress: education as the practice of freedom. New York, Routledge.

hooks, bell (1984) Feminist theory: from margin to center. Boston, South End Press.

Hope, A., Timmel, S. and Hodzi, C. (1984) Training for transformation: a handbook for community workers, Books 1, 2 and 3. Zimbabwe, Mambo Press. 
Hopkin, D. (1985) A teacher's guide to classroom research. Milton Keynes, Open University Press.

Huckle, John and Sterling, Stephen (eds.)(1996) Education for sustainability. London, Earthscan.

Huckle, John (1996) "Realizing sustainability in changing times" in Huckle, John and Sterling, Stephen (eds.) Education for sustainability. London, Earthscan, 3-17.

Hutchings, Jessica (1996) A Maori ecofeminist model for resource management consultation. Unpublished Masters in Environmental Studies thesis, Wellington, Victoria University of Wellington.

Ife, Jim (1999) "Postmodernism, critical theory and social work" in Pease, Bob and Fook, Jan (eds) Transforming social work practice: postmodern critical perspectives. St Leonards, N.S.W., Allen \& Unwin, 211-223.

Ife, Jim (1995) Community development: creating community alternatives vision, analysis and practice. South Melbourne, Addison Wesley Longman.

Janesick, Valerie J. (1994) "The dance of qualitative research design: metaphor, methodolatry, and meaning" in Denzin, Norman K. and Lincoln Yvonna S. (eds.) Handbook of qualitative research. Thousand Oaks, Sage Publications, 209-219.

Jensen, Derrick (1995) Listening to the land. San Francisco, Sierra Club Books.

Jones, Sandra and Joss, Richard (1995) "Models of professionalism" in Yelloly, Margaret and Henkel, Mary (eds.) Learning and teaching in social work. London, Jessica Kingsley Publishers, 16-33.

Joyce, Elaine (1998) "Practice teaching: what's in a name?". Social Work Review, 10 (1) 23-25.

Kearney, Patricia and Le Riche, Pat (1993) "Looking at the ordinary in a new way: the applications of feminist thinking to a post-qualifying social work course". Social Work Education, 12 (2) 19-28.

Keller, Evelyn Fox and Longino, Helen E. (eds) (1996) Feminism and science. Oxford, Oxford University Press.

Kellner, D. and Best, S. (1991) Postmodern theory: critical interrogations. New York, Guildford.

Kelly, L., Regan, L. and Burton, S. (1995) "Defending the indefensible? Quantitative methods and feminist research" in Holland, Janet, Blair, Maud, with Sheldon, Sue (eds.) Debates and issues in feminist research and pedagogy. Clevedon, Multilingual Matters/Open University. 
Kelsey, Jane (1995) The New Zealand experiment: a world model for structural adjustment? Auckland, Auckland University Press/Bridget Williams Books.

Kemp, Susan P. (1995) "Practice with communities" in Meyer Carol H. and Mattaini, Mark A. (eds.) The foundations of social work practice.

Washington, D.C., National Association of Social Workers Press, 176-204.

Kimbrell, Andrew (1997) Lectures given at Schumacher College, Devon, England, as part of a course on "Gender, Nature and Technology", September 1997, attended by Joy Anderton.

King,Ynestra (1990) "Healing the wounds: feminism, ecology and nature/culture dualism" in Diamond, Irene and Orenstein, Gloria Feman (eds. Reweaving the world: the emergence of ecofeminism. San Francisco, Sierra Club Books, 106-121.

King, Ynestra (1989) "The ecology of feminism and the feminism of ecology" in Plant, Judith (ed.) Healing the wounds: the promise of ecofeminism. Philadelphia, New Society Publishers, 1989, p 20.

Knowles, M. (1972) "Innovations in teaching styles and approaches based upon adult learning". Journal of Education for Social Work, 8, 32-39.

Kohn, A. (1986) No contest - the case against competition. Boston, Houghton Mifflin

Kramer-Dahl, Anneliese (1996) "Reconsidering the notions of voice and experience in critical pedagogy" in Luke, Carmen (ed.) Feminisms and pedagogies of everyday life. New York, State University of New York Press, 242-262.

Kramer-Dahl, Anneliese (1995) "Reading and writing against the grain of academic discourse". Discourse: studies in the cultural politics of education, 16 (1) $21-38$.

Kropotkin, P. (1972) Mutual aid: a factor of evolution. New York, Garland.

Lahar, Stephanie (1991) "Ecofeminist theory and grassroots politics". Hypatia, 6 (1) 28-45.

Laing, Tricia and Coleman, Jenny (1998) "A crack in the imperial text: constructions of 'white women' at the intersections of feminism and colonialisms" in Du Plessis, Rosemary and Alice, Lynne (eds.) Feminist thought in Aotearoa/New Zealand: differences and connections. Auckland, Oxford University Press, 4-11.

Land, Helen (1995) "Feminist clinical social work in the 21st century" in Van den Bergh, Nan (ed.) Feminist practice in the 21st century. Washington D.C., National Association of Social Workers Press, 3-19. 
Laragy, Carmel (1996) "Finding a methodology to meet the needs of research: moving towards a participatory approach" in Fook, Jan (ed.) The reflective researcher: social workers' theories of practice research. St Leonards, N.S.W., Allen and Unwin, 85-96.

Lather, Patti (1995) "Feminist perspectives on empowering research methodologies" in Holland, Janet and Blair, Maud, with Sheldon, Sue (eds.) Debates and issues in feminist research and pedagogy. Clevedon, Multilingual Matters Ltd/ Open University, 292-307.

Lather, Patti (1992a) "Post-critical pedagogies: a feminist reading" in Luke, Carmen and Gore, Jennifer (eds.), Feminisms and critical pedagogy. New York, Routledge, 120-137.

Lather, Patti (1992b) "Critical frames in educational research: feminist and poststructural perspectives". Theory into Practice, 31 (2) 87-99.

Lather, Patti (1991a) Feminist research in education: within/against. Victoria, Deakin University Press.

Lather, Patti (1991b) Getting smart: feminist research and pedagogy with/in the postmodern. New York, Routledge.

Legler, Gretchen T. (1997) "Ecofeminist literary criticism" in Warren, Karen J. (ed.) Ecofeminism: women, culture, nature. Bloomington, Indiana University Press, 227-238.

Le Heron, Richard and Pawson, Eric (1996) Changing places: New Zealand in the nineties. Auckland, Longman Paul.

Leonard, P (1997) Postmodern welfare: reconstructing an emancipatory project. London, Sage Publications.

Lishman, Joyce (1998) "Personal and professional development" in Adams, Robert, Dominelli, Lena and Payne, Malcolm (eds.) Social work: themes, issues and critical debates. Basingstoke, Macmillan, 89-103.

Lovelock, J.E. (1979) Gaia: a new look at life on earth Oxford, Oxford University Press.

Luke, Carmen (ed.)(1996) Feminisms and pedagogies of everyday life. Albany, State University of New York Press.

Luke, Carmen (1992) "Feminist politics in radical pedagogy" in Luke, Carmen and Gore, Jennifer (eds.) Feminisms and critical pedagogy, New York, Routledge, 25-53.

Luke, Carmen and Gore, Jennifer (eds.)(1992) Feminisms and critical pedagogy. New York, Routledge. 
McCreary, J.R. (1994) Keynote address to the 1964 conference of the N Z Association of Social Workers. Social Work Review, 6 (4) 4-6.

McLaren, P. (1995) Critical pedagogy and predatory culture: oppositional politics in a postmodern era. London, Routledge.

McTaggart, Robin (1991) "Principles for participatory action research". Adult Education Quarterly, 41 (3) 168-187.

Mander, Jerry (1991) In the absence of the sacred: the failure of technology and the survival of the Indian nations. San Francisco, Sierra Club Books.

Mattaini, Mark A. (1995) "Knowledge for practice" in Meyer, Carol H. and Mattaini, Mark A. (eds) The foundations of social work practice. Washington, D.C., National Association of Social Workers Press, 59-85.

Mayo, Marjorie (1994) Communities and caring: the mixed economy of welfare. Basingstoke, Macmillan.

Meadows, Donella H., Meadows Dennis L. and Randers, Jorgen (1992) Beyond the limits: global collapse or a sustainable future. London, Earthscan.

Mellor, Mary (1997) Feminism \& ecology. Cambridge, Polity Press.

Mellor, Mary (1997b) Conversation with Joy Anderton, December 1997, in Durham, England.

Mellor, Mary (1992) Breaking the boundaries: towards a feminist green socialism. London, Virago .

Menzies, Malcolm, Newell, Heather and Peren, Roger (eds.)(1997) Our country: our choices/He tumanako mo te tau rua mano rua tekau. Prospects for 2020. Wellington, New Zealand Futures Trust.

Merchant, Carolyn (1996) Earthcare: women and the environment. New York, Routledge.

Merchant, Carolyn (1992) Radical ecology: the search for a livable world. New York, Routledge.

Merchant, Carolyn (1980) The death of nature: women, ecology and the scientific revolution. San Francisco, Harper \& Row.

Meyer, Carol H. (1995) "The ecosystems perspective: implications for practice" in Meyer, Carol H. and Mattaini, Mark A. (eds) The foundations of social work practice. Washington, D.C., National Association of Social Workers Press, 16-27. 
Meyer, Carol H. and Mattaini, Mark A. (eds)(1995) The foundations of social work practice. Washington, D.C., National Association of Social Workers Press.

Mies, Maria (1986) Patriarchy and accumulation on a world scale. London, Zed Books.

Mies, Maria and Shiva, Vandana (1993) Ecofeminism. Melbourne, Spinifex.

Milbrath, Lester W. (1989) Envisioning a sustainable society: learning our way out. Albany, State University of New York Press.

Ministry for the Environment (1997) The state of New Zealand's environment, 1997. Wellington, Ministry for the Environment.

Ministerial Advisory Committee on a Maori Perspective for the Department of Social Welfare (1988) Puao-te-ata-tu(daybreak). Wellington [DSW].

Morrow, Rosemary (1997) The earth user's guide to permaculture: teacher's notes. Kenthurst N.S.W., Kangaroo Press.

Moses, Karen (1997) Personal discussion with Joy Anderton about social services training in Aotearoa/New Zealand.

Munford, Robyn and Walsh-Tapiata, W. (eds.)(1999) Strategies for change: community development in Aotearoa/New Zealand. Palmerston North, Massey University, School of Social Policy and Social Work.

Nabhan, Gary (1997) Cultures of habitat: on nature, culture, and story. Washington D.C., Counterpoint.

Nash, Mary (1997) "Who drives social work education in New Zealand?". Social Work Review, 9 (4) 14-19.

Nash, Mary (1994) "Social work education in Aotearoa/New Zealand" in Munford, Robyn and Nash, Mary (eds.) Social work in action. Palmerston North, Dunmore Press, 37-55.

Nash, Mary and Munford, Robyn (1994) "A feminist contribution to social work" in Munford, Robyn and Nash, Mary (eds.) Social work in action. Palmerston North, Dunmore Press, 234-250.

Nattrass, Brian and Altomare, Mary (1999) The Natural Step for business. Gabriola Island, B.C., New Society Publishers.

Nelson, C., Treichler, P.A. and Grossberg, L. (1992) Cultural studies. New York, Routledge.

Nicholson, Linda (ed.) (1997) The second wave: a reader in feminist theory. New York, Routledge.. 
Nielsen, Joyce McCarl (ed.)(1990) Feminist research methods. Boulder, Westview Press.

Oakley, Ann (1974) The sociology of housework. London, Martin Robertson.

Oelschlaeger, Max (1995) Interview in Jensen, Derrick. Listening to the land: conversations about nature, culture, and Eros. San Francisco, Sierra Club Books, 208-221.

Oleson, Virginia (1994) "Feminisms and models of qualitative research" in Denzin, Norman K. and Lincoln, Yvonna S. (eds.) Handbook of qualitative research. Thousand Oaks, Sage Publications, 158-174.

Oleson, V. and Whittaker, E.W.(1968) The silent dialogue: a study in the social psychology of professional socialisation. San Francisco, Jossey Bass.

O'Regan, Pauline and O'Connor, Teresa (1989) Community: give it a go. Wellington, Allen \& Unwin/Port Nicholson Press.

Orner, Mimi (1992) "Interrupting the calls for student voice in "liberatory" education: a feminist postructuralist perspective" in Luke, Carmen and Gore, Jennifer (eds.) Feminisms and critical pedagogy. New York, Routledge, 74-89.

Papell, C.P. and Skolnik, L. (1992) "The reflective practitioner: a contemporary paradigm's relevance for social work education". Journal of Social Work Education, 28 (1) 18-26.

Park, Geoff (2000) New Zealand as ecosystems. Wellington, Department of Conservation.

Park, Geoff (1995) Nga uruora: the groves of life. Wellington, Victoria University Press.

Park, K.M. (1996) "The personal is ecological: environmentalism of social work". Social Work, 4 (3) 320-323.

Parliamentary Commissioner for the Environment (1988) The cities and their people: New Zealand's urban environment. Wellington, Office of the Parliamentary Commissioner for the Environment.

Payne, Malcolm (1997) Modern social work theory. 2nd edition. Basingstoke, Macmillan.

Payne, Phillip (1994) "Restructuring the discursive moral subject in ecological feminism" in Warren, Karen J. (ed.) Ecological feminism. London, Routledge, 139-157. 
Pearson, David (1990) "Community" in Spoonley, Paul, Pearson, David and Shirley, Ian. New Zealand society, a sociological introduction. Palmerston North, Dunmore Press, 25-38.

Pease, Bob and Fook, Jan (eds.)(1999) Transforming social work practice: postmodern critical perspectives. St Leonards, N.S.W., Allen \& Unwin.

Peccei, Aurelio and Ikeda, Daisaku (1984) Before it is too late. Tokyo, Kodansha International.

Pepper, David (1996) Modern environmentalism: an introduction. London, Routledge.

Pere, Rangimarie (Rose) (1982) Ako: concepts and learning in the Maori tradition. Hamilton, University of Waikato, Department of Sociology, Paper No.17.

Pere, Rangimarie (Rose) (1979) "Taku taha Maori: my Maoriness" in $\mathrm{He}$ Maataapuna: a source. Some Maori perspectives. Wellington, New Zealand Planning Council.

Perlman, H. (1962) Helping: Charlotte Towle on social work and social casework. Chicago, University of Chicago Press.

Pietroni, Marilyn (1995) "The nature and aims of professional education for social workers: a postmodern perspective" in Yelloly, Margaret and Henkel, Mary (eds.) Learning and teaching in social work: towards reflective practice. London, Jessica Kingsley, 34-50.

Pilalis, Jennie and Anderton, Joy (1986) "Feminism and family therapy - a possible meeting point". British Journal of Family Therapy, 8, 99-114.

Pile, Steven (1991) "Practising interpretative geography". Transactions of the Institute of British Geography N.S. 16, 458-469.

Plumwood, Val (1994) "The ecopolitics debate and the politics of nature" in Warren, Karen J. (ed.) Ecological feminism. London, Routledge, 64-87.

Plumwood, Val (1993) Feminism and the mastery of nature. London, Routledge.

Plumwood, Val (1992) "Feminism and ecofeminism: beyond the dualistic assumptions of women, men and nature". The Ecologist, 22 (1) 8-13.

Popper, Karl (1988) Transcript from World Congress of Philosophy Address. Brighton, U.K.

Quincy, Lee (1990) "Ecofeminism and the politics of difference" in Diamond, Irene and Orenstein, Gloria Feman (eds.) Reweaving the world: the emergence of ecofeminism. San Francisco, Sierra Club Books, 122-127. 
Reason, Peter (1994) "Three approaches to participative inquiry" in Denzin, Norman K. and Lincoln, Yvonna S. (eds.) Handbook of qualitative research. Thousand Oaks, Sage Publications, 324-339.

Rees, Stuart (1991) Achieving power: practice and policy in social welfare. St Leonards, Allen \& Unwin.

Reinharz, Shulamit (1992) Feminist methods in social research. New York, Oxford University Press.

Resource Management Act 1991: an Act to restate and reform the law relating to the use of land, air and water. Wellington, New Zealand Government.

Reynolds, B. (1942) Learning and teaching in the practice of social work. New York, Russell and Russell.

Ristock, Janice L. and Pennell, Joan (1996) Community research as empowerment: feminist links, postmodern interruptions. Toronto, Oxford University Press.

Robert, K.-H. (1991). "Educating a nation: The Natural Step". Context 28.

Rocheleau, Dianne, Thomas-Slayter, Barbara and Wangari, Esther (eds.)(1996) Feminist political ecology: global issues and local experiences. London, Routledge.

Rodda, Annabel (1991) Women and the environment. London, Zed Books.

Rogge, Mary E. (1993) "Humanity and the natural environment". Journal of Social Work Education, 29 (1) 111-120.

Rossiter, Amy B. (1993) "Teaching from a critical perspective: towards empowerment in social work education". Canadian Social Work Review, 10 (1) 76-90 - reviewed by Imogen Taylor, British Journal of Social Work, 24, 1994, 349-352.

Rossiter, Amy (1996) "A perspective on critical social work". Journal of Progressive Human Services, 7 (2) 23-41.

Rothman, J. (1970) "Three models of community organization practice" in Cox, F., Erlich, J., Rothman, J. and Tropman, J.(eds.) Strategies of community organization: a book of readings. Itasca, Il., F.E. Peacock, 20-36.

Rothman, J. and Tropman, J. E. (1987) "Models of community organization and macro practice perspectives: their mixing and phasing" in Cox, F. M., Erlich J. L., Rothman, J. and Tropman, J. E. (eds) Strategies of community organization: macro practice (4th ed). Itasca, Il., F.E. Peacock, 3-26. 
Rountree, Kathleen and Laing, Tricia (1996) Writing by degrees. Auckland, Longman.

Rowlands, Jo (1997) Questioning empowerment: working with women in Honduras. Oxford, Oxfam.

Ruether, Rosemary Radford (1992) Gaia and God: an ecofeminist theology and earth healing. San Francisco, Harper.

Ruether, Rosemary Radford (1981) To change the world: Christology and cultural criticism. London, SCM Press.

Ruether, Rosemary Radford (1979) "Motherearth and the megamachine: a theology of liberation in a feminine, somatic and ecological perspective" in Christ, Carol P. and Plaskow, Judith (eds.) Womanspirit rising: a feminist reader in religion. San Francisco, Harper \& Row, 43-52.

Ruether, Rosemary Radford (1975) New woman new earth: sexist ideologies and human liberation. New York, Seabury Press.

Sachs, Wolfgang (ed.)(1993) Global ecology: a new arena of political conflict. London, Zed Books.

Salleh, Ariel (1997) Ecofeminism as politics: nature, Marx and the postmodern. London, Zed Books.

Saul, John Ralston (1995) The unconscious civilization. Concord, Anansi (CBC Massey lectures series).

Sawicki, J. (1991) Disciplining Foucault: feminism, power and the body. London, Routledge.

Sawicki, J. (1988) "Feminism and the power of the Foucauldian discourse" in Arac, J. (ed) After Foucault: humanistic knowledge, postmodern challenges. New Brunswick, Rutgers University Press, 161-178.

Schaef, Anne Wilson (1998) Living in process: basic truths for living the path of the soul. NewYork, Ballentine Wellspring.

Schaef, Anne Wilson (1992a) Beyond therapy, beyond science: a new model for healing the whole person. San Francisco, HarperCollins.

Schaef, Anne Wilson (1992b) When society becomes an addict. London, Thorsons.

Schon, D. (1987) Educating the reflective practitioner. San Francisco, JosseyBass.

Schon, D. (1983) The reflective practitioner. New York, Basic Books. 
Schutzman, Mady and Cohen-Cruz, Jan (eds.) (1994) Playing Boal: theatre, therapy, activism. London, Routledge.

Scott, Joan W. (1989) "Commentary: cyborgian socialists?" in Weed, Elizabeth (ed.) Coming to terms: feminism, theory, politics. New York, Routledge.

Seager, Joni (1997) The state of women in the world atlas. London, Penguin.

Seager, Jodi (1996) "'Hysterical housewives" and other mad women" in Rocheleau, Dianne, Thomas-Slayter, Barbara and Wangari, Esther (eds.) Feminist political ecology. London, Routledge, 271-286.

Seager, Jodi (1993) Earth follies: feminism, politics and the environment. London, Earthscan.

Sharpe, Sue (1976) 'Just like a girl': how girls learn to be women. Harmondsworth, Penguin.

Shields, Katrina (1991) In the tiger's mouth: an empowerment guide for social action. Newtown, NSW, Millennium Books.

Shirley, Ian (1997) "Educating social workers in a changing cultural context. Response: a New Zealand perspective". Social Work Review, 9 (4) $12-13$.

Shiva, Vandana (1997) Lectures given at Schumacher College, Devon, England, as part of a course on "Gender, Nature and Technology", September 1997, attended by Joy Anderton.

Shiva, Vandana (1996) Protecting our biological and intellectual heritage in the age of biopiracy. New Delhi, Research Foundation for Science, Technology and Natural Resource Policy.

Shiva, Vandana (1995) Biodiversity based productivity: a framework for an alternative economic assessment for sustainable agriculture. New Delhi, Research Foundation for Science, Technology and Natural Resource Policy.

Shiva, Vandana (1993) "Women's indigenous knowledge and biodiversity conservation" in Mies, Maria and Shiva, Vandana (eds.) Ecofeminism. Melbourne, Spinifex, 164-173.

Shiva, Vandana (1992) "The seed and the earth: women, ecology and biotechnology". The Ecologist, 22 (1) 4-7.

Shiva, Vandana (1989) Staying alive: women, ecology and development. London, Zed Books.

Shiva, Vandana, Jafri, Afsar H, Bedi, Gitanjali and Holla-Bhar, Radha (1997) The enclosure and recovery of the commons: biodiversity, indigenous 
knowledge and intellectual property rights. New Delhi, Research Foundation for Science, Technology and Ecology.

Shiva, Vandana, Jafri, Afsar H and Bedi, Gitanjali (n.d.) Ecological costs of economic globalisation: the Indian experience. New Delhi, Research Foundation for Science, Technology and Ecology.

Shiva, Vandana and Moser, Ingunn (eds.)(1995) Biopolitics: a feminist and ecological reader on biotechnology. London, Zed Books.

Shuman, Michael H. (1998) Going local: creating self-reliant communities in a global age. New York, The Free Press.

Silverman, David (1993) Interpreting qualitative data: methods for analysing talk, text and interaction. London, Sage Publications.

Silvey, Rachel (1998) “"Ecofeminism' in geography”. Ethics, Place and Environment, 1 (2) 243-249.

Simmons, I..G. (1993) Interpreting nature: cultural constructions of the environment. London, Routledge.

Slaughter, Richard A.. (ed.)(1996) The knowledge base of futures studies. Vol 1: Foundations. Vol 2: Organisations, practices, products. Vol 3 Directions and outlooks. Hawthorn, D.D.M. Media Group.

Slicer, Deborah (1994) "Wrongs of passage: three challenges to the maturing of ecofeminism" in Warren, Karen J. (ed.) Ecological feminism. London, Routledge, 29-41.

Slicer, Deborah (1991) "Your daughter or your dog? A feminist assessment of animal research issues". Hypatia, 6 (1) 108-124.

Smith, B. and Noble-Spruell, C. (1986) "An overview of feminist research perspectives" in Marchant, H. and Wearing, B. (eds) Gender reclaimed: women in social work. Sydney, Hale and Iremonger.

Solas, John (1994) The (de)construction of educational practice in social work. Aldershot, Avebury.

Specht, Harry and Courtney, Mark E. (1994) Unfaithful angels: how social work has abandoned its mission. New York, The Free Press.

Spender, Dale (1982) Invisible women: the schooling scandal. London, Writers and Readers Cooperative.

Spender, Dale (1980) Man made language. London, Routledge \& Kegan Paul. 
Spoonley, Paul (1990) "Racism and ethnicity" in Spoonley, Paul, Pearson, David, and Shirley, Ian . New Zealand Society: a sociological introduction. Palmerston North, Dunmore Press, 82-97.

Spretnak, Charlene (1997) "Radical nonduality in ecofeminist philosophy" in Warren, Karen J. (ed.) Ecofeminism: women, culture, nature. Bloomington, Indiana University Press, 425-436.

Spretnak, Charlene (1995) Interview in Jensen, Derrick. Listening to the land: conversations about nature, culture, and Eros. San Francisco, Sierra Club Books, 44-52.

Spretnak, Charlene (1989) "Towards an ecofeminist spirituality" in Plant, Judith (ed.) Healing the wounds. Philadelphia, New Society Publishers.

Stanley, Liz (1992) The auto/biographical I. The theory and practice of feminist auto/biography. Manchester, Manchester University Press.

Stanley, Liz (ed.)(1990) Feminist praxis: research, theory and epistemology in feminist sociology. London, Routledge.

Stanley, Liz and Wise, Sue (eds.)(1993) Breaking out again: feminist ontology and epistemology. 2nd edition. London, Routledge.

Stanley, Liz and Wise, Sue (eds.) (1983) Breaking out: feminist consciousness and feminist research. London, Routledge and Kegan Paul.

Starhawk (1982) Dreaming the dark: magic, sex \& politics. Boston, Beacon Press.

Steinem, Gloria (1984) Outrageous acts and everyday rebellions. London, Jonathan Cape (published in the USA 1983).

Steinem, Gloria (1992) Revolution from within: a book of self-esteem. London, Bloomsbury.

Sterling, Stephen (1996) "Education in change" in Huckle, John and Sterling, Stephen (eds.) Education for sustainability. London, Earthscan, 18-39.

Sturgeon, Noel (1997) Ecofeminist natures: race, gender, feminist theory, and political action. New York, Routledge.

Swigonski, Mary E.(1993) "Feminist standpoint theory and the questions of social work research". Affilia, 8 (2) 171-183.

Swigonski, Mary E. (1994) "The logic of feminist standpoint theory for social work research". Social Work, 39 (4) 387-393.

Sylvan, Richard and Bennett, David (1994) The greening of ethics. Cambridge, The White Horse Press. 
Tait-Rolleston, Waereti, Cairns, Tamati, Fulcher, Leon, Kereopa, Hohepa and Nia Nia, Pare (1997) "He koh kii - na kui ma, na koro ma: a gift of words from our ancestors". Social Work Review, 9 (4) 30-36.

Taylor, Imogen (1994) "Social work education" [review article]. British Journal of Social Work, 24, 761-764.

Tonnies, F (1955) Community and association. London, Routledge.

Towle, Charlotte (1954) The learning in education for the professions, as seen in education for social work. Chicago, University of Chicago Press.

Thorne, B. and Yalom, M. (1982) Rethinking the family: some feminist questions. New York, Longman.

Turner, Frederick (1994) "That Nature is a Heraclitean fire: the human role in a living environment". Address to Federated Farmers of New Zealand conference, Wellington.

Twelvetrees, Alan (1982) Community work. London, Macmillan.

United Nations Conference on Environment and Development (1992) Agenda 21: programme of action for sustainable development. New York, United Nations.

Van den Bergh, Nan (ed.) Feminist practice in the 21st century. Washington D.C., National Association of Social Workers Press.

Vayda, E. and Bogo, M. (1991) "A teaching model to unite classroom and field". Journal of Social Work Education, 27 (3) 271-278.

Wackernagel, Mathis and Rees, William (1996) Our ecological footprint: reducing human impact on the earth. Gabriola Island,B.C., New Society Publishers.

Walkerdine, Valerie (1992) "Progressive pedagogy and political struggle" in Luke, Carmen and Gore, Jennifer (eds.) Feminisms and critical pedagogy. New York, Routledge, 15-24.

Waring, Marilyn (1988) Counting for nothing: what men value and what women are worth. Wellington, Allen \& Unwin/Port Nicholson Press.

Warren, Karen J. (ed.) (1997) Ecofeminism: women, culture, nature. Bloomington, Indiana University Press.

Warren, Karen J. (ed.)(1996) Ecological feminist philosophies. Bloomington, Indiana University Press. 
Warren, Karen J. (1994) "Toward an ecofeminist peace politics" in Warren, Karen J. (ed.) Ecological feminism. London, Routledge, 179-199.

Warren, Karen J. (1990) "The power and the promise of ecological feminism". Environmental Ethics, 12 (2) 125-46.

Warren, Karen J. and Cheyney, Jim (1996) "Ecological feminism and ecosystem ecology" in Warren, Karen J. (ed.) Ecological feminist

philosophies. Bloomington, Indiana University Press, 244-262.

Weedon, Chris (1987) Feminist practice and poststructuralist theory. Oxford, Blackwell.

Weiler, K. (1995) "Freire and a feminist pedagogy of difference" in Holland, Janet and Blair, Maud, with Sheldon, Sue (eds.) Debates and issues in feminist research and pedagogy. Clevedon, Multilingual Matters Ltd/ Open University, 23-44.

Weiner, Gaby (1994) Feminisms in education. Buckingham, Open University Press.

Williams, Raymond (1976) Keywords. London, Croom Helm.

Wilson, Kate and Bradley, Greta. "New challenges in social work education: innovations in the training programme at Hull University. Social Work Education, 1994, 13 (2) 52-73.

World Commission on Environment and Development (WCED)(1987) Our common future: from one earth to one world. New York, Oxford University Press.

Yamaguchi, Kaoru (ed.)(1997). Sustainable global communities in the information age: visions from futures studies. Westport, Conn., Praeger.

Yeo, E. and Yeo, S. (1988) New views of cooperation. London, Routledge.

Yelloly, Margaret and Henkel, Mary (eds.)(1995). Learning and teaching in social work: towards reflective practice. London, Jessica Kingsley.

Zabinski, Catherine (1997) "Scientific ecology and ecological feminism: the potential for dialogue" in Warren, Karen J. (ed.) Ecofeminism: women, culture, nature. Bloomington, Indiana University Press, 314-324. 


\section{APPENDICES}

Research information for participants

Consent form

The four research questions

Student response sheet

Excerpt from course outline of Working with Communities module 
VICTORIA UNIVERSITY OF WELLINGTON
Te Whare Wananga o te Upoko o te lka a Mari

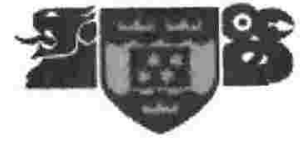

\section{FACULTY OF HUMANITIES AND SOCIAL SCIENCES Department of Applied Social Sciences}

\section{Research information for participants}

\section{Personal detail about the researcher}

I am a senior lecturer in the Department of Applied Social Sciences, Faculty of Humanities and Social Sciences at Victoria University of Wellington, New Zealand. I have been teaching social and community workers for 8 years, my particular fields of teaching being working with families and communities, and feminist social work practice. Prior to my university appointment, I had over 20 years' experience in generic social and community work, and social policy management, facilitation, social audit and family therapy.

My current professional interest lies in exploring the interface between social and environmental sustainability from feminist perspectives and in the context of social work education.

\section{Research project}

The title of this research project is: Educating for sustainable communities: an ecological feminist approach to social work education. The research is being conducted to fulfil the requirements of a Masters by thesis course of study.

\section{Research aims}

The research will focus on an exploration of what contribution ecological feminism can make to social work education. The specific aspect of social work education to be examined will be the teaching of a paper Social Work Practice and Evaluation: Part One, Working with Communities; Part Two, Working with Families, to social work students enrolled on a Diploma or Masters (Applied) course in Social Work at Victoria University. The thesis will explore the meanings of 'sustainable community ' and why education of social and community workers, whose employment will involve actions and policies relating to community, may have as one of its goals educating for the development of 'sustainable communities'.

One of the key subjects of social work discourse is the relationship between theory and practice. For social work educators the challenge is to facilitate a meaningful connection between them. Examination of this 
challenge will be located within an action research methodology involving critical analysis of the pedagogical approaches employed in my teaching of social and community workers over the last 8 years.

The research will seek therefore, to answer the question` How can ecological feminism contribute to social work education for the development of sustainable communities?'.

\section{Aims and objectives}

This research aims at an exploration of what contribution ecological feminism can make to social work education. The twofold objectives reflect the significance of theoretical and practical aspects of social work pedagogy.

Its objectives are to:

- formulate an expanded notion of 'sustainable community', informed by ecological feminism,

- illuminate the processes of educating for sustainable communities

- develop a critical ecological feminist pedagogy for social work practice with communities.

\section{Research methodology}

You are being invited to contribute to this research because you are either a student studying communities or a professional practitioner or academic with expertise and experience in the educational or community fields.

If you have any questions about any aspect of the research, please feel free to ask.

If you decide to participate in this research, you will be invited to sign a consent to participate form, which includes an opportunity to receive a summary of the research on its completion.

You may also be invited to offer feedback to draft accounts of the workshop or discussions you have participated in.

Thank you.

Joy Anderton

Researcher 


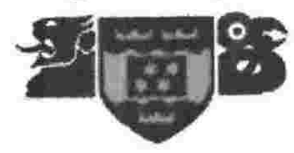

\section{CONSENT TO PARTICIPATION IN RESEARCH ACTIVITIES}

Title of project : Educating for sustainable communities: an ecological feminist approach to social work education

Research/ teaching: An action research project as part of an MA (Applied) by thesis, focusing on educating for sustainability

I have been given and have understood an explanation of this research/teaching project. I have had an opportunity to ask questions and have them answered to my satisfaction. I understand that I may withdraw myself or any information I have provided from this project (before data collection is completed), without having to give reasons and without penalty of any sort.

I agree to the audio/video taping of this workshop/interview/classroom session, on the understanding that it will be used for research, will not identify me by name without my permission, and I may ask to have the tape recorder/video camera turned off at any point (other than when the facilitator is presenting her material) during the workshop without having to explain the reason.

I agree to take part in this research.

Signed:

In my opinion consent was given freely and with understanding.

Signed:

Date: 
VICTORIA UNIVERSITY OF WELLINGTON

$T^{2}$ Whare Wananga o te Upoko o te ika a Mani

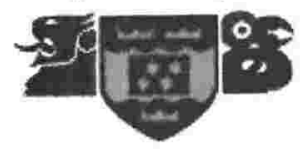

FACULTY OF HUMANITIES AND SOCIAL SCIENCES

Department of Applied Social Sciences

Question 1: AS YOU THINK ABOUT THE NOTION OF 'SUST AINABLE COMMUNITIES, WHAT COMES INTO YOUR MIND? WHAT IMAGES? WHAT IDEAS? WHAT WORDS? WHAT ACTIVITIES?

THANKYOU. Please turn the page to answer Question 2. 
VICTORIA UNIVERSITY OF WELLINGTON

Te Whare Wananga o te Upoko o te Ika a Mani

\section{FACULTY OF HUMANITIES AND SOCIAL SCIENCES \\ Department of Applied Social Sciences}

Question 2. AS YOU THINK ABOUT HOW TO BRING ABOUT SUST AINABLE COMMUNITIES AS YOU UNDERSTAND THEM, WHAT COMES TO MIND? WHAT IMAGES? WHAT IDEAS? WHAT WORDS? WHAT ACTIONS OR ACTIVITIES? 
VICTORIA UNIVERSITY OF WELLINGTON

To Whare Wananga a te Upoko o lo lka a Mani

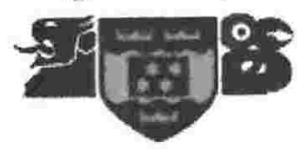

FACULTY OF HUMANITIES AND SOCIAL SCIENCES

Department of Applied Social Sciences

Question 3. YOU HAVE PARTICIPATED IN A

WORKSHOP/DISCUSSION/LECTURE, EXPLORING THE NOTION OF SUSTAINABLE COMMUNITIES. ARE THERE ANY NEW

IMAGES, IDEAS, WORDS OR ACTIVITIES YOU WOULD LIKE TO USE TO DESCRIBE THIS NOTION?

YES/NO

IF YES, COULD YOU PLEASE SAY OR DRAW, WHAT?

THANK YOU. PLEASE TURN THE PAGE FOR QUESTION 4 
VICTORIA UNIVERSITY OF WELLINGTON

$T$ ' Whare Wananga o te Upoko o to Ika a Mani

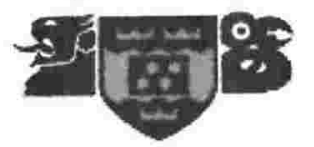

FACULTY OF HUMANITIES AND SOCIAL SCIENCES

Department of Applied Social Sciences

Question 4. CAN YOU DESCRIBE HOW THESE CHANGES HAPPENED? WHAT ACTIONS, ACTIVITIES, IMAGES, WORDS, IDEAS, CONTRIBUTED? ( These could be your own, other participants', or the facilitator's) 
STUDENT RESPONSE SHEET - SUSTAINABLE COMMUNITIES RESEARCH PROJECT

1. Introduction

\begin{tabular}{lllllr}
\multicolumn{2}{l}{ Useful } & & \multicolumn{2}{c}{ Not useful } \\
5 & 4 & 3 & 2 & 1
\end{tabular}

2. Completing forms

\begin{tabular}{lllll}
\multicolumn{2}{l}{ Useful } & & \multicolumn{2}{c}{ Not useful } \\
5 & 4 & 3 & 2 & 1
\end{tabular}

3. Mini-lecture

\begin{tabular}{lrlllr}
\multicolumn{2}{l}{ Useful } & & \multicolumn{2}{c}{ Not useful } \\
5 & 4 & 3 & 2 & 1
\end{tabular}

4. The action (role play)

(a) as actors

\begin{tabular}{llllll}
\multicolumn{2}{l}{ Useful } & & \multicolumn{2}{c}{ Not useful } \\
5 & 4 & 3 & 2 & 1
\end{tabular}

(b) as spectators

\begin{tabular}{lllll}
\multicolumn{2}{l}{ Useful } & & \multicolumn{2}{c}{ Not useful } \\
5 & 4 & 3 & 2 & 1
\end{tabular}

5. Reflecting on the action

\begin{tabular}{lllll}
\multicolumn{2}{l}{ Useful } & & \multicolumn{2}{c}{ Not useful } \\
5 & 4 & 3 & 2 & 1
\end{tabular}


6. Extending the reflection from micro to macro

\begin{tabular}{lrrrr}
\multicolumn{2}{l}{ Useful } & & \multicolumn{2}{c}{ Not useful } \\
5 & 4 & 3 & 2 & 1
\end{tabular}

7. Any other comments?

$\underline{\text { THANK YOU }}$ 


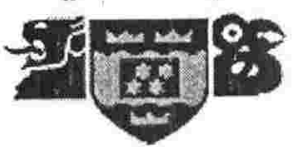

DEPARTMENT OF APPLIED SOCIAL SCIENCES

SOWK $831 / 521$

\section{SOCIAL WORK PRACTICE AND EVALUATION}

PRINCIPLES AND PRACTICE OF SOCIAL WORK 2

\section{MODULE ONE:}

\section{WORKING WITH COMMUNITIES}

COURSE OUTLINE 


\section{Page}

Course Details 1

Timetable 2

Description of Paper and Course Aims, Objectives and Context

Course Programme

1. What is the Learning Context?

2. What is "Community"? 5

3. What are the key principles of
working with communities?

4. What are the skills and knowledge
for practice?

5. How is the learning assessed? 10

Additional Reading List $\quad 11$

Assessment, Assignments \& Terms Requirements 13

Grievance Procedures/Statute on Conduct 15

Essay Marking Schedule $\quad 16$

$\begin{array}{lr}\text { Student Learning Contract and Terms } & 18\end{array}$

Moderator Letter 


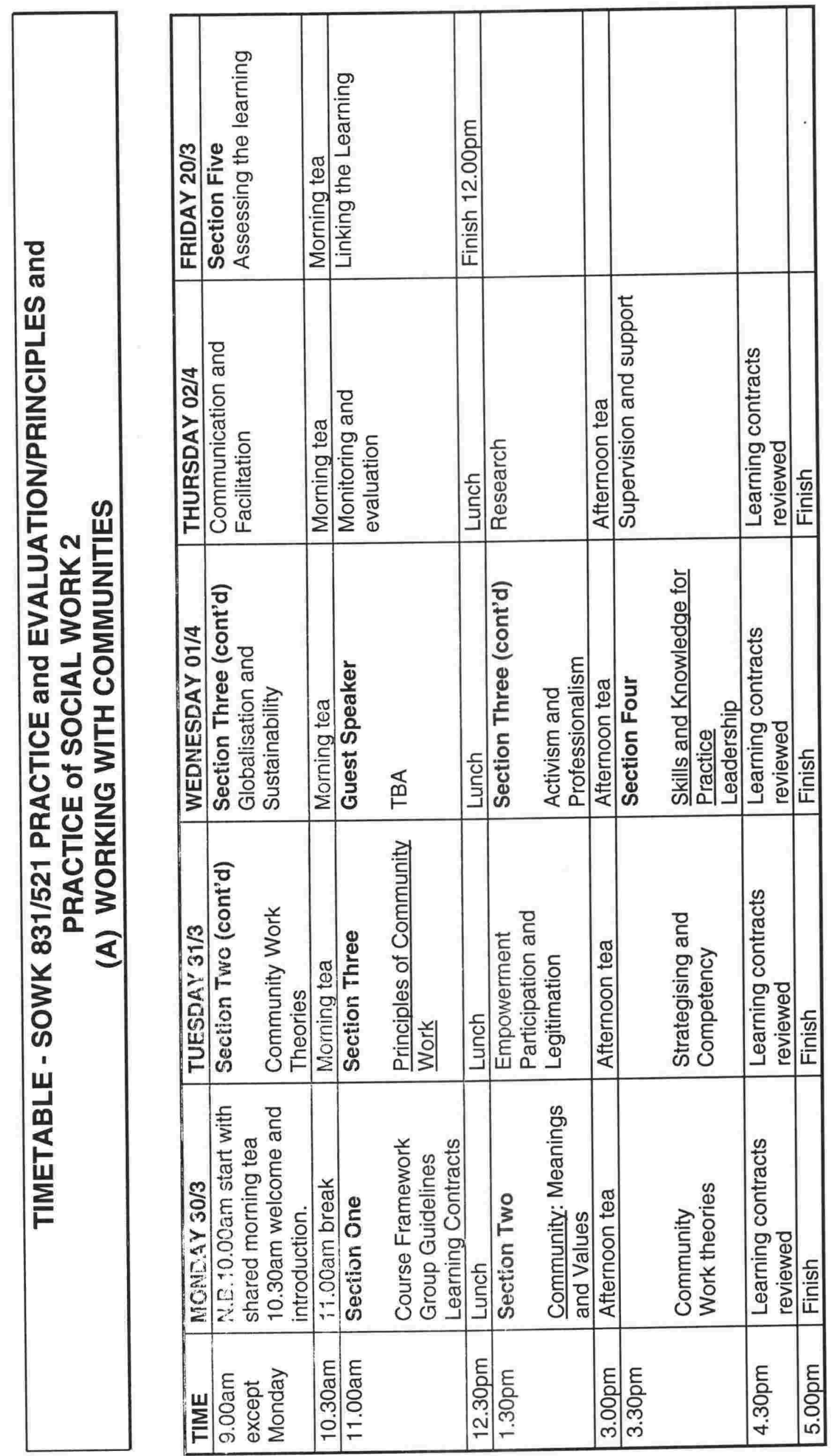

告 
SOUK 831 1521
SOCIAL WORK PRACTICE AND
ALUATIONPRINCIPLES AND PRACTICE OF SOCIAL WORK 2

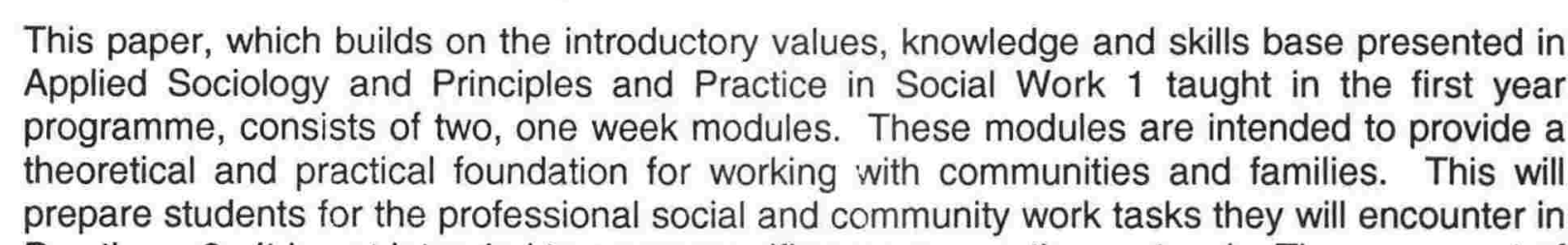




\section{SECTION ONE: WHAT IS THE LEARNING CONTEXT?}

Learning does not take place in a vacuum. It has context.

1. The group comprising students and lecturers needs to draw up group guidelines for how each will contribute to the learning process.

2. As part of the agreement made by students who enrol in a course, the tutors have prepared a course of study. The frameworks and rationale will be outlined.

3. "Aim for nothing, reach nowhere", so designing a learning contract is vital to the learning process.

\section{KEY REFERENCE}

SOWK $831 / 521 \quad$ Selected Readings No. 1.

\section{RELATED REFERENCES}

"Social Work in Action" Chapter 2

\section{LEARNING OUTCOMES}

Students should have

- a beginning understanding of the concept of a learning context

- begun work on their own learning goals within a learning partnership

- $\quad$ participated in collaborative design of learning group guidelines

- a beginning understanding of the frameworks within which "working with communities" will be studied. 
1. Small group activity to explore what students already know about this concept.

2. Mini-lecture to provide historical context to the development of "community" and an introduction to the various theoretical and value bases of community work.

\section{KEY REFERENCES}

Selected Readings

Nos. 2, 3, 4, 5

\section{RELATED REFERENCES}

"Social Work in Action" Chapter 6

\section{LEARNING OUTCOMES}

Students should be able to:

- enunciate a working definition of community as a baseline for community work.

- describe the main features and value bases, of different theoretical approaches, to community work. 


\section{EMPOWERMENT, PARTICIPATION \& LEGITIMACY.}

- What is power?

- What does empowerment mean in theory, in practice?

- How does a worker become "legitimate" in a community?

- Who holds the power?

- What does empowerment mean in relation to community development?

- What part does participation in decision-making play in empowerment of communities?

- What are the barriers to citizen participation and how might they be turned into bridges?

\section{STRATEGISING AND COMPETENCY}

- What are the tools or processes used by community workers to achieve community goals?

- How do these processes "fit" with the business environment currently encouraged in many social services?

- How is competency assessed?

- Whose outputs are being monitored?

\section{GLOBALISATION AND SUSTAINABILITY}

- Who is my "neighbour"?

- What is the impact of corporatisation of world markets on community development?

- What is the role of the State in the community and vice versa?

- What are the characteristics of a sustainable community?

- What does sustainability mean? 


\section{ACTIVISM AND PROFESSIONALISM}

- Whose interests are being guarded?

- What happens when loyalties conflict?

\section{KEY REFERENCES}

Selected Readings No. $6,7,8,9,10,11,12$

\section{RELATED REFERENCES}

"Social Work in Action" Chapters: 3, 8, 10, 13

\section{LEARNING OUTCOMES}

Students should be able to articulate:

- the key principles of working with communities

- examples from their own experiences of how those principles can be applied. 


\section{SECTION FOUR: WHAT ARE THE SKILLS AND KNOWLEDGE FOR PRACTICE?}

\section{LEADERSHIP}

- What are the challenges for community leadership?

- Whose visions and priorities guide community leadership?

- How does empowering leadership avoid capture by `single issue’ lobbies?

\section{COMMUNICATION AND FACILITATION}

- What are the elements of effective facilitation?

- What are the key elements of advocacy?

- What are the key elements of conflict management?

\section{MONITORING \& EVALUATION}

- What are the skills required for assessing a community and its strengths?

- What are the indicators of a strong community?

- How are they monitored?

\section{RESEARCH}

- What is action-based research?

- How can the community benefit from "grass roots" research?

\section{SUPERVISION AND SUPPORT}

- What are the resources for sustaining community strength?

- What are some models of community work supervision and peer support? 


\section{KEY REFERENCES}

"Assessing Changing Communities: a practical guide to studying a community, its people, their needs and human services"

$$
\begin{aligned}
& \text { Anderton J, \& Darracott P (1991) } \\
& \text { DSW: Wellington (Closed Reserve, VUW) }
\end{aligned}
$$

“We Are Doing Well - Aren't We - a guide to planning, monitoring and evaluating community projects"

Coup O, de Joux M and Higgs G (1990)

Internal Affairs Monograph Series No. 14.

(Closed Reserve VUW)

"The Zen of Groups.A handbook for people meeting with a purpose"

Hunter D, Bailey A and Taylor B (1992)

Tandem: Auckland

(Closed Reserve or 3 Day loan - VUW)

"The Art of Facilitation" Hunter D, Bailey A and Taylor B (1992)

Tandem: Auckland

(Closed Reserve or 3 Day loan - VUW)

\section{LEARNING OUTCOMES}

Students should be able to:

- identify the skills required to operate as an effective community worker

- demonstrate a knowledge of the activities and processes needed to sustain themselves and the communities they work within. 


\section{ASSESSING THE LEARNING}

- How can I demonstrate that the knowledge, and skills, are being learnt?

- How does completion of the set assignments contribute to student learning?

- What are the resources to achieve "success"?

\section{FEEDBACK TO TUTORS - FEEDBACK TO STUDENTS}

- How could the learning have been more successful?

- What was positive?

- Suggestions for change

\section{LINKING THE LEARNING}

- What links have been made with other modules?

- What links have been made with first placement?

- Where does this module lead to?

- What opportunities exist for community-focused 2nd year placements?

\section{LEARNING OUTCOMES}

1. Completion of personal learning contract

2. Completion of UTDC evaluation form

3. Completion of set assignments to a satisfactory level by due dates. 


\section{ADDITIONAL READING LIST}

A book of required selected readings is provided.

One text is provided.

- "Social Work in Action", Munford R, Nash M (Eds) (1994), Dunmore Press: Palmerston North, NZ

- $\quad$ Additional articles may be provided during the module.

The following is a list of materials to assist you in gaining the knowledge base required for successful completion of this course. It is expected that reference will be made to a selection appropriate to your essay topic, plus others you find for yourself.

"Maori Land"

Asher G \& Naulls D (1987)

Planning Paper No. 29. New Zealand Planning Council. 1987.

"Poor New Zealand: An Open Letter on Poverty"

Coventry R., \& Waldegrave C (1988)

Platform Publishing, Wellington. 1988.

"A Community Work Perspective"

Craig W (1987)

Massey University, Palmerston North. (Closed Reserve)

"Meeting Needs in the Community: A Discussion Paper on Social Services"

Davey J \& Dwyer M (1984)

New Zealand Planning Council, Planning Paper

"Pedagogy of the Oppressed"

Freire P (1972)

Penguin, England. (Closed Reserve)

"A Question of Honour? Labour and the Treaty"

Kelsey J (1990)

Allen \& Unwin, Wellington.

"Community: Give It A Go"

O'Regan P \& O"Conner T (1989)

Allen \& Unwin, Wellington. (Closed Reserve)

"Royal Commission on Social Policy"

Peters M \& Niarshall J (1988)

"Social Policy and the Move to Community". Vol III, part II, pp 607-602.

"New Zealand Perspectives for Social Change Workers"

Shannon P (1986)

University of Otago. 
"Development Tracks : the theory and practice of community development"

Shirley P (Ed) 1982

Dunmore: Palmerston North (Closed Reserve or 3 Day)

"Mana Wahine Maori" Te Awekotuku N (1991)

New Women's Press, Auckland.

"Royal Commission on Social Policy"

Tamasese K, Masoe-Clifford P \& Ne'emia-Garwood S (1988)

"Pacific Island Peoples' Perspective", April Report, Vol IV, pp 573-592.

"Ka Whawhai Tonu Matou - Struggle Without End"

Walker R (1990)

Penguin Books, Auckland.

"Poor Man Oranges: Women in Community Houses in Auckland"

Wilcox W (1987)

internal Affairs, Wellington.

"Royal Commission on Social Folicy"

Winiata W (1988)

"Tapu Iwi Resources and their Quantification", April Report, Vol III, part II, p789.

"Community Issues in New Zealand"

Bell C (Ed) 1997

Dunmore: Paimerston North

Closed Reserve:

in Study Hall, VUW Library

3 Day

On 3 Day Loan, VUW Library 
Assessment for SOWK $831 / 521$ is entirely internal and consists of two parts, each contributing $50 \%$ of the paper's assessment.

The assignments for Working with Communities consist of:

\section{ASSIGNMENT ONE: COMMUNITY PROJECT}

1. Identify a community (based on geographical identity, whanau/hapu/iwi, interest or commitment) with which you are familiar.

Prepare a brief (approx. 1500 words) profile of the community using current demographic, economic, social, environmental, cultural and political data as well as personal and anecdotal material.

Identify some aspect of the community which a member (this could be yourself or another) of the community considers unsustainable. Describe what this aspect is, and how it became unsustainable.

Worth 25 marks

2. Imagine that you are employed as a community worker/iwi authority worker (or a social worker operating from a community perspective) within the community you have profiled.

Write a report (approx. 1500 words) detailing

- how you would address the issue identified in Section 1, including:

i) what criteria for sustainability would guide your approach

ii) what processes would you consider appropriate in addressing the issue

iii) what difficulties may you encounter

iv) what support (including resources) would you seek.

Invite a member of the chosen community (other than yourself!) to moderate your work by reading it and making a one paragraph comment on the report's usefulness as a vehicle for social change. This paraçraph is to be included in the final report. Please use the letter of introduction provided in this outline.

Worth 25 marks

( 5 marks for the inclusion of the moderators report, 20 marks for the overall report)

FINAL DATE FOR SUBMISSION OF COMMUNITY PROFILE AND REPORT 04 May 1998

$\begin{array}{llllll}\text { Expected return of assignments } & -25 & \text { May } & 1998\end{array}$ 


\section{STUDENT LEARNING CONTRACT AND TERMS}

NAME:

QUALIFICATION: Diploma

MA(Applied) (please circle one)

NAMES/S

OF

LEARNING

PARTNER/S:

LIST OF PERSONAL LEARNING OBJECTIVES FOR THIS MODULE:

1.

2.

3.

4.

SELF-ASSESSMENT OF PROGRESS IN REACHING LEARNING OBJECTIVES:

$\begin{array}{llllll}\text { 1. } & 1 & 2 & 3 & 4 & 5 \\ & \text { None } & \text { A little } & & & 5 \\ \text { 2. } & 1 & 2 & 3 & 4 & 5 \\ \text { 3. } & 1 & 2 & 3 & 4 & 5\end{array}$

ATTENDANCE:

Mon am__ Tues am__ Wed am__Thurs am__Fri am__

$\mathrm{pm}$

$\mathrm{pm}$

$\mathrm{pm}$

$\mathrm{pm}$

SIGNED (STUDENT):

SIGNED (LEARNING PARTNER): 
Dear

\section{MODERATOR COMMENT}

Your name has been given by who is a student at Victoria University, as someone willing to make comments on her/his assignment which is part of the requirements to complete a Diploma or Masters in Social Work.

The assignment is part of the assessed work for a paper, Social Work Practice and Evaluation/Social Work Practice 2, Working With Communities. The student should show you a copy of the assignment as well as giving you the assignment to read.

We would appreciate your making a brief (a paragraph is plenty) comment on the accuracy and relevance of their assignment and on its usefulness in assisting the community to make positive change.

Please hand your comment to the student, who will attach it to their assignment.

Thank you very much for taking the time to assist the student with their learning.

Yours sincerely

Joy Anderton

Course Co-ordinator 